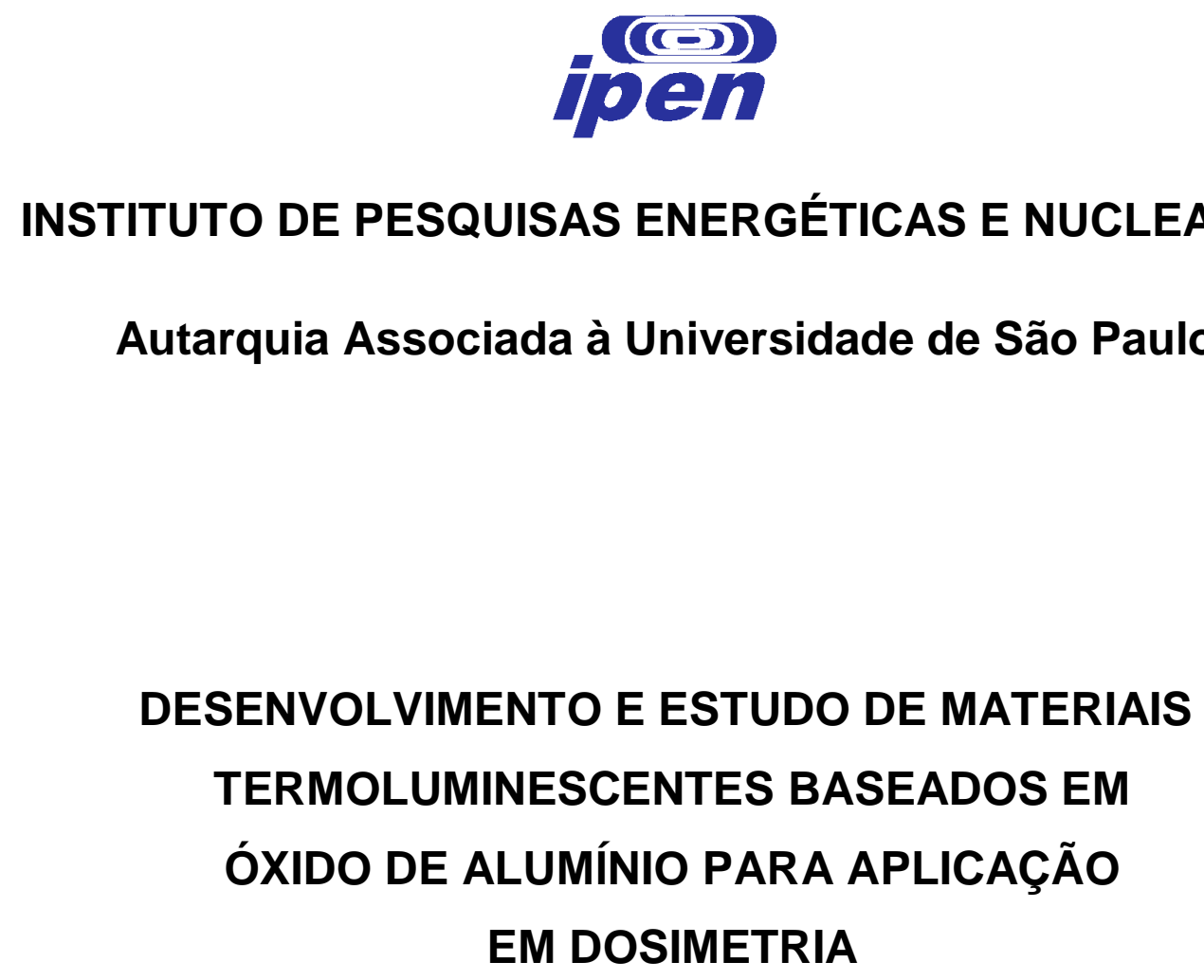

David Tadashi Fukumori

Tese apresentada como parte dos requisitos para obtenção do Grau de Doutor em Ciências na Área de Tecnologia Nuclear - Aplicações

Orientadora:

Profa. Dra. Letícia Lucente Campos Rodrigues 
Ao Instituto de Pesquisas Energéticas e Nucleares, aos pesquisadores, aos tecnologistas $e$ aos interessados em TL e OSL. 


\section{AGRADECIMENTOS}

Devo ao Instituto de Pesquisas Energéticas e Nucleares (IPEN) e à Comissão Nacional de Energia Nuclear (CNEN) a grande parte de minha capacitação pessoal e profissional.

A estrutura organizacional do IPEN, muitos laboratórios, equipamentos e técnicas mudaram desde que fui admitido como servidor. Tive a oportunidade de exercer minhas atividades no Laboratório de Descontaminação, na Supervisão de Radioproteção e no Laboratório de Materiais Dosimétricos (LMD).

Quero manifestar os meus agradecimentos ao atual superintendente do IPEN, Dr. Nilson Dias Vieira Junior e aos dirigentes da instituição pelo meu aprendizado e pela oportunidade para o desenvolvimento deste trabalho.

Expresso minha admiração e respeito à Dra. Linda Viola Ehlin Caldas, atual gerente da Metrologia das Radiações e Diretora de Segurança Nuclear, que não tem medido esforços para atuar também junto à pós-graduação do IPEN.

Sou grato à Dra. Letícia Lucente Campos Rodrigues, gerente adjunta da GMR e orientadora do doutorado, por ter-me admitido no LMD, onde pude ter o contato com o crescimento de cristais de $\mathrm{CaSO}_{4}$ :Dy e com a produção de pastilhas dosimétricas. Os rastros do conhecimento deixados na área de materiais termoluminescentes e da dosimetria foram e continuam sendo muito valiosos aos que a seguem. Não foram menos preciosos os pareceres, sugestões, críticas e as correções referentes a este trabalho; não esquecendo seu profissionalismo, dedicação ao trabalho, coleguismo e amizade.

Sob esta Gerência, fui o responsável pelo LMD e pelo controle da qualidade dos cristais de $\mathrm{CaSO}_{4}: \mathrm{Dy}$, enquanto o Sr. Antônio Cornélio de Souza produziu milhares de pastilhas dosimétricas de $\mathrm{CaSO}_{4}$ :Dy sinterizadas com politetrafluoretileno. Essas pastilhas são utilizadas no IPEN para a monitoração externa da radiação e em muitos trabalhos de dosimetria por termoluminescência.

Desejo citar "in memorian" o Dr. Achilles Afonso Suares, chefe do antigo Centro de Proteção Radiológica e Dosimetria onde fui admitido e o Dr. Sudernaique Fernandes de Deus, professor do curso de Proteção Radiológica. 
Sou grato ao Prof. Dr. Gian-Maria Agostino Angelo Sordi, orientador do Mestrado, cuja dissertação sobre a "contaminação radioativa das roupas protetoras feitas de tecido e sua descontaminação em soluções aquosas" tinha em vista reduzir os riscos da contaminação dos trabalhadores.

Agradeço ao Prof. Dr. Alberto Saburo Todo, líder incentivador do grupo da Supervisão de Radioproteção do IPEN, da COPESP e da UCRI, e coordenador do grupo de atendimento à emergência radiológica, na época em que o Dr. Laércio Antônio Vinhas foi o Diretor da Segurança Nuclear.

Sou grato ao Engenheiro Flávio Betti que instalou a placa de aquisição de dados no leitor de termoluminescência Harshaw modelo 2000 e desenvolveu o programa para a aquisição dos dados da curva TL. A placa instalada e o programa desenvolvido em LabView ${ }^{\circledR}$ permitiram a obtenção da curva TL na planilha Excel da Microsoft ${ }^{\circledR}$.

Recordo-me com satisfação da receptividade da Dra. Margit Osvay na ocasião da minha visita ao Instituto de Isótopos da Hungria. Agradeço à Dra. Margit pelas amostras do dosímetro de $\mathrm{Al}_{2} \mathrm{O}_{3}: \mathrm{Mg}, \mathrm{Y}$.

Agradeço à empresa Elfusa Geral de Eletrofusão Ltda. pelo fornecimento da amostra de alumina eletrofundida.

Agradeço ao Prof. Dr. Shigueo Watanabe que permitiu que assistisse às suas aulas sobre termoluminescência. Agradeço à Profa. Dra. Elizabeth Mateus Yoshimura e ao Prof. Dr. Eduardo Gardenali Yukihara pelo curso sobre OSL ministrado no Instituto de Física da Universidade de São Paulo.

Agradeço à Dra. Dolores R. R. Lazar, professora da disciplina Ciência dos Materiais, que me introduziu ao Laboratório de Insumos do Centro de Ciência e Tecnologia de Materiais (CCTM) para estudar o método da coprecipitação. Ao Dr. Walter Kenji Yoshito que me acompanhou no processo de obtenção da alumina em laboratório e na confecção de pastilhas sinterizadas. Ao Dr. Valter Ussui pelas informações sobre os difratogramas de raios $\mathrm{X}$ dos compostos do alumínio.

Usufruí dos préstimos oferecidos pelo CCTM, lembrando especialmente do colega Rene Ramos de Oliveira do Laboratório da Difração de Raios X, e dos colegas do Laboratório de Microscopia Eletrônica de Varredura.

Sou grato à Dra. Maria José Armelin da Radioquímica que fez a análise das amostras de alumina por ativação neutrônica; ao Dr. Marcos Scapin pela análise da composição do vidro de cal e soda. 
Devo minha gratidão ao Dr. Wilson Calvo e à Dra Margarida Hamada do Centro de Tecnologia das Radiações (CTR); aos engenheiros Elizabeth S. R. Somessari e Carlos G. da Silveira pelas irradiações das amostras. À Dra. Luci Diva Brocardo Machado e ao Marcelo Bardi pela análise termogravimétrica das amostras de alumina obtida por coprecipitação.

Sou levado também a agradecer aos colegas da GMR, que fazem parte do cotidiano: Aldo Ramos de Oliveira, Ana Maria de S. Silva, Ana Maria S. Galante, Claudinei T. Cescon, Donata C. de Oliveira Zanin, Gelson Pinto dos Santos, Dr. Joaquim Carlos Sanches Cardoso, Maíra Goes Nunes, Marcos Xavier, Maria da Penha A. Potiens, Maria de Fátima F. Martins, Marina Ferreira Lima, Orlando Rodrigues Jr., Osvaldo Cordeiro Alípio, Raphael E. Diniz, Tereza de M. S. Vasconcelos, Valdir de S. Carvalho, Vicente de P. de Campos e Vítor Vívolo.

Desejo sucesso aos colegas da GRP, particularmente à Dra. Teresinha de Morais da Silva que também atuou no LMD e também ao Dr. Demerval Leônidas Rodrigues, Carlos Alberto Rodrigues da Costa, Francisco Mário Feijó Vasques, Dr. Fábio Fumio Suzuki, Eduardo Gerulis, Dra. Janete Cristina G. G. Carneiro, José Carlos Barbosa da Silva, Hélio F. Leôncio, Dra. Malvina Boni Mitake, Massao Kamonseki, Matias Puga Sanches e à Sandra Aparecida Bellintani.

Aos colegas da pós-graduação e bolsistas Dra. Maíra Tiemi Yoshizumi, Christianne Cobello Cavinato e Luciana C. Matsushima.

Quero agradecer também às pessoas não citadas nominalmente, mas que fazem parte desta organização - IPEN - e que contribuem para gerar conhecimentos e habilidades.

Aos da limpeza, jardinagem, segurança, cantina, manutenção, informática, saúde, alimentação, biblioteca, administração, gráfica, secretaria, ensino, empresas terceirizadas; aos fornecedores, técnicos, engenheiros, pesquisadores e aos tecnologistas. Muito obrigado!

Aos do meu lar Neuza, Olivia e Vincent, minha gratidão pelo carinho, diálogo, compreensão e apoio.

Sou muito grato a Deus pela saúde, inspiração e pela vida. A existência não teria significado, nem haveria relacionamento humano se não fosse a maravilhosa graça do doador da vida e do detentor dos mistérios da ciência. 
"Ainda que eu tenha o dom de profecia e saiba todos os mistérios e todo o conhecimento, e tenha uma fé capaz de mover montanhas, se não tiver amor, nada serei”.

"If I have the gift of prophecy

and can fathom all mysteries and all knowledge,

and if I have a faith that can move mountains,

but have not love, I am nothing".

[Apóstolo Paulo, na primeira carta aos coríntios, capítulo 13, versículo 2. International Bible Society, Holy Bible portuguese-english New International Version. Editora Vida, São Paulo, 2003.] 


\title{
DESENVOLVIMENTO E ESTUDO DE MATERIAIS TERMOLUMINESCENTES BASEADOS EM ÓXIDO DE ALUMÍNIO PARA APLICAÇÃO EM DOSIMETRIA
}

\author{
David Tadashi Fukumori
}

\section{RESUMO}

O óxido de alumínio foi um dos primeiros compostos investigados, com vista a detectar e medir a radiação por meio da termoluminescência (TL). Comumente referido como "alumina", o óxido de alumínio tem características interessantes para o desenvolvimento de materiais para a dosimetria. Seu número atômico efetivo é intermediário entre o do osso e do tecido mole do corpo. Pode ser transformado em material termoluminescente pela inserção de elementos químicos em sua estrutura cristalina. Além da TL, a alumina pode apresentar luminescência opticamente estimulada (OSL), fenômeno que também pode ser usado para determinar a dose de radiação. Neste estudo, dois métodos foram investigados para inserir íons metálicos na alumina. $\mathrm{O}$ primeiro método foi baseado na capacidade de adsorção da alumina e o segundo denominado método da coprecipitação foi baseado na formação simultânea de compostos insolúveis. As amostras obtidas por adsorção de íons $\mathrm{Cu}^{2+}$ e $\mathrm{Mn}^{2+}$ não mostraram resultados satisfatórios. No entanto, as pastilhas de óxido de alumínio impurificado com $\mathrm{Tm}^{3+}$ via coprecipitação mostraram sinais de TL e OSL. Foi verificado também que a alumina eletrofundida disponível comercialmente é um material que apresenta resposta TL e OSL. Este material que contém diversos íons metálicos em sua estrutura foi transformado em pastilhas por sinterização com vidro. As curvas da resposta TL em função da temperatura e da resposta TL e OSL em função da dose foram determinadas. Os resultados obtidos indicam que estudos mais aprofundados das pastilhas desenvolvidas podem melhorar suas características para que sejam aplicadas em dosimetria.

Palavras-chave: termoluminescência (TL), luminescência opticamente estimulada (OSL), óxido de alumínio, materiais dosimétricos. 


\title{
DEVELOPMENT AND STUDY OF THERMOLUMINESCENT MATERIALS BASED ON ALUMINUM OXIDE FOR DOSIMETRY APPLICATION
}

\author{
David Tadashi Fukumori
}

\begin{abstract}
The aluminum oxide was one of the former compounds investigated with a view to detecting and measuring radiation by means of the thermoluminescence (TL). Commonly referred to as "alumina", aluminum oxide has interesting features for the development of materials for dosimetry. Its effective atomic number has an intermediate value between the bone and soft tissue of the body. It can be transformed into TL material by the insertion of chemical elements in its crystal structure. In addition to the TL, the alumina can provide optically stimulated luminescence (OSL) which can also be used to determine the radiation dose. In this study, two methods were investigated in order to insert metal ions in alumina. The first method was based on the adsorption capacity of alumina and the second named coprecipitation method was based on the simultaneous formation of insoluble compounds. The samples obtained by adsorption of $\mathrm{Cu}^{2+}$ and $\mathrm{Mn}^{2+}$ ions did not show satisfactory results. However, the aluminum oxide impurified with $\mathrm{Tm}^{3+}$ by coprecipitation showed TL and OSL signals. It was also found that the commercially available electrofused alumina is a material that exhibits TL and OSL. This material that contains various metal ions in its structure was made into pellets by sintering with glass. The TL response curves as a function of temperature and the TL and OSL responses as a function of the dose were determined. The obtained results indicate that further studies of the developed pellets can improve the characteristics in order to be applied in dosimetry.
\end{abstract}

Keywords: thermoluminescence (TL), optically stimulated luminescence (OSL), aluminum oxide, dosimetric materials. 


\section{SUMÁRIO}

Página

1. INTRODUÇÃ

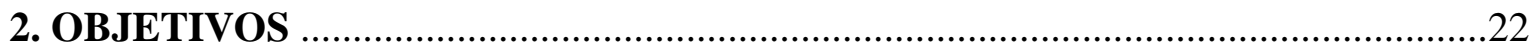

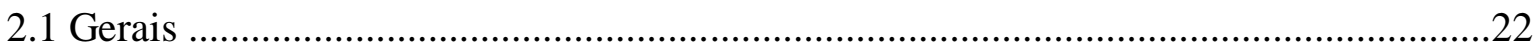

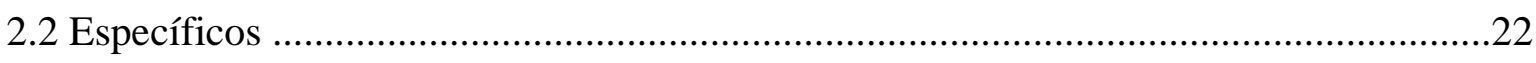

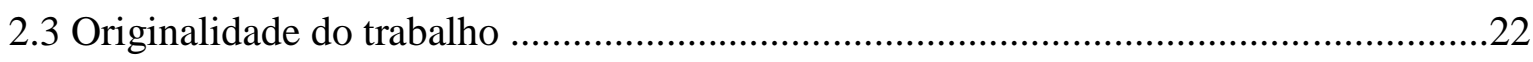

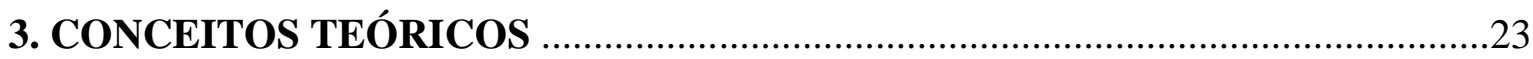

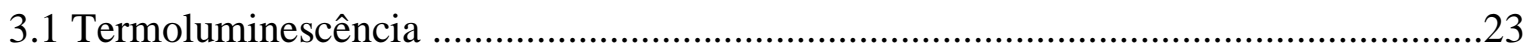

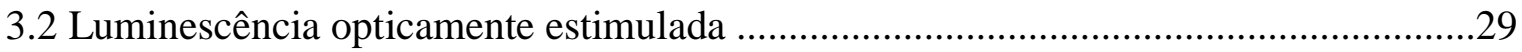

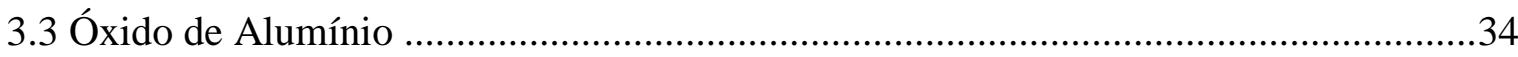

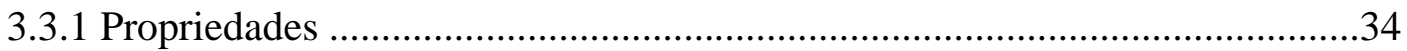

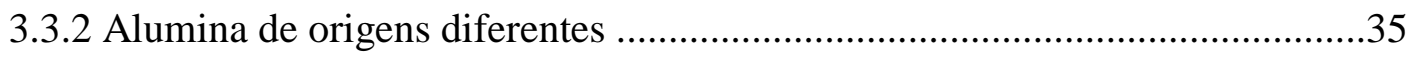

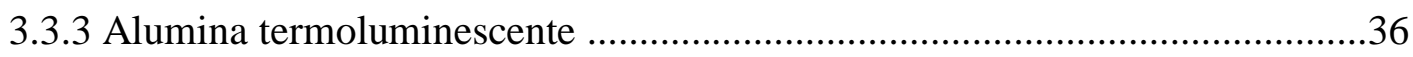

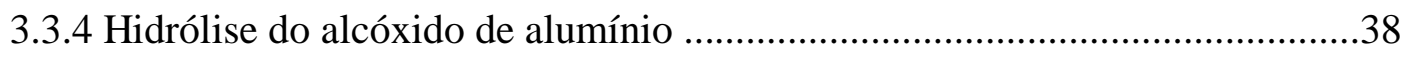

3.3.5 Precipitação do hidróxido de alumínio .............................................................39

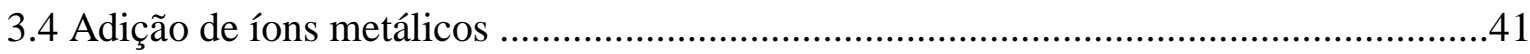

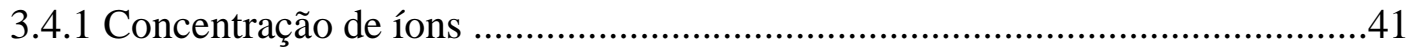

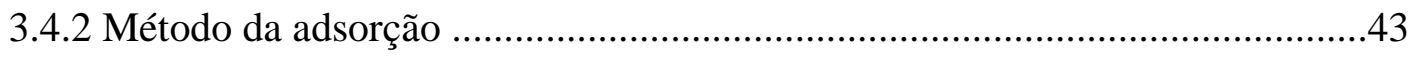

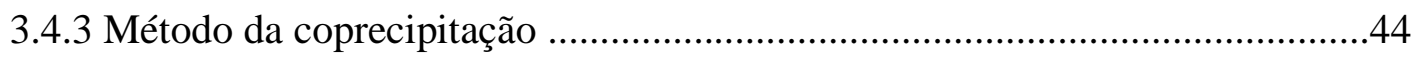

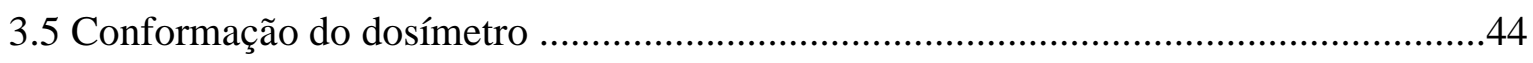

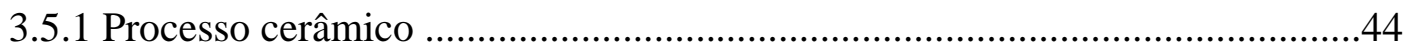

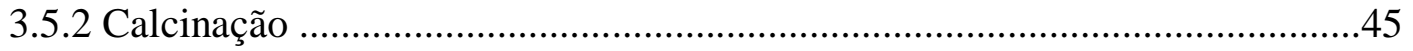

3.5.3 Compactação .......................................................................................4

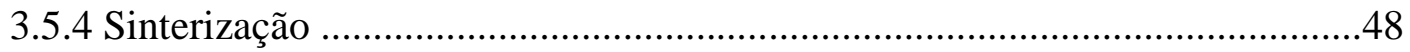

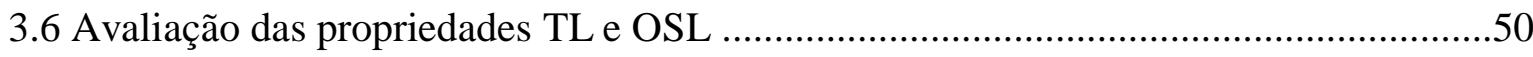

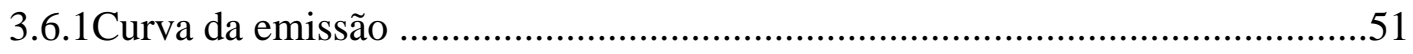

3.6.2 Resposta em função da dose .................................................................51

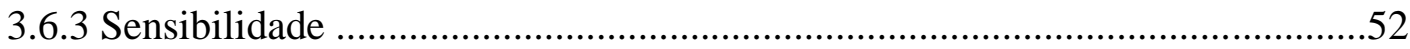




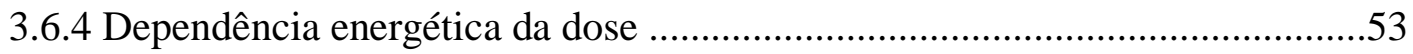

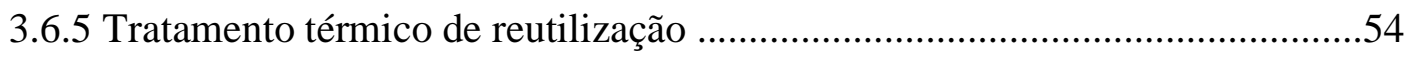

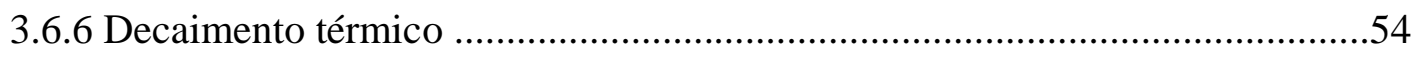

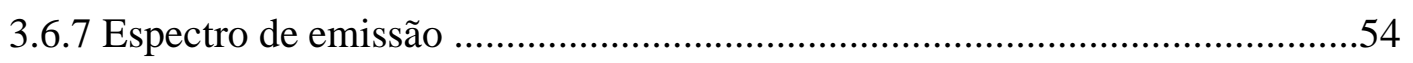

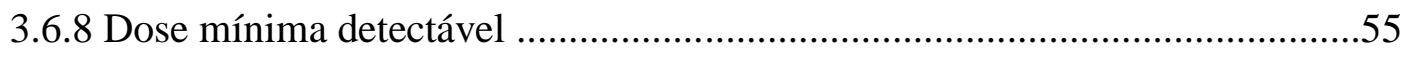

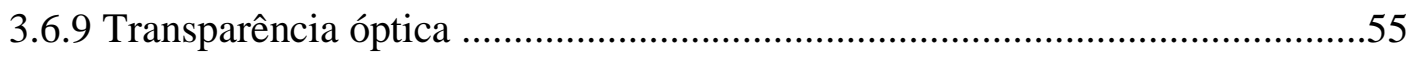

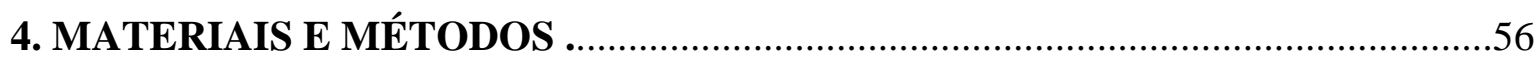

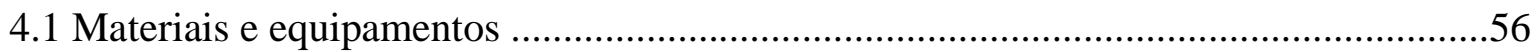

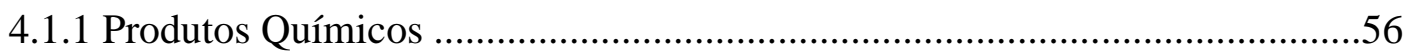

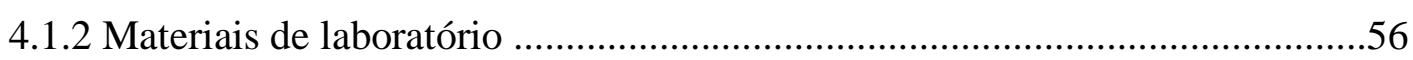

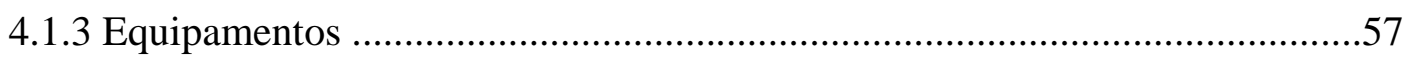

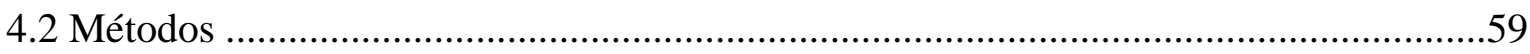

4.2.1 Obtenção de alumina impurificada por adsorção ...........................................59

4.2.2 Obtenção de alumina impurificada por coprecipitação...................................60

4.2.3 Confecção de pastilhas por compactação e sinterização ................................61

4.2.4 Confecção de pastilhas de alumina eletrofundida ........................................62

4.3 Verificação experimental das propriedades TL e OSL ..............................................63

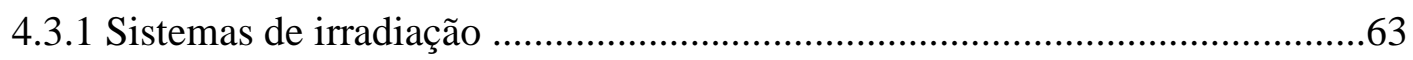

4.3.2 Sistema HARSHAW de leitura TL ..............................................................64

4.3.3. Sistema RIS $\varnothing$ de leitura TL e OSL .............................................................66

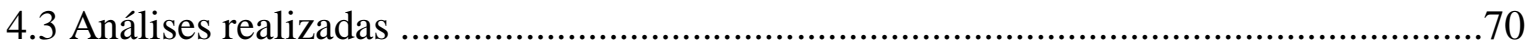

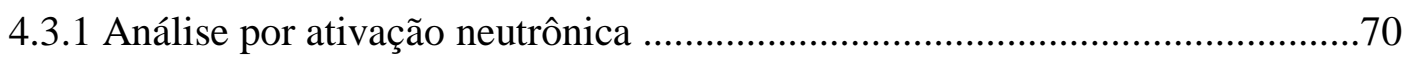

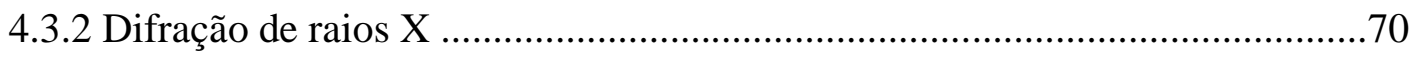

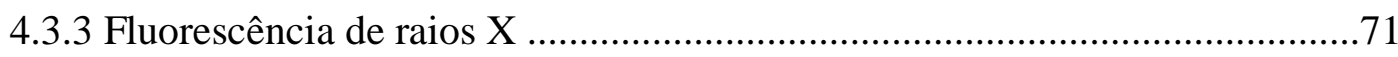

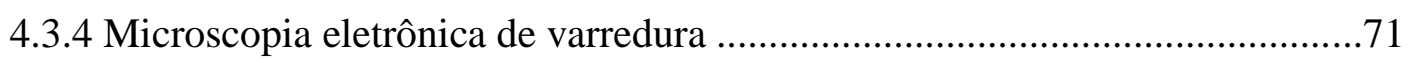

4.3.5 Análise termogravimétrica ................................................................ 71

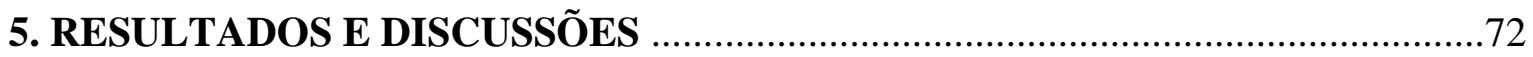

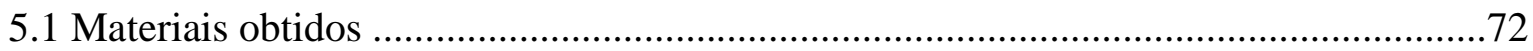

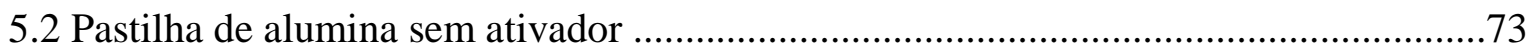

5.3 Pastilha de alumina impurificada por adsorção ............................................................ 75

5.4 Pastilha de alumina impurificada por coprecipitação ................................................... 79

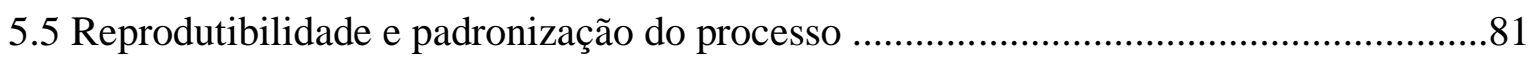

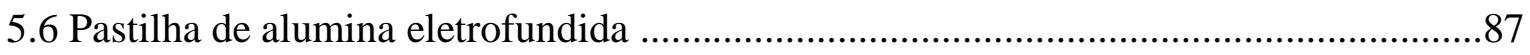




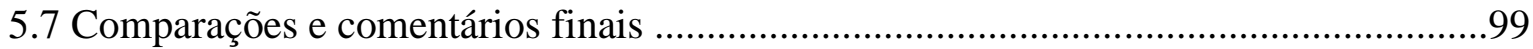

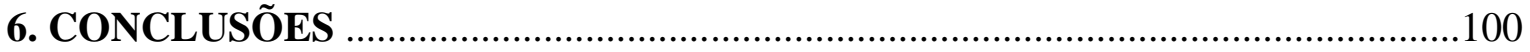

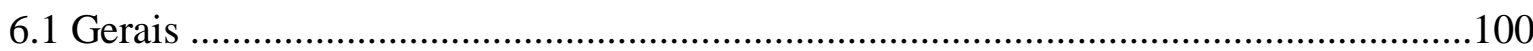

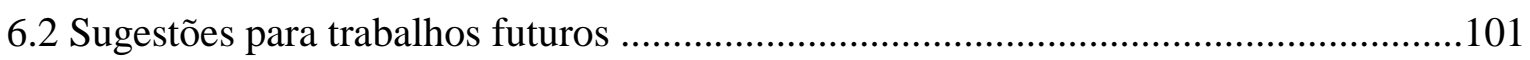

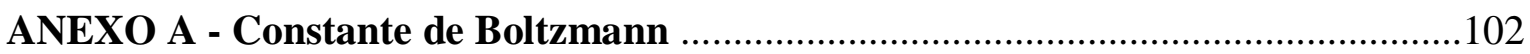

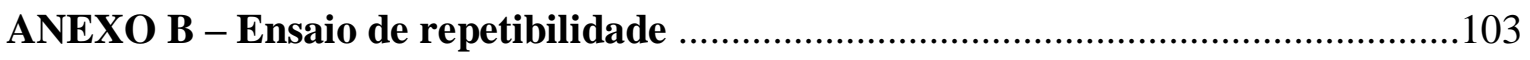

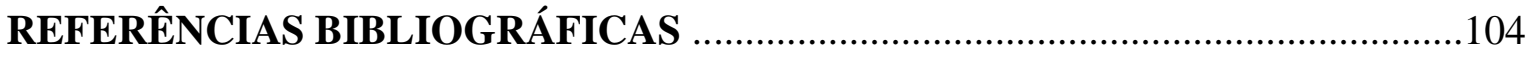




\section{LISTA DE TABELAS}

\section{CONCEITOS TEÓRICOS}

Página

TABELA 3.1- Densidade e condutividade térmica do $\mathrm{Al}_{2} \mathrm{O}_{3}$ segundo sua pureza .35

TABELA 3.2 - Propriedades do trihidróxido, óxido-hidróxido e do óxido de alumínio.....41

\section{RESULTADOS E DISCUSSÕES}

TABELA 5.1 - Valores médios da massa, diâmetro, espessura e da densidade das amostras de pastilhas obtidas.

TABELA 5.2 - Concentração de Fe, K e de Na em alumina obtida por calcinação de hidróxido comercial e precipitado em laboratório.

TABELA 5.3 - Resposta TL em função da dose da pastilha ALTM.

TABELA 5.4 - Grandezas físicas medidas e as respostas TL e OSL das pastilhas ALTM selecionadas.

TABELA 5.5 - Grandezas físicas medidas e as respostas TL e OSL das pastilhas ALBT selecionadas

TABELA 5.6 - Grandezas medidas e calculadas antes e depois do processo de sinterização das pastilhas ALBT .85

TABELA 5.7 - Composição da alumina eletrofundida. . .87

TABELA 5.8 - Composição do vidro utilizado na sinterização da pastilha EAG. .88

TABELA 5.9 - Respostas TL e OSL das pastilhas EAG selecionadas . .97 


\section{LISTA DE FIGURAS}

Página

\section{CONCEITOS TEÓRICOS}

FIGURA 3.1 - Modelo simplificado das bandas de energia para explicar a TL..................23

FIGURA 3.2 - Curva da TL obtida pela equação de Randall-Wilkins................................26

FIGURA 3.3 - Curvas da TL de primeira ordem com valores crescentes de $\mathrm{n}_{0} \ldots \ldots \ldots \ldots \ldots \ldots . . . . . . .27$

FIGURA 3.4 - Curva da TL obtida pela equação de Garlick-Gibson..................................29

FIGURA 3.5 - Intensidade OSL em função do tempo de estimulação..................................32

FIGURA 3.6 - Técnicas de OSL conforme o modo de estimulação ...................................33

FIGURA 3.7 - Ilustração da compactação uniaxial do pó para a conformação da pastilha em molde de três orifícios

\section{MATERIAIS E MÉTODOS}

FIGURA 4.1 - Esquema para a produção de pastilhas pelo método da adsorção.

FIGURA 4.2 - Esquema para a obtenção da alumina impurificada pelo método da

coprecipitação.

FIGURA 4.3 - Leitor de TL marca Harshaw modelo 2000. O módulo A à esquerda encerra o tubo fotomultiplicador que detecta a TL. O módulo B à direita é um picoamperímetro integrador automático

FIGURA 4.4 - Módulo B do leitor Harshaw modelo 2000, com a parte interna à mostra onde foi posicionada a placa de aquisição de dados

FIGURA 4.5 - Leitor TL/OSL RIS $\varnothing$ modelo DA-20 e seu controlador.

FIGURA 4.6 - Leitor RIS $\varnothing$ com o compartimento de amostras aberto.

FIGURA 4.7 - Tela do programa “Sequence Editor” para fornecer instruções ao leitor RIS $\varnothing$.

FIGURA 4.8 - Tela do programa "Analist" que permite visualizar e analisar as curvas da TL e da OSL

FIGURA 4.9 - Ilustração mostrando a luz de estimulação e o filtro de detecção utilizado para a leitura OSL. 


\section{RESULTADOS E DISCUSSÕES}

FIGURA 5.1 - Pastilhas EAG, ALTM e ALBT.

FIGURA 5.2 - Difratogramas de raios X das amostras da alumina calcinada em diferentes

temperaturas. . .74

FIGURA 5.3 - Difratograma de raios X da pastilha ALCP. .74

FIGURA 5.4 - Micrografia da superfície de fratura da pastilha ALCP. . .75

FIGURA 5.5 - Micrografia do hidróxido de alumínio impurificado com $\mathrm{Mn}^{2+}$, com ampliação de 100x.

FIGURA 5.6 - Micrografia do hidróxido de alumínio impurificado com $\mathrm{Mn}^{2+}$, com ampliação de 1000x.

FIGURA 5.7 - Micrografia do hidróxido de alumínio impurificado com $\mathrm{Mn}^{2+}$, com ampliação de 15000x. .77

FIGURA 5.8 - Micrografia da superfície de fratura da pastilha ALMN. .77

FIGURA 5.9 - Difratogramas de raios X do hidróxido de alumínio impurificado com $\mathrm{MnSO}_{4}$ e da pastilha ALMN.

FIGURA 5.10 - Curvas da TL da pastilha ALTM irradiada com fonte beta de ${ }^{90} \mathrm{Sr} /{ }^{90} \mathrm{Y}$ com doses de 100, 200, 300, 500 e 800 mGy..... .79

FIGURA 5.11 - Resposta TL em função da dose da pastilha ALTM. 81

FIGURA 5.12 - Curvas da OSL da pastilha ALTM. .81

FIGURA 5.13 - Resposta TL da pastilha ALBT em função da dose beta .84

FIGURA 5.14 - Curvas OSL da pastilha ALBT irradiadas com fontes beta. .84

FIGURA 5.15 - Resposta OSL da pastilha ALBT em função da dose beta .85

FIGURA 5.16 - Curvas da TGA e da DSC das amostras de $\mathrm{Al}_{2} \mathrm{O}_{3}$ impurificadas com túlio.

FIGURA 5.17 - Difratogramas de raios X do vidro de cal e soda, dos cristais de alumina eletrofundida e da pastilha EAG.

FIGURA 5.18 - Micrografia da superfície de fratura da pastilha de alumina eletrofundida sinterizada com vidro (EAG) .90

FIGURA 5.19 - Curva TL da alumina eletrofundida fornecida pela ELFUSA.

FIGURA 5.20 - Curvas TL da pastilha EAG (a) sem tratamento térmico de pós-irradiação (TTPI) e (b) com TTPI. .91

FIGURA 5.21 - Resposta TL em função da dose das pastilhas EAG. 
FIGURA 5.22 - Resposta TL das pastilhas EAG para doses acima de $800 \mathrm{mGy}$. (a) sem

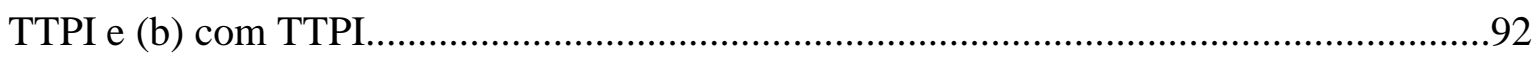

FIGURA 5.23 - Curva TL da pastilha EAG obtida por meio do leitor RIS $\emptyset$......................93

FIGURA 5.24 - Curvas da TL da pastilha EAG correspondentes a 2, 4, 8 e 12 Gy de

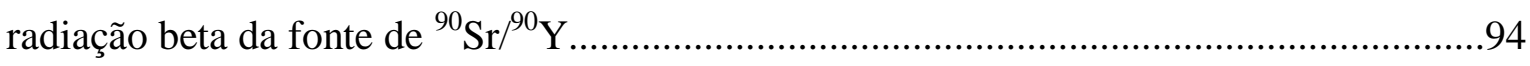

FIGURA 5.25 - Deslocamento dos picos da TL para temperaturas mais altas, com o

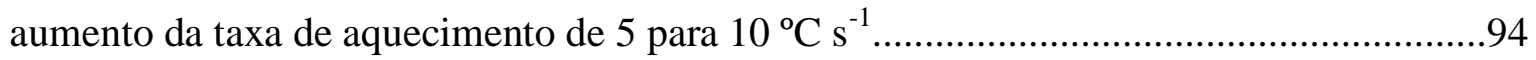

FIGURA 5.26 - Resposta TL em função da dose beta da pastilhas EAG............................95

FIGURA 5.27 - Curvas OSL de pastilhas EAG irradiadas com fonte beta.........................96

FIGURA 5.28 - Resposta OSL das pastilhas EAG em função da dose de radiação

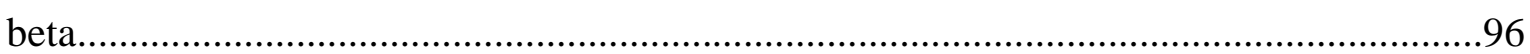

FIGURA 5.29 - Efeito do aquecimento escalonado no sinal da OSL (step annealing).......97 FIGURA 5.30 - Perfis das curvas TL de quatro pastilhas EAG distintas observados no leitor RIS $\varnothing$ .98

FIGURA 5.31 - Perfis das curvas OSL de quatro pastilhas EAG distintas observados no leitor RIS $\emptyset$. 


\section{LISTA DE ABREVIATURAS E SIGLAS}

ALBT - Pastilha sinterizada de alumina impurificada com túlio (de $20 \mathrm{mg}$ ).

ALCP - Pastilha sinterizada de alumina precipitada sem ativador.

ALMN - Pastilha sinterizada de alumina impurificada com manganês.

ALTM - Pastilha sinterizada de alumina impurificada com túlio.

ASCII - American Standard Code for Information Interchange (Código Padrão Americano para o Intercâmbio de Informação).

BC - Banda de Condução.

BP - Banda Proibida.

BV - Banda de Valência.

CCTM - Centro de Ciência e Tecnologia de Materiais.

COPESP - Coordenadoria de Projetos Especiais (da Marinha do Brasil).

CNEN - Comissão Nacional de Energia Nuclear.

CQMA - Centro de Química do Meio Ambiente.

CRPq - Centro de Reatores de Pesquisas.

CTR - Centro de Tecnologia das Radiações.

CW-OSL - Continuous Wave OSL.

DSC - Differencial Scanning Calorimetry.

EAG - Electrofused Alumina-Glass (pastilha de alumina eletrofundida sinterizada com vidro).

ELFUSA - Elfusa Geral de Eletrofusão Ltda.

GMR - Gerência de Metrologia das Radiações.

HCP - Hexagonal Close-Packed.

IPEN - Instituto de Pesquisas Energéticas e Nucleares.

LED - Light Emitting Diode (diodo emissor de luz).

LMD - Laboratório de Materiais Dosimétricos.

LM-OSL - Linearly Modulated OSL.

OSL - Optically Stimulated Luminescence.

POSL - Pulsed OSL.

PTFE - Polytetrafluoroethylene (politetrafluoretileno). 
PVA - Polyvinyl Alcohol (álcool polivinílico).

$\mathrm{R}$ - Recombination (Centro de recombinação).

RIS $\varnothing$ - Nome do Laboratório Nacional da Dinamarca, atualmente designado RIS $\varnothing$ DTU National Laboratory for Sustainable Energy.

$\mathrm{T}$ - Trap (armadilha).

TFM - Tubo fotomultiplicador.

TGA - Thermogravimetric Analysis (análise termogravimétrica).

TL - Termoluminescence (termoluminescência ou termoluminescente).

TLD-100 - Dosímetro TL de fluoreto de lítio comercializado pela empresa Harshaw.

TR - Terra-rara ou terras-raras.

UCRI - Unidade Crítica. 


\section{INTRODUÇÃO}

A dosimetria das radiações tem sido um paralelo à tecnologia nuclear, dada a necessidade de medir e de controlar as doses de radiação recebidas pelos trabalhadores envolvidos com materiais radioativos e com dispositivos geradores de radiações ionizantes, bem como para restringir a dose de radiação dos indivíduos do público.

A termoluminescência é um fenômeno independente da incandescência térmica verificado em determinados cristais não-condutores. Quando expostos à radiação ionizante, os materiais termoluminescentes emitem luz ao serem aquecidos. Esses materiais são úteis à dosimetria, quando a intensidade luminosa ou a quantidade da luz emitida apresentar uma correlação com a dose de radiação (Campos, 1998).

A termoluminescência é usualmente designada pela forma abreviada TL. É também comum empregar a mesma abreviação com o significado qualitativo para discriminar o material que exibe a termoluminescência como material TL. Vários minerais, materiais cerâmicos e compostos inorgânicos são termoluminescentes (TL) e podem ter utilidade em dosimetria das radiações.

A possibilidade da utilização de materiais TL em dosimetria das radiações começou a ser investigada em 1947, na Universidade de Wisconsin. A pesquisa incluía o estudo da TL em cristais, a tentativa de desenvolver dosímetros e a construção de instrumentos de medição. Daniels e seus colaboradores estudaram a TL do fluoreto de lítio e do óxido de alumínio. Os resultados da investigação da TL de diferentes óxidos de alumínio foram publicados por Rieke \& Daniels (1957).

No entanto, o fluoreto de lítio estudado por Cameron e seus colaboradores (1968) teve maior repercussão como material dosimétrico. Coube à empresa Harshaw Chemical Company a patente do dosímetro de fluoreto de lítio dopado com magnésio e titânio (LiF:Mg,Ti), dosímetro mundialmente conhecido por TLD-100. A mesma empresa produziu e comercializou vários tipos de dosímetros e instrumentos para a medição da TL (Cox, 2004).

A TL do óxido de alumínio pode ser promovida ou intensificada pela inserção de certos elementos químicos na sua estrutura cristalina. O processo de inserção de elementos na estrutura de um material é denominado “dopagem” ou “impurificação”. Vários métodos 
de dopagem foram experimentados por diferentes pesquisadores para obter óxido de alumínio termoluminescente para dosimetria (McKeever et al., 1995).

Segundo McKeever e seus colaboradores (1995), o óxido de alumínio termoluminescente impurificado com silício e titânio $\left(\mathrm{Al}_{2} \mathrm{O}_{3}: \mathrm{Si}, \mathrm{Ti}\right)$ foi obtido por Mehta e Sengupta. Mais recentemente, as propriedades TL desse material foram estudadas por Bhatt et al. (2008).

Dosímetros cerâmicos de $\mathrm{Al}_{2} \mathrm{O}_{3}: \mathrm{Mg}, \mathrm{Y}$ foram desenvolvidos na Hungria; cujas características foram apresentadas por Osvay \& Biró (1980). O método de obtenção e suas propriedades foram descritos por McKeever e seus colaboradores (1995).

Em 1990, cristais de óxido de alumínio deficientes de ânions e ativado com carbono foram anunciados como material TL muito sensível à radiação ionizante. Os cristais representados por $\alpha-\mathrm{Al}_{2} \mathrm{O}_{3}: \mathrm{C}$ foram obtidos no Instituto Politécnico de Urais da antiga União Soviética em um processo envolvendo a fusão do óxido de alumínio em ambiente altamente redutor (Akselrod et al., 1990, 1993). O material obtido foi indicado para avaliar doses baixas de radiação, entre $0,05 \mathrm{mGy}$ e $1 \mathrm{~Gy}$, sendo útil para dosimetria pessoal e medições ambientais.

Nos anos que se seguiram ao anúncio do $\alpha-\mathrm{Al}_{2} \mathrm{O}_{3}: \mathrm{C}$, muitos pesquisadores estudaram suas características (Prokic \& Bøtter-Jensen, 1993; Kortov et al., 1994 e 1996). Foi constatado que o sinal da TL era susceptível ao decaimento óptico induzido pela luz. As características do $\alpha-\mathrm{Al}_{2} \mathrm{O}_{3}: \mathrm{C}$ mostraram-se úteis à técnica da luminescência opticamente estimulada (Akselrod et al., 1998; Bøtter-Jensen et al., 2003).

A luminescência opticamente estimulada é conhecida pela forma abreviada OSL, originada das iniciais dos termos em inglês. A técnica da OSL foi estendida à dosimetria ambiental, pessoal, de doses altas, médica, retrospectiva, espacial e à datação arqueológica. A empresa Landauer comercializa equipamentos e oferece os serviços de dosimetria baseados na OSL do $\alpha-\mathrm{Al}_{2} \mathrm{O}_{3}$ :C. Os dosímetros foram registrados com a marca Luxel ${ }^{\circledR}$ (Bøtter-Jensen et al., 2003; Akselrod et al., 2007).

Métodos alternativos de preparação de $\alpha-\mathrm{Al}_{2} \mathrm{O}_{3}: \mathrm{C}$ de grau dosimétrico foram investigados por Kulkarni e seus colab. (2005). Cristais de alumina alfa foram impurificados abaixo do ponto de fusão, em vácuo, na presença de grafite, resultando em monocristais de $\alpha-\mathrm{Al}_{2} \mathrm{O}_{3}: \mathrm{C}$ com vacância de íon negativo.

O óxido de alumínio é um material comumente designado "alumina" que se apresenta geralmente em forma de pó utilizado para a produção de alumínio metálico, para 
a fabricação de cerâmica, abrasivos, refratários e de isoladores elétricos (Constantino et al., 2002). Reúne certas características interessantes para o desenvolvimento de material para a dosimetria. Pode ser obtido em laboratório com custo relativamente baixo. Seu número atômico efetivo é intermediário entre o do osso e o do tecido mole do corpo (Bos, 2001).

O ponto de fusão do óxido de alumínio é muito elevado, situado acima de $2000{ }^{\circ} \mathrm{C}$. Considerando que a tecnologia para crescimento de cristais a partir de materiais sólidos fundidos requer fornos, equipamentos, materiais e técnicas para temperaturas altas, subentende-se que investimento inicial para a obtenção de cristais via fusão do óxido de alumínio pode ser muito oneroso (Scheel \& Fukuda, 2003).

No Brasil, diversos pesquisadores têm se dedicado aos estudos da termoluminescência de materiais naturais e sintetizados em laboratório, com o intuito de obter dosímetros para a medição da radiação. Uma revisão sobre materiais termoluminescentes e sua aplicação em dosimetria da radiação foi feita por Campos (1998). Os estudos incluem a fenomenologia da termoluminescência, as características específicas necessárias para que um material seja utilizado como dosímetro termoluminescente, as propriedades dosimétricas, o funcionamento de um sistema dosimétrico e suas aplicações.

O IPEN mantém o conhecimento e a técnica para produzir pastilhas dosimétricas de $\mathrm{CaSO}_{4}:$ Dy sinterizadas com teflon ${ }^{\circledR}$ para detecção da radiação beta, X e gama . Essas pastilhas são consideradas dosímetros de alta sensibilidade e seu processo de obtenção foi aperfeiçoado na década de 80 (Campos \& Lima, 1987; Campos et al.; 1989). Os dosímetros de $\mathrm{CaSO}_{4}$ :Dy são utilizados na monitoração pessoal externa, em dosimetria clínica e ambiental (Campos, 1998).

O processo cerâmico seguindo a rota da tecnologia do pó permite obter corpos policristalinos de materiais sinterizados bem abaixo do ponto de fusão da alumina (Rahaman, 2003). No IPEN, dosímetros de alumina foram produzidos por sinterização, para uso em radioterapia (Rocha \& Caldas, 1999; Silva et al., 2000).

Pesquisadores da Universidade Federal de Pernambuco obtiveram óxido de alumínio termoluminescente dopado com térbio $\left(\alpha-\mathrm{Al}_{2} \mathrm{O}_{3}: \mathrm{Tb}\right)$ e óxido de alumínio dopado com túlio $\left(\alpha-\mathrm{Al}_{2} \mathrm{O}_{3}: \mathrm{Tm}\right)$ pelo método da combustão (Barros et al., 2010). Seus estudos

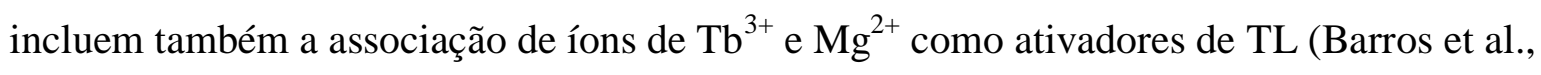
2010b).

Neste trabalho, dois métodos para inserir íons metálicos em alumina foram investigados e testados. O primeiro método foi baseado na capacidade de adsorção e o 
segundo método foi baseado na formação simultânea de compostos pouco solúveis com hidróxido de alumínio, designado método da coprecipitação.

O método da coprecipitação é utilizado para sintetizar materiais cerâmicos com interesse científico; é relativamente simples e barato (Lazar et al., 2008). Esse método foi adotado para obter a pastilha de óxido de alumínio impurificado com $\mathrm{Tm}^{3+}$. A pastilha sinterizada foi irradiada e lida no sistema combinado de leitura TL e OSL e suas propriedades foram apresentadas.

Foi verificado também que a alumina eletrofundida disponível comercialmente como abrasivo (Marinescu et al., 2007) é um material que apresenta sinais TL e OSL. Esse material que contém vários íons metálicos na sua composição foi transformado em pastilhas por meio da sinterização vítrea para estudo de suas propriedades dosimétricas.

Os resultados preliminares dos estudos dos dosímetros produzidos no IPEN com óxido de alumínio impurificado com túlio e com alumina eletrofundida foram apresentados por Fukumori e seus colaboradores (2011).

Inevitavelmente novos materiais serão criados com a modernização dos equipamentos nos campos da cerâmica avançada, ciência e engenharia dos materiais (Kortov, 2007). 


\section{OBJETIVOS}

\subsection{Gerais}

Este trabalho foi elaborado com o objetivo de desenvolver materiais termoluminescentes baseados no óxido de alumínio $\left(\mathrm{Al}_{2} \mathrm{O}_{3}\right)$ pela inserção de elementos químicos em sua estrutura cristalina, utilizando diferentes técnicas analíticas para a caracterização morfológica desses materiais. Têm-se também como objetivo estudar as propriedades dos materiais desenvolvidos para avaliar a possibilidade de sua aplicação em dosimetria externa das radiações, empregando as técnicas da termoluminescência (TL) e da luminescência opticamente estimulada (OSL).

\subsection{Específicos}

Os objetivos específicos deste trabalho foram

- rever a bibliografia referente aos materiais termoluminescentes feitos de $\mathrm{Al}_{2} \mathrm{O}_{3}$, dando atenção maior às técnicas de obtenção e às propriedades dosimétricas,

- adicionar íons de $\mathrm{Mn}^{2+} \mathrm{e} \mathrm{Cu}^{2+}$ no óxido de alumínio pelo método da adsorção,

- adicionar íons de $\mathrm{Tm}^{3+}$ no óxido de alumínio pelo método da coprecipitação,

- obter pastilhas sinterizadas de óxido de alumínio,

- verificar e caracterizar as propriedades TL e OSL dos materiais desenvolvidos,

- verificar a reprodutibilidade do processo de produção e padronizar.

\subsection{Originalidade do trabalho}

- Produzir materiais que apresentam TL e OSL por meio da inserção de $\mathrm{Tm}^{3+}$ na estrutura cristalina do óxido de alumínio pelo método da coprecipitação e sinterização.

- Estudar as propriedades TL e OSL das pastilhas sinterizadas de óxido de alumínio impurificado com túlio $\left(\alpha-\mathrm{Al}_{2} \mathrm{O}_{3}: \mathrm{Tm}\right)$.

- Estudar as propriedades TL e OSL das pastilhas desenvolvidas por meio da sinterização vítrea de alumina eletrofundida. 


\section{CONCEITOS TEÓRICOS}

\subsection{Termoluminescência}

Há grande quantidade de literatura sobre a TL e suas aplicações em dosimetria. Citam-se Cameron et al. (1968), Becker (1973), Portal (1981, 1986), Maresh et al. (1989), Shani (1991), McKeever et al. (1995), Campos (1998) e Furetta (2003). Uma revisão dos conceitos teóricos sobre a TL e as aplicações foi feita por Bos (2007).

O fenômeno da TL e muitas das suas propriedades são explicados com auxílio de um modelo simplificado das bandas de energia dos materiais isolantes, representado esquematicamente na FIG. 3.1 (Campos, 1998; Bos, 2007).

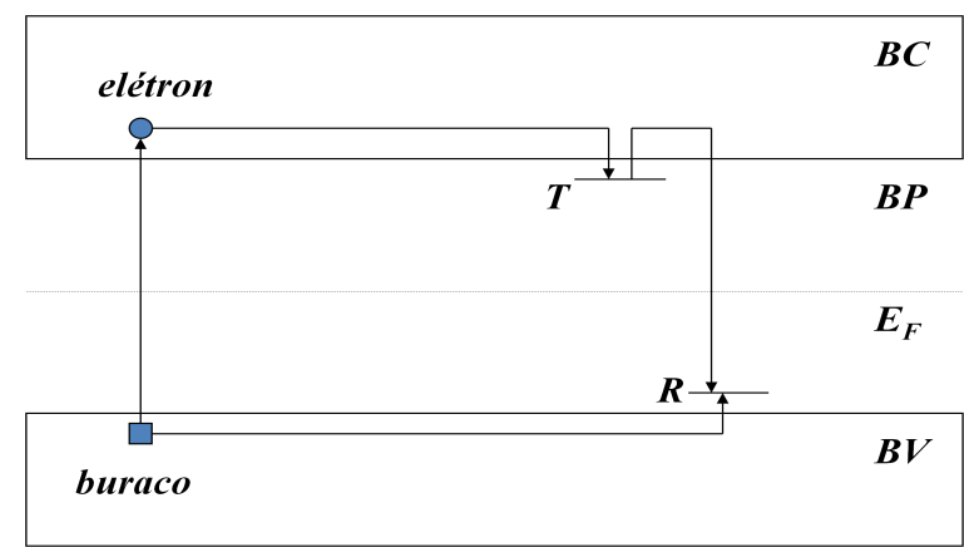

FIGURA 3.1 - Modelo simplificado das bandas de energia para explicar a TL, adaptado de Campos (1998).

Os materiais TL geralmente são cristalinos e isolantes. Os átomos de um sólido cristalino constituem uma estrutura rígida de unidades repetitivas denominadas células unitárias. Os orbitais dos elétrons mais energéticos dos átomos ordenados na estrutura cristalina se sobrepõem, formando bandas contínuas de energia, discriminadas como banda de condução (BC), banda proibida (BP) e banda de valência (BV).

No estado fundamental, esse tipo de material exibe a banda de valência repleta de elétrons, enquanto a banda de condução está completamente vazia. A BV e a BC estão separadas pela banda proibida, correspondente à diferença de energia $\mathrm{E}_{\mathrm{g}}$. Para o óxido de 
alumínio puro, a energia correspondente ao espaçamento entre as bandas é $\mathrm{E}_{\mathrm{g}}=7,4 \mathrm{eV}$ (Kingery, 1976). A BP é dividida em duas metades pela linha de equilíbrio de Fermi $\left(\mathrm{E}_{\mathrm{F}}\right)$.

Ao ser submetido a um campo de radiação ionizante, elétrons da banda de valência podem ser ejetados à banda de condução, concomitantemente à formação de buracos na banda de valência. Na FIG. 3.1, o elétron está representado por (o) e o buraco por ( $\square$ ).

Os elétrons levados à $\mathrm{BC}$ percorrem livremente pela banda até serem capturados pela armadilha $(\mathrm{T})$, situada na banda proibida. Analogamente aos elétrons ejetados à BC, os buracos percorrem a banda de valência até se tornarem presos no centro de recombinação $(\mathrm{R})$.

A armadilha $\mathrm{T}$ e o centro de recombinação $\mathrm{R}$ ocorrem na banda proibida como níveis de energia metaestáveis em consequência de defeitos ou impurezas existentes na estrutura cristalina do material.

Os elétrons e buracos formados durante a irradiação dos cristais e capturados nos níveis de energia metaestáveis $\mathrm{T}$ e $\mathrm{R}$ permanecem presos por um determinado tempo. Esse tempo de permanência dos elétrons e buracos nas armadilhas é expresso pela probabilidade de escape.

Ao aquecer os cristais irradiados, a probabilidade de os elétrons presos na armadilha $\mathrm{T}$ serem liberados para a $\mathrm{BC}$ aumenta em função da temperatura. Os elétrons e os buracos liberados podem se recombinar em $\mathrm{R}$ e emitir fótons de luz, nos processos radiativos designados de "termoluminescência".

O tratamento físico e matemático da TL foi desenvolvido por Randall e Wilkins em 1945 e por Garlick e Gibson em 1948. Os modelos são tradicionalmente conhecidos e envolvem a cinética de primeira e de segunda ordem (McKeever et al., 1995).

O modelo de Randall-Wilkins que descreve o processo da TL de primeira ordem compreende um tipo de armadilha $\mathrm{T}$ e um só tipo de centro de recombinação $\mathrm{R}$ como ilustrado na FIG. 3.1.

A probabilidade $(p)$ de os carregadores de carga (elétrons ou buracos) serem liberados das armadilhas é função da temperatura $(T)$ e está relacionada à energia $(E)$ necessária para que os elétrons superem a barreira de potencial que os mantém presos. A relação é expressa pela equação 3.1 .

$$
p=s \exp (-E / k T)
$$


Onde,

$s$ é o fator de frequência $\left(\mathrm{s}^{-1}\right)$,

$E$ é a energia de ativação ou profundidade da armadilha $(\mathrm{eV})$,

$k$ é a constante de Boltzmann e

$T$ é a temperatura absoluta (K).

A energia $E$ requerida para liberar o elétron da armadilha está ao redor de 1,0 a 1,2 eV. A constante de Boltzmann vale 8,617 $10^{-5} \mathrm{eV} \mathrm{K}^{-1}$ ou 1,381 10 $0^{-23} \mathrm{~J} \mathrm{~K}^{-1}$ (ANEXO A).

À medida que a temperatura aumenta, aumenta também a probabilidade de os elétrons presos serem liberados e de ocorrer recombinação com os buracos. A intensidade da termoluminescência em função do tempo $I(t)$ é proporcional à taxa de recombinação dos elétrons e buracos em R e é dada pela equação 3.2.

$$
I(t)=I_{o} \exp (-p t)
$$

Onde, $I_{o}$ é a intensidade inicial no tempo $t=t_{o}$.

Se os elétrons e buracos liberados sob o aquecimento não forem novamente presos e se todos eles recombinarem radiativamente, ou seja, com emissão de luz, a intensidade $I(T)$ será proporcional à taxa de liberação de elétrons e será dada pela equação 3.3 de Randall-Wilkins (Mckeever et al., 1995; Furetta, 2003).

$$
I(T)=n_{0} s \exp \left(-\frac{E}{k T}\right) \exp \left[-\left(\frac{s}{\beta}\right) \int_{T o}^{T} \exp \left(-\frac{E}{k T}\right) d T\right]
$$

Onde,

$n_{\mathrm{o}}$ é o número total de elétrons presos na armadilha no instante $t=0 \mathrm{e}$ $\beta$ é a taxa de aquecimento, ou seja, $\beta=d T / d t$ e $T(t)=T_{o}+\beta t$.

No modelo simplificado, $s$ é considerado uma constante independente da temperatura, e o seu valor é da ordem da frequência de vibrações da estrutura cristalina, isto é, de $10^{12}$ a $10^{14} \mathrm{~s}^{-1}$ (Bos, 2007).

A intensidade da luz emitida em função da temperatura pela equação 3.3 resulta na curva da TL, de um pico simples, caracterizado pelo valor próprio de $E$ e de $s$. Significa que ao aquecer um material termoluminescente que obedece a cinética de primeira ordem, 
a partir de uma certa temperatura, a intensidade da luminescência $I(T)$ aumenta, atinge a máxima em $T_{m}$ e, então, diminui até o esgotamento dos elétrons presos na armadilha $\mathrm{T}$, dando uma curva na forma de um pico.

A curva da TL em função da temperatura $T$ obtida com o programa Excel da Microsoft ${ }^{\circledR}$ por meio da equação de Randall-Wilkins é mostrada na FIG. 3.2. A curva foi obtida atribuindo valores de $n_{o}=1,010^{22} \mathrm{~cm}^{-3} ; s=1,010^{12} \mathrm{~s}^{-1} ; E=1,0 \mathrm{eV} ; \beta=4 \mathrm{~K} \mathrm{~s}^{-1}$; de $T_{o}=300 \mathrm{~K}$ a $\mathrm{T}=520 \mathrm{~K}$. A $T_{m}$ está localizada em $442 \mathrm{~K}$. Os valores de $I(T)$ foram normalizados, atribuindo $I_{m}=1$.

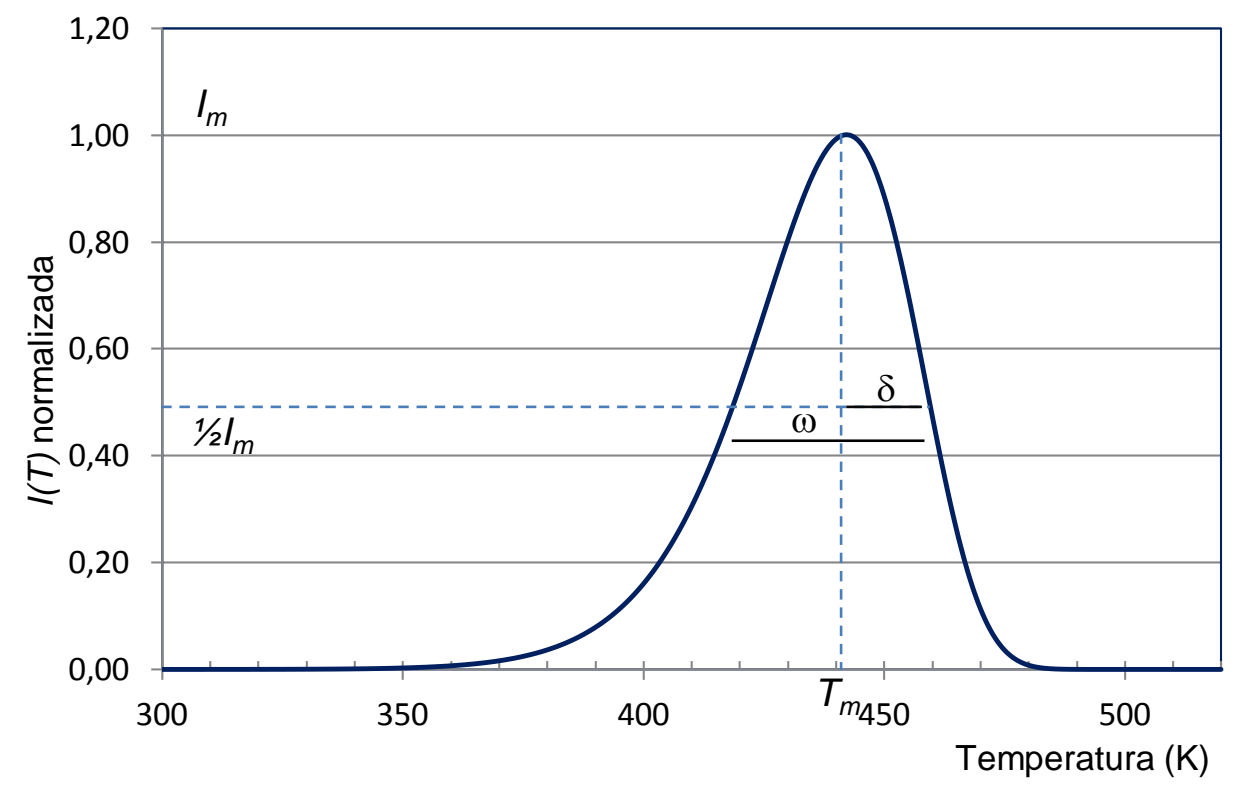

FIGURA 3.2 - Curva da TL obtida pela equação de Randall-Wilkins.

A curva da TL de primeira ordem tem forma assimétrica, sendo mais larga na parte de temperatura baixa que a parte superior. Um fator de geometria $\left(\mu_{\mathrm{g}}\right)$ é definido pela equação 3.4. Na equação, $\delta$ é a largura da parte mais estreita e $\omega$ é a largura total, tomadas na horizontal para $I=1 / 2 I_{m}$.

Os picos teóricos de primeira ordem possuem fator de geometria $\mu_{\mathrm{g}}=0,42$ (McKeever et al., 1995; Bos, 2007).

$$
\mu_{\mathrm{g}}=\delta / \omega
$$


Na parte de temperatura baixa, no início do pico da curva da TL, a intensidade é dominada pela exponencial $\exp (-E / k T)$. Se a intensidade $I(T)$ for colocada em gráfico em função de $1 / T$, espera-se uma relação linear com a inclinação $-E / k$, de onde a energia de ativação $E$ pode ser determinada.

Se os valores de $E$, $s$ e $\beta$ forem mantidas constantes, observa-se que $T_{m}$ se mantém constante, ainda que valores de $n_{o}$ sejam alterados. As curvas de $I(T)$ em função da temperatura mostradas na FIG. 3.3 foram obtidas atribuindo-se valores de $n_{o}$ proporcionais a um, dois, quatro, oito décimos de $1,010^{22} \mathrm{~cm}^{-3}$.

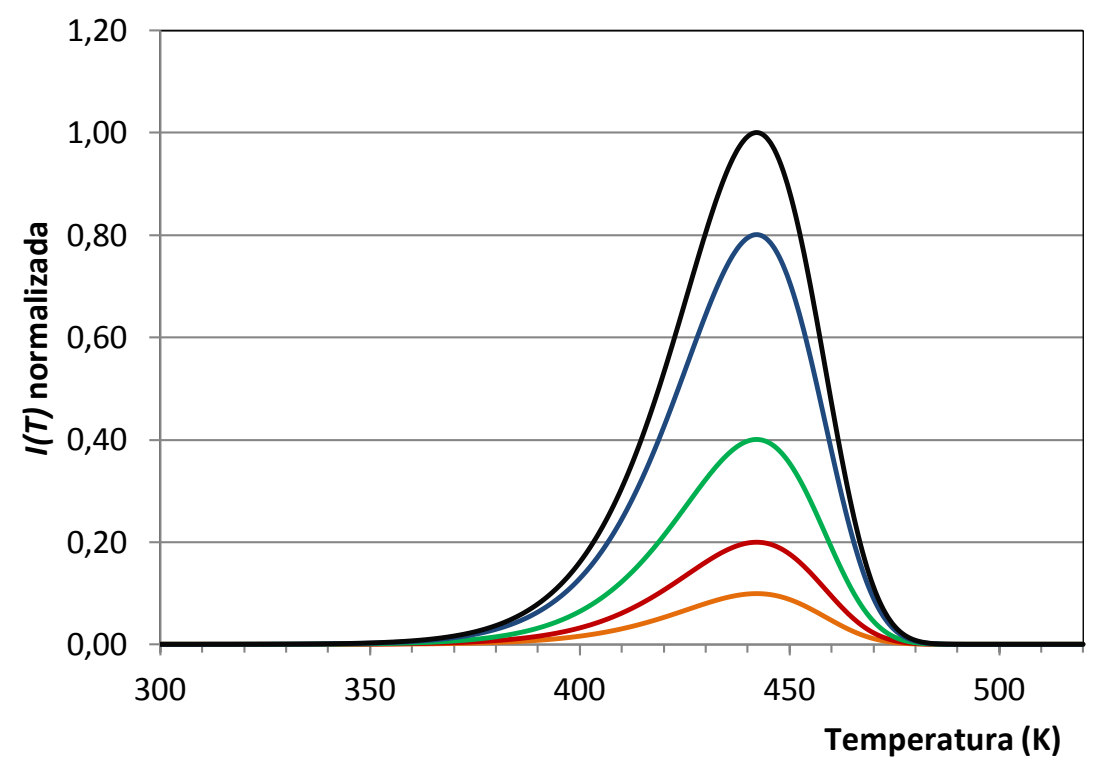

FIGURA 3.3 - Curvas da TL de primeira ordem com valores crescentes de $n_{o}$.

Verifica-se que $n_{o}$ é uma constante multiplicativa e não influencia a forma da curva da TL, mas a sua amplitude. A altura do pico e a área sob a curva são proporcionais a $\mathrm{n}_{o}$, ou seja, à dose de radiação.

Cada pico da curva TL é caracterizado pelo seu próprio valor de $E$ e de $s$. Os picos de temperaturas baixas correspondem a armadilhas com profundidades menores e são mais sensíveis ao decaimento térmico.

$\mathrm{O}$ modelo de Randall-Wilkins considera a condição de quase equilíbrio (QE), ou seja, que a concentração de elétrons na BC é quase estacionária e que a probabilidade de os elétrons serem novamente presos é nula ou desprezível, comparada com a probabilidade de recombinação. 
Variando a taxa de aquecimento $(\beta)$ durante a leitura da TL, $T_{m}$ desloca para a região de temperatura mais alta e, portanto, a localização do pico da TL deve ser especificada com a taxa de aquecimento correspondente.

A variação da temperatura do pico $\left(T_{m}\right)$ com a taxa de aquecimento pode ser usada para determinar a energia de ativação $(E)$ e o fator de frequência $(s)$.

A condição para a $I(T)$ máxima é $d I / d t=0$, da qual se deduz a expressão 3.5.

$$
\beta E /\left(k T_{m}^{2}\right)=s \exp \left\{-E /\left(k T_{m}\right)\right\}
$$

A partir da equação 3.5 obtém-se 3.6.

$$
\ln \left(\beta / T_{m}^{2}\right)=\ln (s k / E)-E / k T_{m}
$$

A equação 3.6 define uma reta, cuja inclinação é -E/k e que intercepta o eixo da coordenada em $\ln (s k / E)$.

\section{Cinética de segunda ordem}

A equação de Garlick-Gibson da intensidade da TL em função da temperatura é expressa pela equação 3.7 (Furetta, 2003). A equação envolve a cinética de segunda ordem em que a intensidade da termoluminescência $I(T)$ é expressa em termos do número de elétrons presos no instante $\mathrm{t}=0$ elevado ao quadrado $\left(\mathrm{n}_{\mathrm{o}}{ }^{2}\right)$.

$$
I(T)=\left[n_{0}^{2} s^{\prime} \exp \left(-\frac{E}{k T}\right)\right]\left[1+\left(n_{0} \frac{s^{\prime}}{\beta}\right) \int_{T o}^{T} \exp \left(-\frac{E}{k T}\right) d T\right]^{-2}
$$

Onde, $s^{\prime}=s / N, s$ é o fator de frequência $\left(\mathrm{s}^{-1}\right)$ e $N$ é a concentração total das armadilhas disponíveis.

A resolução da equação de Garlick-Gibson resulta na curva TL mostrada na FIG 3.4. A curva foi obtida atribuindo valores de $n_{o}=1,010^{22} \mathrm{~cm}^{-3} ; s=1,010^{12} \mathrm{~s}^{-1}$; $E=1,0 \mathrm{eV} ; \beta=4 \mathrm{~K} \mathrm{~s}^{-1} ; \mathrm{N}=10^{18} \mathrm{~cm}^{-3} ; T_{o}=250 \mathrm{~K} \mathrm{e} \mathrm{T}=430 \mathrm{~K}$. A $T_{m}$ está localizada em $327 \mathrm{~K}$. Os valores de $I(T)$ foram normalizados, atribuindo $I_{m}=1$. 


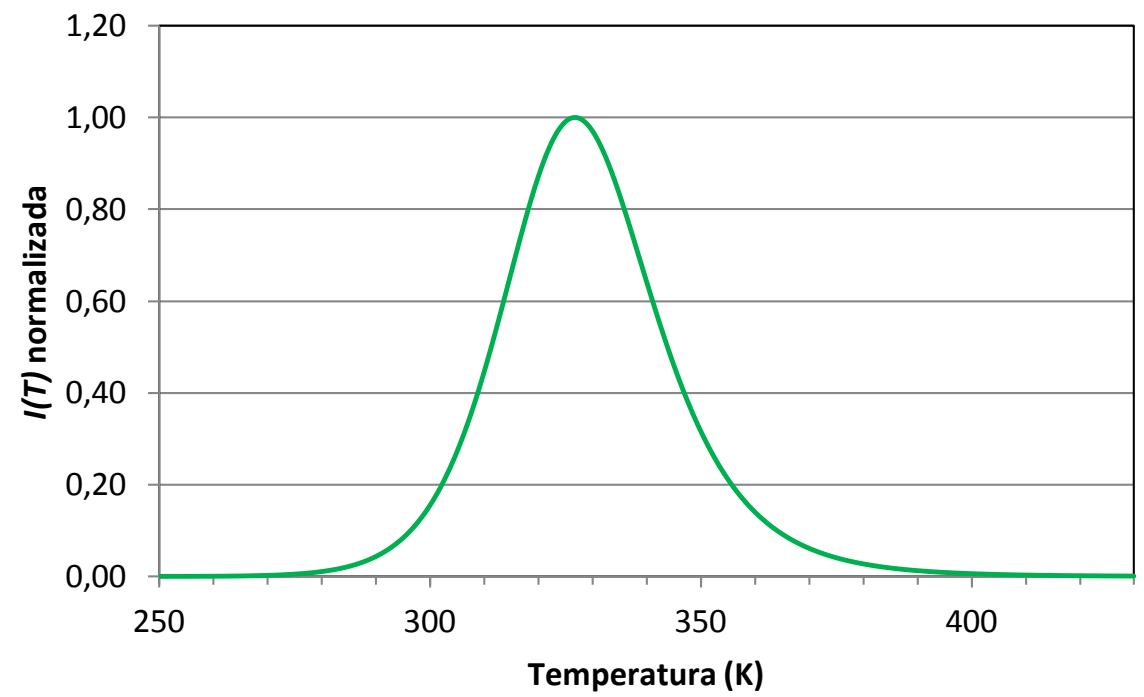

FIGURA 3.4 - Curva da TL obtida pela equação de Garlick-Gibson.

A forma da curva da TL que envolve a cinética de segunda ordem é aproximadamente simétrica, com a metade superior do pico levemente maior que a parte inferior. $\mathrm{O}$ fator geométrico para os picos de segunda ordem vale $\mu_{\mathrm{g}}=0,52$ (McKeever et al., 1995; Bos, 2007).

Os elétrons liberados das armadilhas podem ser novamente presos nas armadilhas antes de eles se recombinarem. Isto causa um atraso na TL e uma distribuição da emissão numa faixa mais larga de temperatura. O número inicial de elétrons presos $n_{o}$ afeta a forma da curva. Com o aumento do valor de $n_{o}$, a temperatura do pico $T_{m}$ diminui e o tamanho do pico aumenta. Isto significa que aumentado a dose, diminui a profundidade da armadilha $(E)$. A altura do pico não é proporcional à área do pico, embora o desvio seja pequeno (Bos, 2007).

\subsection{Luminescência opticamente estimulada}

A luminescência opticamente estimulada é conhecida pela sigla OSL do inglês "optically stimulated luminescence". Refere-se à luminescência de um material irradiado quando exposto à luz.

O Laboratório Nacional RIS $\varnothing$ da Dinamarca produz leitores automatizados de TL desde 1982. Na década de 90, o Laboratório produziu acessórios para os leitores TL existentes, que possibilitaram a leitura OSL. Tornou-se líder mundial de fornecimento de 
equipamentos para medições automatizadas de TL e OSL (RIS $\varnothing$ National Laboratory, 2003).

As propriedades OSL do óxido de alumínio impurificado com carbono $\left(\alpha-\mathrm{Al}_{2} \mathrm{O}_{3}\right.$ :C) foram relatadas por Akselrod et al. (1998).

Bøtter-Jensen (2000) desenvolveu técnicas de medições OSL para serem aplicadas à dosimetria retrospectiva, usando minerais e cerâmicas. A dosimetria retrospectiva pretende reconstituir o quadro de dose após acidentes nucleares. As doses são determinadas pelas medições da OSL de amostras de quartzo e de feldspato extraído de materiais cerâmicos como tijolos, ladrilhos, vasos e porcelanas.

Os conceitos teóricos e práticos da OSL foram publicados por Bøtter-Jensen e seus colaboradores em 2003. As vantagens e desvantagens da dosimetria por TL e da dosimetria por OSL foram debatidas por McKeever e Moscovitch (2003).

O Laboratório de Dosimetria da Radiação da Universidade do Estado de Oklahoma teve participação significativa no desenvolvimento da técnica POSL (Pulsed Optially Stimulated Luminescence), cujo princípio consiste em expor uma amostra irradiada a uma fonte de luz pulsada de laser e detectar a luminescência emitida entre os pulsos, e não durante os pulsos, discriminando a luminescência do laser usada para a estimulação (Akselrod et al., 1998).

Os métodos baseados em OSL encontram aplicações na dosimetria ambiental, pessoal, de doses altas, médica, retrospectiva, dosimetria espacial e datação arqueológica (McKeever et al., 2004).

A técnica OSL tornou-se uma ferramenta útil à área médica para dosimetria in vivo e in vitro, para a terapia com radiação e para a mamografia diagnóstica (Akselrod et al., 2007).

A tecnologia OSL está licenciada para Landauer Inc e o seu dosímetro é comercializado sob a marca registrada Luxel $^{\mathrm{TM}}$. Landauer é fornecedora de serviços de dosimetria e atende a hospitais, clínicas médicas e odontológicas, universidades, laboratórios e usinas de energia nuclear (Bøtter-Jensen et al., 2003).

A pesquisa e o desenvolvimento nas áreas de dosimetria TL e OSL continuam tanto para o desenvolvimento e melhoria de equipamentos, dos materiais, dos métodos e das aplicações.

Um livro sobre os fundamentos da OSL e aplicações foi lançado em formato digital em 2011 (Yukihara \& McKeever, 2011). 
O fenômeno da OSL pode ser explicado de forma semelhante à TL, utilizando o modelo simplificado das bandas de energia apresentado na FIG. 3.1. Os materiais que apresentam OSL possuem defeitos na estrutura cristalina, que aprisionam elétrons e buracos formados durante irradiação.

Os elétrons aprisionados na armadilha da banda proibida (BP) são liberados para a banda de condução (BC) pela estimulação óptica (ou iluminação) da amostra irradiada. A OSL origina-se da recombinação dos elétrons liberados pelo estímulo óptico com os buracos em $\mathrm{R}$.

Os sinais da OSL não devem ser confundidos com fotoluminescência que não é dependente da irradiação prévia da amostra.

A OSL é medida numa região espectral diferente do comprimento de onda $(\lambda)$ da luz utilizada para a estimulação. A integral da luminescência durante o período de estimulação é medida como função da dose de radiação.

A probabilidade $(p)$ de escape dos elétrons presos da armadilha pela estimulação óptica é dada por:

$$
p=\sigma \phi
$$

Onde,

$\sigma=$ secção de choque da fotoionização,

$\phi=$ fluxo de fótons (fótons por unidade de tempo por unidade de área).

Assim como na teoria da TL, o modelo de primeira ordem considera que todas as cargas que escapam das armadilhas recombinam imediatamente produzindo a luminescência.

Se a leitura da OSL é feita pela iluminação contínua do dosímetro com luz de estimulação com comprimento de onda $(\lambda)$ apropriada, a curva da OSL em função do tempo de estimulação é uma exponencial segundo a expressão 3.9.

$$
I_{O S L}(t)=n_{o} \sigma \phi e^{-\sigma \phi t}
$$

A curva OSL em função do tempo de estimulação é apresentada na FIG. 3.5, atribuindo valores de $\sigma \phi$ iguais a $0,05 \mathrm{~s}^{-1}, 0,02 \mathrm{~s}^{-1}$ e $0,01 \mathrm{~s}^{-1}$. Observa-se que o sinal OSL 
diminui durante a estimulação óptica, como uma curva de decaimento, à medida que as cargas presas nas armadilhas são exauridas.

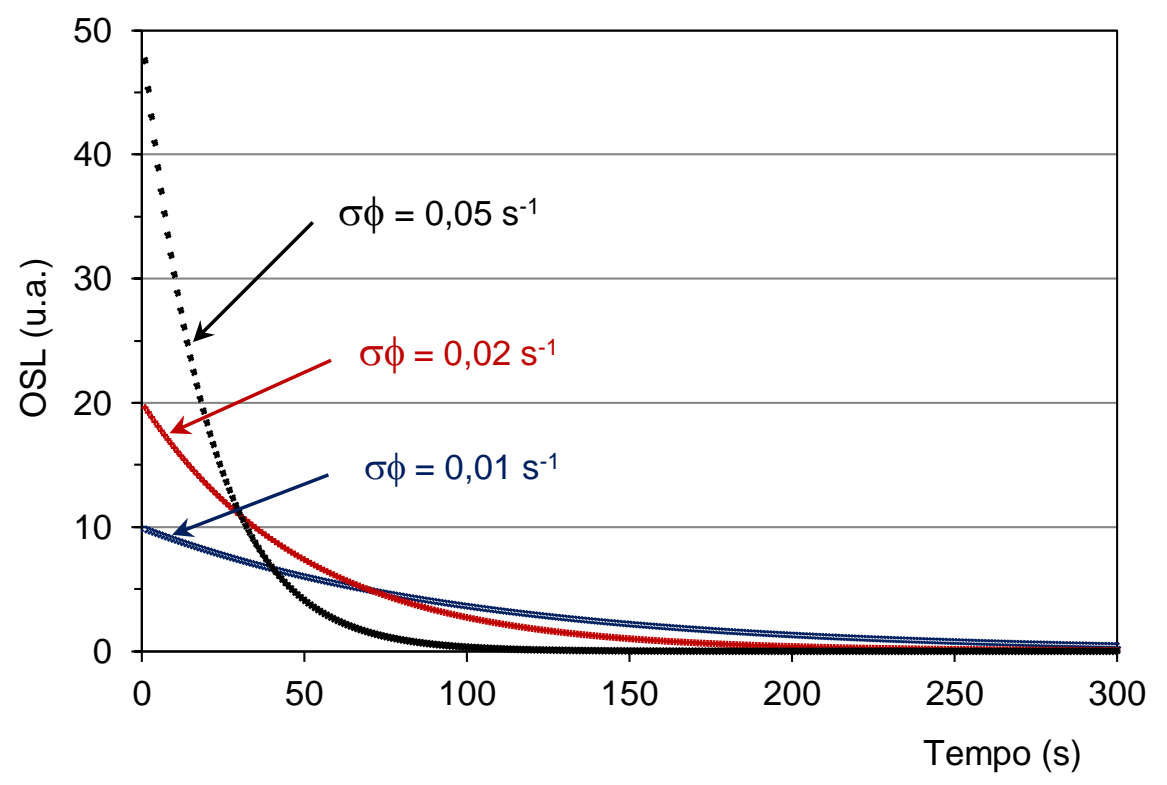

FIGURA 3.5 - Intensidade OSL em função do tempo de estimulação (Yukihara \& McKeever, 2008).

A integral da $I_{O S L}$ é proporcional ao número de elétrons inicialmente presos $\left(n_{o}\right)$. Se um material irradiado (com $\sigma$ definido) for estimulado com luz de comprimento de onda $\lambda$ e intensidade da iluminação $\phi$, a integral da $I_{O S L}$ será proporcional à dose de radiação $D$, conforme a equação 3.10 , onde $a$ é a constante de proporcionalidade.

$$
\int_{t o}^{t} I_{O S L}(t) d t=a D
$$

A intensidade inicial $\left(I_{o}\right)$ da OSL também é proporcional à dose de radiação e ao fluxo de fótons $\phi$ definido pela potência da luz de estimulação.

A OSL tem a vantagem sobre a TL ao ser medida à temperatura ambiente. Ao evitar o aquecimento do material sensível, a probabilidade de ocorrer alterações no material e diminuição da eficiência da luminescência é reduzida. Além disso, a técnica OSL permite realizar várias medições sucessivas de uma mesma amostra.

Embora a leitura OSL possa ser feita à temperatura ambiente, o sinal OSL pode ser afetado pelo aquecimento da amostra. O sinal é completamente eliminado quando a amostra for aquecida ao redor de $500{ }^{\circ} \mathrm{C}$. 
A OSL geralmente é observada em materiais cujo sinal da TL sofre decaimento óptico. Esses materiais permitem fazer estudos associados de TL e OSL. Porém, as armadilhas $\mathrm{T}$ de elétrons responsáveis pela OSL podem ter ou não relação com aquelas da $T L$.

As armadilhas rasas estão relacionadas com o fenômeno da fosforescência e com aumento inicial na intensidade do sinal OSL logo após a irradiação. Para evitar a interferência da fosforescência, introduz-se um tempo de espera entre a irradiação e a leitura do dosímetro.

Distinguem-se três técnicas de OSL conforme o modo de estimulação, designado abreviadamente por CW-OSL, LM-OSL e POSL. Os modos de estimulação estão apresentados esquematicamente na FIG. 3.5.

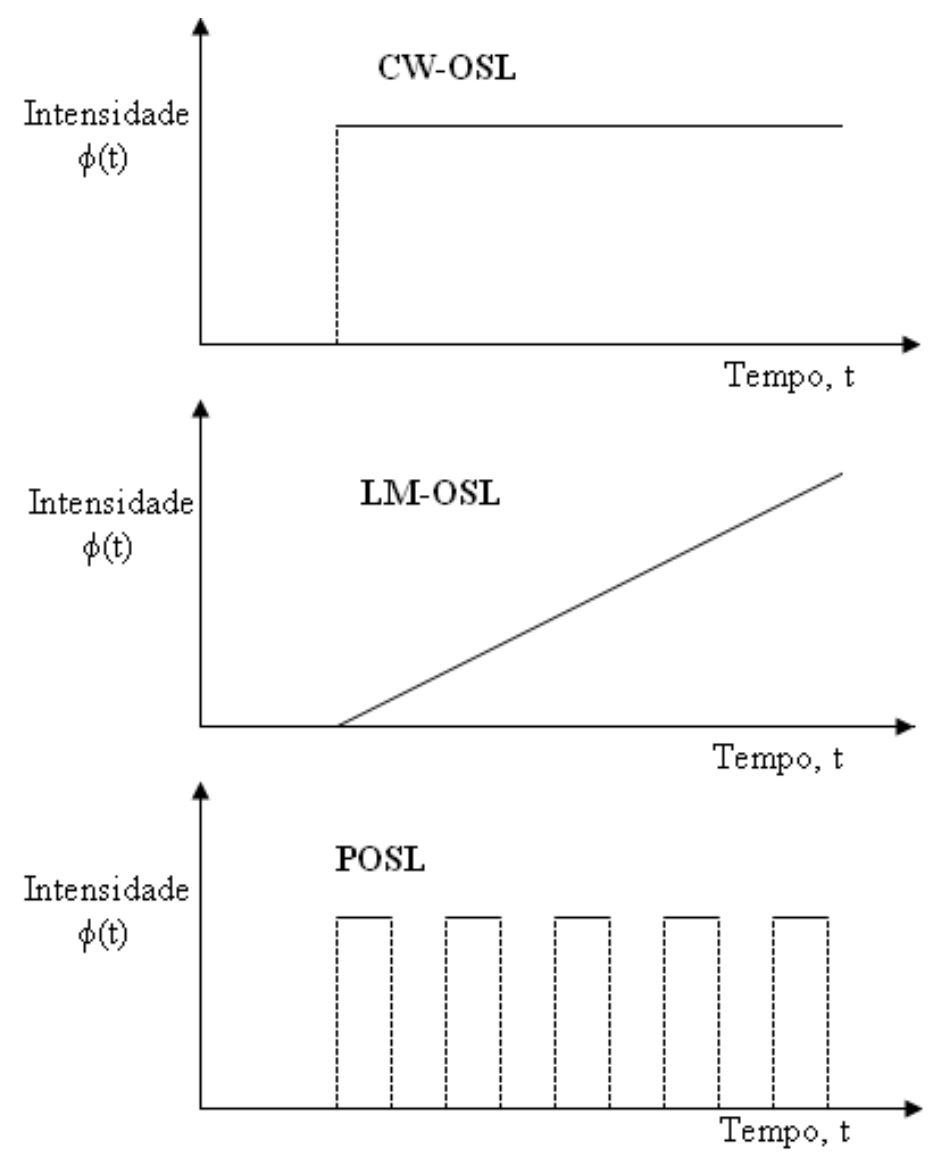

FIGURA 3.6 - Técnicas de OSL conforme o modo de estimulação (adaptado de Akselrod et al., 2007).

CW-OSL refere-se à luminescência resultante da estimulação de onda contínua, isto é, o sinal da OSL é monitorado continuamente durante o período de estimulação enquanto 
a intensidade da luz de estimulação é mantida constante. É a modalidade de maior aplicação por causa de sua simplicidade.

LM-OSL decorre da modulação linear, ou seja, quando a intensidade da luz de estimulação é aumentada linearmente enquanto a OSL é medida.

No modo POSL, a fonte de estimulação é pulsada e a OSL é lida entre os pulsos, como já foi descrito anteriormente.

\section{3 Óxido de Alumínio}

\subsubsection{Propriedades}

A fórmula química do óxido de alumínio é $\mathrm{Al}_{2} \mathrm{O}_{3}$. $\mathrm{O}$ alumínio tem valência 3+e o oxigênio 2-. A neutralidade elétrica dos íons no cristal da alumina é mantida pela relação de dois $\mathrm{Al}^{3+}$ para três íons $\mathrm{O}^{2-}$. Os íons $\mathrm{Al}^{3+}$ e $\mathrm{O}^{2-}$ estão ligados por forças de Coulomb. A ligação entre eles possui $63 \%$ de caráter iônico, correspondente a diferença de eletronegatividade igual a dois $(\Delta \mathrm{en}=3,5-1,5)$.

A estrutura cristalina do coríndon $\alpha-\mathrm{Al}_{2} \mathrm{O}_{3}$ é descrita como hexagonal de empacotamento compacto HCP (do inglês hexagonal close-packed). Os ânions $\mathrm{O}^{2-}$ maiores que os cátions estão dispostos em arranjo HCP, enquanto os cátions se fixam nos interstícios entre os ânions. Os átomos de alumínio ocupam 2/3 das posições intersticiais octaédricas disponíveis para manter a neutralidade da carga elétrica. Um terço dessas posições octaédricas permanecem vazias (Kingery, 1976; Papin, 1997; Akselrod et al., 2007).

Os raios iônicos na configuração do coríndon são respectivamente $0,053 \mathrm{~nm}$ e $0,138 \mathrm{~nm}$ para $\mathrm{Al}^{3+} \mathrm{e} \mathrm{O}^{2-}$. Os íons ordenados nos retículos do cristal têm energia de coesão elevada e conferem ao coríndon a dureza e o ponto de fusão elevados, não compressibilidade e propriedades isolantes.

O coríndon é extremamente duro. A dureza é 9 na escala de Mohs usada em mineralogia. O rubi e a safira pertencem ao grupo do coríndon (Schumann, 1995).

O ponto de fusão do óxido de alumínio está ao redor de $2050{ }^{\circ} \mathrm{C}$. Sua massa molar é $101,96 \mathrm{~g} \mathrm{~mol}^{-1}$ e a massa específica do coríndon é $3,98 \mathrm{~g} \mathrm{~cm}^{-3}$.

Os defeitos naturais mais citados na alumina são as lacunas (ou vacâncias) de oxigênio, as vacâncias de alumínio e os íons de alumínio na posição intersticial. A fim de conservar a neutralidade elétrica do cristal, três lacunas de oxigênio são formadas para cada duas lacunas de alumínio (Papin, 1997). 
O óxido de alumínio pode apresentar diferentes propriedades dependendo da origem ou de seu processo de obtenção. O produto comercial designado por "alumina" geralmente é um pó branco que pode ser óxido de alumínio anidro ou com algum grau de hidratação. Pode apresentar propriedades adsorventes, abrasivas e refratárias.

A densidade e a condutividade térmica do óxido de alumínio estão apresentadas na TAB. 3.1, segundo o grau de pureza. Esses valores foram obtidos das propriedades dos materiais de engenharia selecionados por Callister Jr. (2002).

TABELA 3.1 - Densidade e condutividade térmica do $\mathrm{Al}_{2} \mathrm{O}_{3}$ segundo sua pureza

\begin{tabular}{ccc}
\hline $\begin{array}{c}\text { Pureza } \\
(\%)\end{array}$ & $\begin{array}{c}\text { Densidade } \\
\left(\mathrm{g} \mathrm{cm}^{-3}\right)\end{array}$ & $\begin{array}{c}\text { Condutividade térmica } \\
\left(\mathrm{W} \mathrm{m}^{-1} \mathrm{~K}^{-1}\right)\end{array}$ \\
\hline 99,9 & 3,98 & 39 \\
96 & 3,72 & 35 \\
90 & 3,60 & 16 \\
\hline
\end{tabular}

\subsubsection{Alumina de origens diferentes}

Alumina industrial. $\mathrm{O}$ óxido de alumínio industrial é obtido principalmente pelo processo Bayer (Constantino et al., 2002). O processo consiste em tratar a bauxita com hidróxido de sódio transformando-a em uma solução de aluminato de sódio. A solução é separada da parte insolúvel por decantação e filtração. O hidróxido de alumínio é obtido da neutralização da solução de aluminato, na forma de cristais de gibbsita, representados por $\mathrm{Al}(\mathrm{OH})_{3}$. Os agregados policristalinos de gibbsita quando submetidos à calcinação em fornos rotativos à temperatura de aproximadamente $1000{ }^{\circ} \mathrm{C}$, produzem a alumina praticamente anidra, referida por alumina calcinada. Uma grande parte da alumina industrial é destinada à produção de alumínio metálico. É utilizada também na fabricação de cerâmica, vidro, materiais abrasivos, adsorventes e de catalisadores (Seidel, 2004).

$\mathrm{O}$ produto industrial com características amorfas e utilizado como adsorvente e como catalisadores é denominada de maneira genérica de alumina gama (ou $\gamma$-alumina).

Alumina eletrofundida. É um produto comercial utilizado como abrasivo devido à sua dureza alta. É obtida pela fusão da alumina calcinada em forno a arco elétrico. $\mathrm{O}$ processo de eletrofusão consiste em fundir a alumina calcinada de alta pureza em forno elétrico do tipo Higgins, com eletrodos de grafite. A temperatura do processo ultrapassa $2000{ }^{\circ} \mathrm{C}$, quando a alumina passa ao estado líquido. Após o resfriamento, os blocos solidificados são quebrados e triturados em granulometria adequada para a utilização 
(Marinescu, 2007). A alumina eletrofundida branca contém 99,5\% de $\mathrm{Al}_{2} \mathrm{O}_{3}$, dureza 9,0 na escala Mohs, peso específico é $3,65 \mathrm{~g} \mathrm{~cm}^{-3}$. Seu ponto de fusão é $2040{ }^{\circ} \mathrm{C}$. Apresenta a estrutura cristalina do coríndon e contêm vários íons metálicos como impurezas.

Alumina ativada. A alumina ativada obtida pelo aquecimento do hidróxido de alumínio é porosa, possui superfície específica elevada, parcialmente hidroxilada e propriedades adsorventes. A superfície específica pode atingir cerca de $300 \mathrm{~m}^{2} \mathrm{~g}^{-1}$. É comercializada sob diferentes especificações, tamanho dos grãos e grau de atividade. É utilizada em cromatografia por adsorção em coluna.

A atividade representa a capacidade de adsorção, está relacionada à superfície ativa e é promovida pelo aquecimento para remover a água e outros materiais adsorvidos. A ativação ótima é atingida ao aquecê-la a $400^{\circ} \mathrm{C}$ durante aproximadamente quatro horas, até não haver a desorção de água (Pearson, 2004).

A alumina é classificada segundo Brockmann e Schadder em cinco tipos (I a V) conforme a capacidade de retenção de corantes azóicos. A alumina com atividade grau I é a mais ativa. A atividade diminui com o conteúdo de água, sendo que a de grau $\mathrm{V}$ que é a menos ativa tem $15 \%$ de água (Vichenewski, 2007).

\subsubsection{Alumina termoluminescente}

$\mathbf{A l}_{2} \mathbf{O}_{3}:$ Si,Ti. Foi preparado com a alumina em pó comercial, com grânulos de 100 a 200 mesh, lavada com $\mathrm{HCl}$ quente e água destilada. A adição de ativador foi feita, misturando o pó com os sais dos ativadores na forma de carbonato ou óxido, formando uma pasta com água, seguida por calcinação em chama a cerca de $2000{ }^{\circ} \mathrm{C}$ para formar grânulos fundidos. A concentração dos ativadores no material mais sensível é 300 ppm de Si e 10 ppm de Ti. Os grânulos foram triturados e misturados com $2 \%$ de acetato de celulose em solução com acetona. A pasta foi seca e prensada. As pastilhas foram sinterizadas à temperatura próxima à de fusão em chama, durante poucos minutos (McKeever e al., 1995).

$\mathbf{A l}_{2} \mathbf{O}_{3}: \mathbf{M g}, Y$. Foi preparado a partir da precipitação de hidróxido de alumínio com amônia, com os íons dopantes e posterior calcinação do precipitado entre 1000 e $1300{ }^{\circ} \mathrm{C}$. $\mathrm{O}$ magnésio e o ítrio foram introduzidos como $\mathrm{MgSO}_{4}$ e $\mathrm{Y}_{2} \mathrm{O}_{3}$ na concentração de $0,5 \%$

em peso, na fase de coprecipitação, para produzir dosímetros para $10^{-1}$ a $5.10^{3} \mathrm{~Gy}$. Uma concentração de 1,0 \% em peso de cada dopante foi empregada para obter dosímetros para 
$10^{-3}$ a $10^{2}$ Gy. O pó com 1 a $5 \mu \mathrm{m}$ foi prensado a frio em pastilhas e sinterizado a $1600{ }^{\circ} \mathrm{C}$ no ar (McKeever e al., 1995).

$\alpha-\mathbf{A l}_{2} \mathbf{O}_{3}:$ C. Cristais de coríndon obtidos pelo método de Verneuil foram usados como matérias-primas. Bastões do cristal com $5 \mathrm{~mm}$ de diâmetro e $500 \mathrm{~mm}$ de comprimento foram crescidos a partir do material fundido, sob condições fortemente redutoras e na presença de grafite. O material crescido é deficiente em ânions, apresentando vacâncias de oxigênio em sua estrutura (Akselrod et al., 1990; 1993).

Os bastões foram cortados com ferramenta de diamante em discos com $1 \mathrm{~mm}$ de espessura. No estágio final da produção, os detectores de $\alpha-\mathrm{Al}_{2} \mathrm{O}_{3}: \mathrm{C}$ foram tratados a $950{ }^{\circ} \mathrm{C}$ por 30 minutos ao ar, para remover as tensões oriundas do crescimento, corte e polimento dos cristais e esvaziar as armadilhas profundas. O monocristal produzido continha de 100 a 5000 ppm de carbono. O material em pó foi obtido triturando os cristais de $\alpha-\mathrm{Al}_{2} \mathrm{O}_{3}: \mathrm{C}$ em moinho de bolas (Akselrod et al., 1990; 1993).

O pico da curva TL foi localizado ao redor de 185 a $190{ }^{\circ} \mathrm{C}$. A emissão TL tem um comprimento de onda ao redor de $420 \mathrm{~nm}$, que corresponde a máxima sensibilidade espectral dos fotomultiplicadores de baixo ruído. Foi atribuída uma sensibilidade de 40 a 60 vezes a do TLD-100. O número atômico efetivo do $\alpha-\mathrm{Al}_{2} \mathrm{O}_{3}: \mathrm{C}$ é 10,2 . A resposta TL para a radiação de $30 \mathrm{keV}$ é 2,9 vezes mais alta que a de $1,25 \mathrm{MeV}$ do ${ }^{60} \mathrm{Co}$ (Prokic \& Bøtter-Jensen, 1993).

Apresenta decaimento térmico de $3 \%$ ao ano em condição otimizada. Acima de 1 Gy ocorre a supralinearidade e saturação a $10 \mathrm{~Gy}$. Os cristais podem ser reutilizados repetidamente a baixas doses, sem necessidade de um tratamento térmico adicional. Para medidas de baixa dose ou após uma dose total de 0,1 Gy os detectores podem ser tratados termicamente no ar, em cadinhos de quartzo a $800^{\circ} \mathrm{C}$ por 10 a 15 minutos, seguido de um resfriamento rápido no ar fora do forno.

A sensibilidade do $\alpha-\mathrm{Al}_{2} \mathrm{O}_{3}: \mathrm{C}$ diminui em temperaturas altas (Kortov et al., 1994).

$\mathrm{O}$ dosímetro de $\alpha-\mathrm{Al}_{2} \mathrm{O}_{3}: \mathrm{C}$ foi comercializado como TLD-500K, pela Victoreen (Akselrod et al., 1993).

$\mathbf{A l}_{2} \mathbf{O}_{3}$ :M. Papin (1997) estudou a influência dos defeitos puntuais sobre a termoluminescência da alumina, variando as condições de síntese. A alumina gama foi obtida da decomposição do alúmem de amônio, "dopada" por impregnação e levada à 
calcinação acima de $1000{ }^{\circ} \mathrm{C}$. Constatou-se uma transição inicial rápida da alumina gama para alfa à temperatura de $1100{ }^{\circ} \mathrm{C}$. Cerca de $80 \%$ da transformação para a fase alfa ocorreu a $1150{ }^{\circ} \mathrm{C}$ e praticamente total em $1250^{\circ} \mathrm{C}$. Não se detectou a fase gama acima de $1300{ }^{\circ} \mathrm{C}$. Os estudos foram conduzidos com compostos de $\mathrm{Mg}^{2+}, \mathrm{Cr}^{3+}, \mathrm{Th}^{4+}, \mathrm{Fe}^{3+} / \mathrm{Fe}^{2+}$ na forma de nitrato. Verificou-se que quanto maior a temperatura do tratamento térmico, mais pronunciado é a emissão termoluminescente da alumina. No experimento sob atmosfera de oxigênio, a amostra tratada a $1500{ }^{\circ} \mathrm{C}$ produziu sinal TL mais pronunciado. Foram obtidas amostras de alumina sensíveis às radiações $\mathrm{X}$, UV e gama, com potenciais para serem utilizadas em dosímetros termoluminescentes, com picos da TL entre 190 e $360{ }^{\circ} \mathrm{C}$. O trabalho sobre a influência das condições de calcinação na termoluminescência da alumina foi publicado em 1996 (Papin et al., 1996).

Há muitos métodos para a obtenção de materiais dosimétricos termoluminescentes. Kortov (2007) aponta a tendência e a expectativa de os materiais termoluminescentes com boas características dosimétricas serem obtidos por modernas rotas da cerâmica avançada, incluindo materiais nanocristalinos e nitreto de alumínio (AlN).

A hidrólise de alcóxido de alumínio que pode produzir óxido de alumínio de alta pureza em escala nanométrica.

\subsubsection{Hidrólise do alcóxido de alumínio}

Os alcóxidos mais conhecidos são os dos elementos silício, alumínio, zircônio e titânio. Os do silício foram muito investigados, especialmente o TEOS tetraetilortosilicato, cuja fórmula molecular é $\mathrm{Si}\left(\mathrm{OC}_{2} \mathrm{H}_{5}\right)_{4}$, reagente com custo não muito elevado.

Similarmente aos alcóxidos de Si, compostos como o isopropóxido ou sec-butóxido de alumínio podem ser hidrolizados, obtendo-se produtos poliméricos de alumínio (Segal, 1989; Airold \& Fernandes de Farias, 2004).

As equações 3.11 e 3.12 referem-se às reações de condensação e a equação 3.13 representa a hidrólise produzida pelo alcóxido de alumínio.

$$
\begin{gathered}
\mathrm{Al}(\mathrm{OR})_{3}+\mathrm{H}_{2} \mathrm{O} \longrightarrow \mathrm{Al}(\mathrm{OR})_{2} \mathrm{OH}+\mathrm{ROH} \\
2 \mathrm{Al}(\mathrm{OR})_{2} \mathrm{OH}+\mathrm{H}_{2} \mathrm{O} \longrightarrow \mathrm{RO}-\mathrm{Al}(\mathrm{OH})-\mathrm{O}-\mathrm{Al}(\mathrm{OH})+2 \mathrm{ROH}
\end{gathered}
$$




$$
\mathrm{Al}(\mathrm{OR})_{3}+3 \mathrm{H}_{2} \mathrm{O} \rightarrow \mathrm{Al}(\mathrm{OH})_{3}+3 \mathrm{ROH}
$$

O produto obtido por meio da rota de gel polimérico derivado de alcóxidos metálicos depende da composição química do alcóxido, concentração dos reagentes, $\mathrm{pH}$ da solução, da temperatura e do tempo de envelhecimento.

A estrutura do gel hidrolizado pode mudar com o passar do tempo, durante a remoção do líquido e na secagem. Além disso, os produtos resultantes desse método são sensíveis à umidade e ao ambiente.

Quando as diversas variáveis da formação do gel forem controladas, podem-se obter óxidos que apresentam propriedades superiores aos óxidos convencionais.

O óxido de alumínio produzido pela calcinação dos polímeros da hidrólise de alcóxidos de alumínio é constituído de partículas muito finas com dimensões nanométricas, de elevada pureza química e boa homogeneidade; propriedades que permitem a sinterização de materiais cerâmicos em temperaturas mais baixas que a sinterização de pós convencionais.

No entanto, o custo dos alcóxidos de alumínio é ainda relativamente alto quando comparado com sais e hidróxido de alumínio para produzir o óxido de alumínio. Por causa do preço e das dificuldades inerentes ao controle das variáveis da formação do gel, a rota do gel polimérico é indicada para síntese de objetos pequenos, filmes, fibras e pós para produção de cerâmica e vidro em escala de laboratório.

\subsubsection{Precipitação do hidróxido de alumínio}

As soluções aquosas de sais de alumínio têm caráter ácido. Os pequenos íons de $\mathrm{Al}^{3+}$ possuem cargas elétricas elevadas e são capazes de promover a hidrólise, retirando elétrons das moléculas vizinhas de água tornando-se doadores de prótons, conforme a equação 3.14 .

$$
\left[\mathrm{Al}\left(\mathrm{H}_{2} \mathrm{O}\right)_{6}\right]^{3+}+\mathrm{H}_{2} \mathrm{O} \longrightarrow\left[\mathrm{Al}\left(\mathrm{H}_{2} \mathrm{O}\right)_{5} \mathrm{OH}\right]^{2+}+\mathrm{H}_{3} \mathrm{O}^{+}
$$

A hidrólise é expressa de forma geral pela equação 3.15 . 


$$
\left[\mathrm{Al}\left(\mathrm{H}_{2} \mathrm{O}\right)_{6}\right]^{3+}+\mathrm{h} \mathrm{H} \mathrm{H}_{2} \mathrm{O} \longrightarrow\left[\mathrm{Al}(\mathrm{OH})_{\mathrm{h}}\left(\mathrm{H}_{2} \mathrm{O}\right)_{6-\mathrm{h}}\right]^{(3-\mathrm{h})+}+\mathrm{h} \mathrm{H}_{3} \mathrm{O}^{+}
$$

As espécies $\left[\mathrm{Al}(\mathrm{OH})_{\mathrm{h}}\left(\mathrm{H}_{2} \mathrm{O}\right)_{6-\mathrm{h}}\right]^{(3-\mathrm{h})+}$ tendem a se condensarem, formando diferentes espécies polinucleares, (Segal, 1989). A condensação ou a polimerização pode ser representada pela equação 3.16 .

$$
\mathrm{n}\left[\mathrm{Al}(\mathrm{OH})_{\mathrm{h}}\left(\mathrm{H}_{2} \mathrm{O}\right)_{6-\mathrm{h}}\right]^{(3-\mathrm{h})+} \longrightarrow\left\{\left[\mathrm{Al}(\mathrm{OH})_{\mathrm{h}}\left(\mathrm{H}_{2} \mathrm{O}\right)_{6-\mathrm{h}}\right]^{(3-\mathrm{h})+}\right\}_{\mathrm{n}}
$$

Com o aumento do $\mathrm{pH}$, as espécies polinucleares atingem dimensões coloidais, formam agregados e se precipitam na forma de hidróxido de alumínio.

A reação de uma solução de sal de alumínio e uma base com a formação de hidróxido de alumínio é representada pela equação estequiométrica simplificada 3.17. A formação do óxido-hidróxido de alumínio pode ser representada pela equação 3.18.

$$
\begin{gathered}
\mathrm{Al}^{3+}+3 \mathrm{OH}^{-} \rightarrow \mathrm{Al}(\mathrm{OH})_{3} \\
\mathrm{Al}^{3+}+3 \mathrm{OH}^{-} \rightarrow \mathrm{AlO}(\mathrm{OH})+\mathrm{H}_{2} \mathrm{O}
\end{gathered}
$$

As equações 3.17 e 3.18 são estequiométricas e não dizem respeito à estrutura dos compostos formados que podem se apresentar sob uma variedade de polimorfos cristalinos e gelatinosos.

O hidróxido de alumínio é praticamente insolúvel em água, tem constante de solubilidade muito pequena. Sua estrutura depende das condições de sua obtenção tais como espécie e concentração dos reagentes, taxa de precipitação, temperatura, $\mathrm{pH}$, grau de agitação e tempo de envelhecimento. Pode conter diversas espécies poliméricas ou de agregados, juntamente com moléculas de água e íons da solução precursora incorporados na estrutura.

Os hidróxidos de alumínio são classificados em cristalinos ou gelatinosos (Misra, 2004). Os trihidróxidos e os óxido-hidróxidos de alumínio são reconhecidos conforme a respectiva estrutura cristalina. Os trihidróxidos são: bayerita $\left[\alpha-\mathrm{Al}(\mathrm{OH})_{3}\right]$, gibbsita $\left[\gamma-\mathrm{Al}(\mathrm{OH})_{3}\right]$, e nordstrandita. $\mathrm{O}$ óxido-hidróxido ocorre na forma de diaspório $[\alpha-\mathrm{AlO}(\mathrm{OH})]$ e de boehmita $[\gamma-\mathrm{AlO}(\mathrm{OH})]$. O prefixo alfa é utilizado para designar as 
estruturas de empacotamento hexagonal da bayerita e do diaspório. A gibbsita e a boehmita que apresentam o empacotamento cúbico recebem o prefixo gama. $\mathrm{O}$ hidróxido gelatinoso referido por como "pseudo-boehmita" pode conter uma variedade de produtos amorfos ou com algum grau de cristalinidade (Wefers, 1990; Misra, 2004).

As propriedades do trihidróxido, óxido-hidróxido e do óxido de alumínio estão relacionadas na TAB 3.2, baseadas respectivamente nos minerais gibbsita, boehmita e coríndon.

TABELA 3.2 Propriedades do trihidróxido, óxido-hidróxido e do óxido de alumínio

\begin{tabular}{ccccc}
\hline Mineral & Fórmula & Mol & Dureza Moh & Densidade \\
\hline Gibbsita & $\mathrm{Al}(\mathrm{OH})_{3}$ & 78,004 & 2,5 a 3,5 & 2,42 \\
Boehmita & $\mathrm{AlO}(\mathrm{OH})$ & 59,989 & 3,5 a 4,0 & 3,01 \\
Coríndon & $\mathrm{Al}_{2} \mathrm{O}_{3}$ & 101,960 & 9,0 & 3,98 \\
\hline
\end{tabular}

\subsection{Adição de íons metálicos}

\subsubsection{Concentração de íons}

A TL de certos materiais pode ser promovida pela inserção de determinados elementos químicos em sua estrutura cristalina. Os elementos que promovem a TL são denominados "ativadores", “dopantes" ou "impurezas".

A adição intencional de elementos na estrutura de um material é referida por “dopagem" ou "impurificação" que, no caso, são realizadas especificamente para "ativar" a TL do material.

A adição de átomos estranhos à estrutura cristalina do material hospedeiro pode dar origem a defeitos substitucionais e intersticiais, dependendo do tamanho atômico, da valência e da concentração.

Os ativadores podem pertencer a diferentes elementos químicos. Uma atenção é dada aos metais de transição, especialmente aos elementos terras-raras (TR), por causa de seus efeitos ópticos (Abrão, 1994).

No óxido de alumínio, quando os cátions bivalentes como o $\mathrm{Mg}^{2+}$ substituem os íons $\mathrm{Al}^{3+}$, outros defeitos são formados para compensar a falta de carga positiva, quer seja pela vacância de oxigênio ou pela presença de $\mathrm{Al}^{3+}$ intersticial. 
Os cátions com a mesma valência do $\mathrm{Al}^{3+}$ tais como o $\mathrm{Cr}^{3+}, \mathrm{Y}^{3+}$ e dos elementos lantanídeos não introduzem diferença de carga elétrica por substituição, mas introduz distorções na estrutura cristalina, por causa da diferença do tamanho dos íons.

Os íons tetravalentes de $\mathrm{Ti}^{4+}$ e de $\mathrm{Si}^{4+}$ introduzem um excesso de carga positiva e podem acarretar a criação de vacâncias de alumínio e a formação de oxigênio intersticial.

Geralmente, o íon é adicionado em quantidade muito pequena em relação ao material base e a sua concentração é expressa em porcentagem por mol (\% mol). Há uma concentração ótima em que se verifica maior intensidade da termoluminescência. Quando a concentração for aumentada além da ótima, os centros de TL do material podem interferir entre si e reduzir a intensidade da TL (McKeever e al., 1995).

As impurezas presentes nas matérias-primas ou contaminações introduzidas durante o processamento podem alterar as características da termoluminescência do produto.

Um material TL pode conter mais de um elemento ativador, com a formação de estruturas complexas onde ocorre o mecanismo da TL (McKeever e al., 1995).

A concentração do ativador em porcentagem em mol é dada por:

$$
\mathrm{P}(\% \operatorname{mol})=\left(\mathrm{n}_{\mathrm{a}} / \mathrm{n}_{\mathrm{b}}\right) 100
$$

Onde,

$\mathrm{n}_{\mathrm{a}}$ é a quantidade em mol do ativador ou do dopante e

$\mathrm{n}_{\mathrm{b}}$ é a quantidade em mol do material base ou do hospedeiro.

A concentração do ativador em termos de massa é dada pela equação 3.20.

$$
\mathrm{P}(\% \mathrm{~mol})=\left(\mathrm{m}_{\mathrm{a}} \mathrm{M}_{\mathrm{b}} / \mathrm{m}_{\mathrm{b}} \mathrm{M}_{\mathrm{a}}\right) 100
$$

Onde,

$\mathrm{m}_{\mathrm{a}}$ é a massa do ativador $(\mathrm{g})$,

$\mathrm{M}_{\mathrm{a}}$ é a massa molar do ativador $\left(\mathrm{g} \mathrm{mol}^{-1}\right)$,

$\mathrm{m}_{\mathrm{b}}$ é a massa do $\mathrm{Al}_{2} \mathrm{O}_{3}(\mathrm{~g}) \mathrm{e}$

$\mathrm{M}_{\mathrm{b}}$ é a massa molar do $\mathrm{Al}_{2} \mathrm{O}_{3}\left(101,96 \mathrm{~g} \mathrm{~mol}^{-1}\right)$.

A concentração ótima citada está ao redor de 0,1\% em mol (Barros et al., 2010). 


\subsubsection{Método da adsorção.}

O método da adsorção baseia-se no fato de que a alumina possui uma grande capacidade para adsorver íons e moléculas. Essa capacidade é verificada notoriamente em alumina designada "ativada" que compreende as formas de óxido de alumínio parcialmente hidroxilado. É atribuída aos grupos hidroxilas da superfície, que possuem caráter anfótero e atuam como ácido ou base. Esses grupos retêm íons de metais de soluções (Baumgarten, 1999).

Os principais parâmetros que descrevem a adsorção de íons na alumina são a quantidade de alumina suspensa na solução, a área da superfície específica, a concentração de sítios de adsorção na superfície, constantes de equilíbrio de adsorção e pH.

A capacidade adsorvente é aumentada quando o tamanho das partículas for reduzido e o número de sítios de adsorção na superfície for alto. Ao adsorver a umidade do ar, a capacidade adsorvente da alumina é reduzida. Para reverter essa capacidade adsorvente a alumina é submetida a um aquecimento ao redor de $400{ }^{\circ} \mathrm{C}$, durante cerca de 4 horas.

Quando uma solução iônica for colocada em contato com a alumina, os cátions $\left(\mathrm{M}^{\mathrm{n}+}\right)$ fixam na superfície, conforme a equação 3.21.

$$
\text { Superfície }(-\mathrm{O})_{2} \mathrm{Al}-\mathrm{OH}+\mathrm{M}^{\mathrm{n}+}===\operatorname{Superfície}(-\mathrm{O})_{2} \mathrm{Al}-\mathrm{OM}^{(\mathrm{n}-1)+}+\mathrm{H}_{3} \mathrm{O}^{+}
$$

O volume $(V)$ da solução de ativador com uma concentração $\left(\mathrm{C}_{\mathrm{L}}\right)$ para "dopar" uma quantidade de $\mathrm{Al}_{2} \mathrm{O}_{3}$, na concentração de $\mathrm{P} \%$ em mol pode ser expresso como:

$$
\mathrm{V}=\mathrm{P} \mathrm{m}_{\mathrm{b}} /\left(100 \mathrm{M}_{\mathrm{b}} \mathrm{C}_{\mathrm{L}}\right)
$$

Onde,

V é o volume de ativador em $\mathrm{mL}$,

P é a percentagem em mol do dopante no material base, em \% mol,

$\mathrm{m}_{\mathrm{b}}$ é a massa correspondente ao $\mathrm{Al}_{2} \mathrm{O}_{3}$,

$\mathrm{M}_{\mathrm{b}}$ é a massa de $\mathrm{Al}_{2} \mathrm{O}_{3}$ por mol, em $\mathrm{g} \mathrm{mol}^{-1}\left(101,96 \mathrm{~g} \mathrm{~mol}^{-1}\right) \mathrm{e}$

$\mathrm{C}_{\mathrm{L}}$ é a concentração da solução de ativador, em $\mathrm{mol} \mathrm{mL}^{-1}$.

Para $\mathrm{P}=0,1 \% \mathrm{~mol}$

$$
\mathrm{V}=9,807610^{-6} \mathrm{~m}_{\mathrm{b}} \mathrm{C}_{\mathrm{L}}^{-1}
$$




\subsubsection{Método da coprecipitação}

A coprecipitação consiste em formar o hidróxido de alumínio simultaneamente com o hidróxido do íon ativador de TL. O método é adequado para os íons do ativador de TL que formam hidróxidos com solubilidade baixa.

Os valores de $\mathrm{K}_{\mathrm{ps}}$ normalmente são expressos em mol por litro de solução do soluto a $25^{\circ} \mathrm{C}$. Os elementos lantanídeos formam hidróxidos do tipo $\mathrm{M}(\mathrm{OH})_{3}$, cujo produto de solubilidade é expresso por $\mathrm{K}_{\mathrm{ps}}=\left[\mathrm{M}^{3+}\right]\left[\mathrm{OH}^{-}\right]^{3}$.

As terras-raras (TR) que incluem os lantanídeos, Y e Sc são utilizados como ativadores de luminescência em óxidos (Martins \& Isolani, 2005). Os hidróxidos de TR são precipitados em solução de $\mathrm{NH}_{3}$ ou de hidróxidos alcalinos diluídos. Os valores de $\mathrm{K}_{\mathrm{ps}}$ dos hidróxidos são muito pequenos, da ordem do valor atribuído para trihidróxido de alumínio (Abrão, 1994).

$\mathrm{O}$ método não é conveniente para íons de $\mathrm{Cu}^{2+}$, que formam íons complexos solúveis de $\left[\mathrm{Cu}\left(\mathrm{NH}_{3}\right)_{4}\right]^{2+}$ em meio amoniacal.

O método da coprecipitação tem sido utilizado na pesquisa para obtenção de vários compostos cerâmicos. É um método relativamente simples e de custo reduzido (Lazar et al., 2002, 2008; Ussui et al., 2003).

Associado ao método da coprecipitação, Ussui e seus colab. (1996) tem aplicado a técnica da destilação azeotrópica para a síntese de pós cerâmicos, a fím de evitar a aglomeração de partículas e obter pós finos e homogêneos.

\subsection{Conformação do dosímetro}

\subsubsection{Processo cerâmico}

A manipulação de pó em dosimetria apresenta inconveniências como indefinição da forma, perda de massa nas transferências, influência da umidade do ar e falta de escoamento. Essas inconveniências dificultam os procedimentos de tratamento térmico, irradiação e leitura da luminescência.

Vários artifícios como o acondicionamento do pó em capilares de vidro e a transformação em compósitos com politetrafluoretileno (PTFE) foram utilizados para obter unidades que facilitassem seu manuseio como dosímetros (Becker, 1973; Shani, 1991).

O processo cerâmico clássico para a transformação de pó em um corpo sólido segue uma rota geral esquematizada em (3.24). 
Preparação do pó $\rightarrow$ compactação $\rightarrow$ sinterização $\rightarrow$ corpo sólido

As características importantes do pó são pureza química, tamanho das partículas, o grau de aglomeração. Essas características têm influência nos processos subsequentes de compactação e de sinterização.

É desejável que o pó tenha partículas com dimensões menores que $1 \mu \mathrm{m}$, uma distribuição estreita, com forma esférica ou equiaxial e sem aglomerações.

Pós finos com partículas nessas dimensões podem ser preparados por métodos químicos da precipitação. Esses pós são mais apropriados para obter corpos de alta densidade e podem ser sinterizados em temperatura mais baixas que pós com partículas de tamanhos maiores.

A redução mecânica do tamanho das partículas e a homogeneização da mistura de pós apresentam certa limitação e podem introduzir impurezas em consequência do desgaste dos equipamentos.

A utilização de pó fino requer o controle dos processos para reduzir os efeitos prejudiciais da presença de aglomerados (Rahaman, 2003).

\subsubsection{Calcinação}

A calcinação de um material em pó é normalmente feita em temperatura mais baixa que a da densificação. Ela pode ser realizada para remover a umidade e a água de hidratação, decompor substâncias orgânicas ou reduzir carbonatos, nitratos e sulfatos em óxidos.

Ao aquecer uma amostra de hidróxido ou de óxido-hidróxido de alumínio pode ocorrer a vaporização da água e a dehidroxilação. Com o aumento da temperatura, a proporção de hidroxila diminui. O óxido de alumínio passa por diversas formas de transição diferenciadas por letras gregas.

Uma sequência de transformações do óxido-hidróxido de alumínio é exemplificada em 3.25 (Pearson, 2004).

$$
\mathrm{AlO}(\mathrm{OH}) \rightarrow \gamma-\mathrm{Al}_{2} \mathrm{O}_{3} \rightarrow \delta-\mathrm{Al}_{2} \mathrm{O}_{3} \rightarrow \theta-\mathrm{Al}_{2} \mathrm{O}_{3} \rightarrow \alpha-\mathrm{Al}_{2} \mathrm{O}_{3}
$$

A sequência de transformações depende dos precursores, composição e da temperatura. A decomposição térmica e a sequência de transformações resultantes do aquecimento do trióxido de alumínio podem ser completamente diferente da exemplificada 
em 3.25. As formas de transição da alumina são referidas também como polimorfos metaestáveis da alumina e são objetos de investigação (Souza Santos, 2000).

Quando aquecida de 900 a $1000^{\circ} \mathrm{C}$, torna-se praticamente anidra. Acima de $1000^{\circ} \mathrm{C}$, a alumina torna-se insolúvel em ácido, a massa específica aproxima-se de 4 e a dureza ao redor de 9 na escala Moh. Ao redor de $1200{ }^{\circ} \mathrm{C}$ sofre uma transformação exotérmica irreversível, resultando-se na forma estável, conhecida como alumina alfa $\left(\alpha-\mathrm{Al}_{2} \mathrm{O}_{3}\right)$.

A temperatura de transição para a alumina alfa pode variar de 1100 a $1300{ }^{\circ} \mathrm{C}$, dependendo do material de partida, do tamanho da partícula e de outros materiais presentes.

A alumina obtida pela precipitação de hidróxido a partir de um sal de alumínio geralmente contém íons dos reagentes precursores. Os hidróxidos preparados com sais de alumínio, na forma de nitrato, sulfato e cloreto sofrem transformações sucessivas distintas com o aquecimento e apresentam curvas termogravimétricas diferentes na formação da alumina alfa, segundo Temuujin e seus colaboradores (2000).

Castro \& Gouvêa (2003) verificaram que os íons de $\mathrm{Mn}^{2+}$ provocam a diminuição da temperatura de transição de fase da $\gamma$-alumina para a forma alfa.

A calcinação geralmente é acompanhada pela redução da massa decorrente da vaporização da água e de outras substâncias adsorvidas e em consequência da dehidroxilação.

Se a massa inicial da amostra for $\mathrm{m}_{\mathrm{h}}$ e a massa de $\mathrm{Al}_{2} \mathrm{O}_{3}$ anidro for $\mathrm{m}_{\mathrm{Ox}}$, definem-se as equações 3.26 e 3.27 .

$$
\begin{aligned}
& \mathrm{m}_{\mathrm{Ox}}=\left(1-\Delta_{\mathrm{l}}\right) \mathrm{m}_{\mathrm{h}} \\
& \mathrm{m}_{\mathrm{h}}=\left(1+\Delta_{\mathrm{f}}\right) \mathrm{m}_{\mathrm{Ox}}
\end{aligned}
$$

Onde,

$\Delta_{\imath}$ é a fração de $m_{h}$ perdida na calcinação e $\Delta_{\mathrm{l}}=\left(\mathrm{m}_{\mathrm{h}}-\mathrm{m}_{\mathrm{ox}}\right) / \mathrm{m}_{\mathrm{h}}$. e

$\Delta_{\mathrm{f}}$ é a fração perdida em relação a $\mathrm{m}_{\mathrm{Ox}}$, ou seja, $\Delta_{\mathrm{f}}=\left(\mathrm{m}_{\mathrm{h}}-\mathrm{m}_{\mathrm{ox}}\right) / \mathrm{m}_{\mathrm{ox}}$

$\mathrm{Na}$ calcinação de hidróxido de alumínio $\mathrm{Al}(\mathrm{OH})_{3}$ e de óxido-hidróxido de alumínio $\mathrm{AlO}(\mathrm{OH})$, os valores de $\Delta \mathrm{t}$ podem ser calculados a partir de suas massas molares e são respectivamente 0,346 e 0,1502 . 
Os resultados esperados do aquecimento do hidróxido de alumínio foram relacionados a seguir.

(a) Redução de massa em consequência da evaporação de água e de outras substâncias voláteis. Uma parcela é atribuída à dehidroxilação e à condensação.

(b) Alterações das formas de transição, até atingir a forma estável de $\alpha-\mathrm{Al}_{2} \mathrm{O}_{3}$ ao redor de $1200{ }^{\circ} \mathrm{C}$.

(c) Diminuição da superfície específica da alumina ativada a $400{ }^{\circ} \mathrm{C}$ com cerca de 300 a $350 \mathrm{~m}^{2} \mathrm{~g}^{-1}$ para $5 \mathrm{~m}^{2} \mathrm{~g}^{-1}$ da alumina na forma cristalina alfa $\left(\alpha-\mathrm{Al}_{2} \mathrm{O}_{3}\right)$.

(d) Aumento da densidade de 2,5 $\mathrm{g} \mathrm{cm}^{-3}$ do hidróxido de alumínio, $\mathrm{Al}(\mathrm{OH})_{3}$, a 3,9 $\mathrm{g} \mathrm{cm}^{-3}$ do $\alpha-\mathrm{Al}_{2} \mathrm{O}_{3}$.

\subsubsection{Compactação}

O processo de compactação consiste em pressionar uma determinada quantidade de pó contida em um molde de aço, por meio de pino ou punção. A compactação uniaxial realizada em um molde com três orifícios cilíndricos é ilustrada na FIG. 3.7.

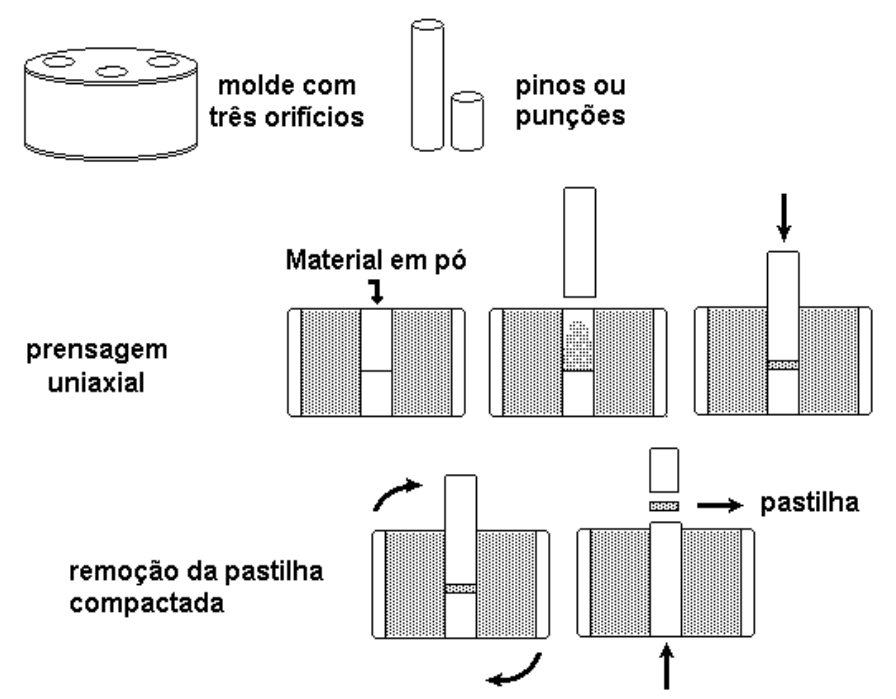

FIGURA 3.7 - Ilustração da compactação uniaxial do pó para a conformação da pastilha em molde de três orifícios.

A densidade (d) da pastilha verde compactada pode ser determinada geometricamente, determinando a massa $(\mathrm{m})$, o diâmetro $(\varnothing)$ e a espessura (e) por meio da equação 3.28 . 


$$
\mathrm{d}=\mathrm{m}\left[\pi(\varnothing / 2)^{2} \mathrm{e}\right]^{-1}
$$

Aditivos. Alguns aditivos são utilizados na compactação com funções lubrificante, plastificante ou ligante. São acrescentados para diminuir o atrito entre as partículas e entre o material e a matriz usada na compactação, aumentar a resistência mecânica e a densidade do compactado.

A resistência e a homogeneidade do compactado podem ser promovidas pela incorporação de produtos como álcool polivinilico (PVA) e ácido esteárico (Segal, 1989; Rahaman, 2003).

Os aditivos devem ser eliminados durante a queima, sem deixar resíduos no processo da sinterização.

\subsubsection{Sinterização}

É o processo da tecnologia do pó, onde as partículas individuais de um corpo compactado são unidas pelo calor em temperaturas elevadas para formar um corpo denso e resistente.

A força motriz para a sinterização é a redução da energia livre da superfície verificado pela diminuição da área superficial das partículas. O processo da sinterização envolve desde a formação de ligamentos nos pontos de contato entre as partículas, resultando numa estrutura contínua e porosa. No estágio inicial da sinterização, o corpo não apresenta resistência. Segue-se o estágio em que ocorrem engrossamento dos pescoços, crescimento dos grãos individuais e redução do tamanho dos poros. A redução do tamanho dos poros resulta na retração do volume e no aumento da densidade do corpo.

A sinterização da alumina é realizada ao redor de 1400 a $1650{ }^{\circ} \mathrm{C}$ (Rahaman, 2003). Essa temperatura requer fornos especiais, pois a maioria dos fornos convencionais atinge a temperatura máxima ao redor de $1200{ }^{\circ} \mathrm{C}$.

Há muitas variáreis que afetam as características da alumina sinterizada. Estas variáveis incluem a pureza da alumina, granulometria e homogeneidade das partículas, grau de compactação do pó, temperatura e tempo de processamento, reações químicas entre os componentes e pelo ambiente gasoso.

De modo geral, a sinterização é favorecida pela diminuição do tamanho das partículas, grau de compactação, elevação da temperatura, pelo aumento do tempo de residência e pela ação dos aditivos. 
Pureza. A alumina de origem industrial com 98 a $99 \%$ de pureza quando sinterizada pode conter poros em sua microestrutura. Esses poros diminuem a transmitância óptica. A TL e a OSL são fenômenos ópticos e a transmitância do material tem seu significado quando a luz emitida em seu interior deve ser percebida pelo sistema de detecção. Se a transmitância for baixa, apenas a luz emitida próxima à superfície tem a chance de ser detectada, sendo uma grande parte absorvida no próprio material.

Tamanho das partículas. A temperatura de sinterização pode ser reduzida pela utilização de partículas menores que $1 \mu \mathrm{m}$. Quando sinterizada com grãos finos a densificação pode atingir $99,7 \%$.

No entanto, o óxido de alumínio na forma de pó muito fino apresenta certas dificuldades. Tratando-se de um material dispersivo e higroscópico, dificulta a determinação de massa, dando origem a incertezas na pesagem. Além disso, a falta de escoamento do pó dificulta sua manipulação.

Aditivos. A sinterização da alumina em pó pode ser promovida pela adição de MgO. A magnésia previne o crescimento descontínuo dos grãos e aumenta a taxa de sinterização, reduz a porosidade e aumenta a transmitância óptica.

$\mathrm{MgO}$ aumenta a taxa de densificação por um fator 3 e a taxa de crescimento dos grãos por um fator 2,5. Há evidências que o $\mathrm{MgO}$ aumenta a difusibilidade superficial, ajudando a mobilidade dos poros, conservando-os nos contornos dos grãos até que sejam eliminados pela difusão no estado sólido.

A alumina translúcida de baixa porosidade e alta transmitância óptica foi utilizada na cápsula da lâmpada de sódio. $\mathrm{MgO}$ e $\mathrm{Y}_{2} \mathrm{O}_{3}$ foram utilizados como adjuvantes para a sinterização da alumina translúcida. A incorporação de $\mathrm{Y}_{2} \mathrm{O}_{3}$ diminui a temperatura e o tempo de sinterização.

Várias técnicas podem ser usadas para monitorar o processo da sinterização. A retração pode ser determinada diretamente pelas medidas das dimensões iniciais e após um tempo ou atingir uma determinada temperatura.

A retração linear (RL) é definida pela equação 3.29.

$$
\mathrm{RL}=\left(\mathrm{L}-\mathrm{L}_{\mathrm{o}}\right) / \mathrm{L}_{\mathrm{o}}
$$


onde, $\mathrm{L}_{\mathrm{o}}$ é o comprimento inicial e L é o comprimento após um certo tempo. O sinal negativo normalmente não é considerado. A densidade do corpo sinterizado pode ser determinada pela equação 3.28 .

Sinterização vítrea. $\mathrm{O}$ vidro é um material que apresenta uma transparência óptica expressiva, estrutura amorfa e propriedades isotrópicas. Entre vários formadores de vidro, a sílica é o composto mais comum. Na formação do vidro, a rede cristalina da sílica é rompida pela adição de $\mathrm{Na}_{2} \mathrm{O}, \mathrm{K}_{2} \mathrm{O}, \mathrm{MgO}$ e $\mathrm{CaO}$. Os íons de $\mathrm{Na}^{+}, \mathrm{K}^{+}, \mathrm{Mg}^{++}$e $\mathrm{Ca}^{++}$ permanecem nos interstícios da rede ligados ionicamente.

$\mathrm{O}$ vidro de cal e soda é um material de boa transparência à luz visível, ultravioleta $\mathrm{e}$ à infravermelha. É constituído por cerca de 70 a $75 \%$ de $\mathrm{SiO}_{2}, 10$ a $18 \%$ de $\mathrm{Na}_{2} \mathrm{O}$ e 5 a $14 \%$ de $\mathrm{CaO}$. Pode conter também pequenas porcentagens de outros óxidos como $\mathrm{MgO}$, $\mathrm{K}_{2} \mathrm{O}$ e $\mathrm{Al}_{2} \mathrm{O}_{3}$. Sua estrutura não é cristalina e não apresenta uma temperatura definida de solidificação.

$\mathrm{O}$ vidro de cal e soda tem a vantagem de apresentar ponto de amolecimento mais baixo que o vidro borossilicato ou de alto teor de sílica. Em temperatura ao redor de $1400^{\circ} \mathrm{C}$, o vidro encontra-se no estado líquido e a sua viscosidade é muito baixa. Permite a sua conformação em temperaturas entre 700 e $1000{ }^{\circ} \mathrm{C}$, quando a sua viscosidade situa entre $10^{6}$ a $10^{3}$ Pa-s (Callister Jr., 2002).

Os efeitos indesejáveis da sinterização com vidro são a adesão à superfície do recipiente e a formação de cristais como consequência da devitrificação.

A formação de cristais dos componentes do vidro de cal e soda ocorre a cerca de $750{ }^{\circ} \mathrm{C}$ e atinge a taxa máxima de crescimento em $970{ }^{\circ} \mathrm{C}$ e pode comprometer sua transparência (CWC, 2000).

A sinterização utilizando o vidro de cal e soda pode ser feita à temperatura ideal para evitar a formação de cristais e a adesão no recipiente e suficientemente alta para reduzir o tempo de residência.

As partículas dos cristais de $\alpha-\mathrm{Al}_{2} \mathrm{O}_{3}$ são unidas por adesão à fase vítrea que preenche os vãos por capilaridade, verificando uma retração do corpo compactado.

\subsection{Avaliação das propriedades TL e OSL}

Conforme Campos (1998), muitos compostos cerâmicos são termoluminescentes. Entretanto, um material pode ser utilizado como dosímetro quando apresentar propriedades adequadas para a sua aplicação em dosimetria. 


\subsubsection{Curva de emissão}

É a intensidade da TL em função da temperatura ou do tempo de aquecimento. A curva da TL pode apresentar vários picos, mas é desejável que o material dosimétrico tenha de preferência um único pico cuja altura ou área sob o qual seja proporcional à dose de radiação.

$\mathrm{O}$ pico dosimétrico na temperatura deve estar localizado entre 180 e $250{ }^{\circ} \mathrm{C}$. Os picos de temperaturas mais baixas podem sofrer decaimento térmico. O pico localizado acima de $250{ }^{\circ} \mathrm{C}$ são mais estáveis. Porém, as leituras TL realizadas nessa região de temperatura sofrem a influência das radiações infravermelhas provenientes do aquecimento, a não ser que seja utilizado um filtro óptico para minimizar o efeito.

O pico depende da taxa de aquecimento como previsto pela teoria. Um aquecimento mais rápido pode resultar em um deslocamento do pico para temperaturas mais altas.

A curva da OSL decresce exponencialmente à medida que o material irradiado for iluminado, conforme a teoria da subseção 3.2.

\subsubsection{Resposta em função da dose}

É a relação da TL ou da OSL em função da dose de radiação. O ideal é que o material tenha uma resposta linear numa faixa ampla de dose.

Muitos materiais usados na prática mostram efeitos não-lineares designados de supra e sub-linearidade com o aumento da dose.

A resposta em função da dose normalizada (ou índice de supra-linearidade) é definida pela equação 3.30 (McKeever et al., 1995).

$$
\mathrm{F}(\mathrm{D})=[\mathrm{F}(\mathrm{D}) / \mathrm{D}] /\left[\mathrm{F}\left(\mathrm{D}_{1}\right) / \mathrm{D}_{1}\right]
$$

Onde, $\mathrm{F}(\mathrm{D})$ é a resposta de dose a uma dose $\mathrm{D}$ e $\mathrm{D}_{1}$ é uma dose baixa onde a resposta de dose é linear.

O dosímetro ideal deve satisfazer $F(D)=1$, em um intervalo amplo de dose, por exemplo, desde fração de Gray (Gy) até vários milhares de Gy. Porém, em muitos materiais, a igualdade $\mathrm{F}(\mathrm{D})=1$ é satisfeita apenas em um intervalo estreito de dose, até poucos Gy.

A supra-linearidade é comumente observada em muitos materiais, quando $F(D)>1$. A sub-linearidade é verificada principalmente na proximidade da saturação. 
A faixa linear da resposta com a dose permite determinar o fator de calibração $\left(f_{c}\right)$. Este fator relaciona a leitura TL ou OSL com a dose, conforme a equação 3.31.

$$
D=f_{c} F(D)
$$

Onde, o fator de calibração corresponde ao inverso do coeficiente angular da reta da resposta com a dose.

\subsubsection{Sensibilidade}

A sensibilidade é definida como a intensidade da TL por unidade de dose absorvida. Conforme Furetta (2003), a sensibilidade (S) de um dosímetro termoluminescente pode ser expressa como a resposta TL em unidade do leitor, por unidade de dose (D) e unidade de massa (m) da amostra, de acordo com a equação 3.32.

$$
\mathrm{S}=\mathrm{TL} /(\mathrm{D} \mathrm{m})
$$

A sensibilidade depende de fatores tais como eficiência do sistema de detecção da TL, taxa de aquecimento, forma física do material de interesse, do tratamento térmico aplicado, do tipo e da energia da radiação ionizante.

Por causa da dificuldade de ser medida em termos absolutos, a sensibilidade é expressa em termos relativos, comparando o sinal TL do material de interesse com o sinal do TLD-100. Esse material foi tomado como referência, pois é amplamente utilizado. A radiação gama de ${ }^{60} \mathrm{Co}\left(\mathrm{E}_{\text {médio }}=1,25 \mathrm{MeV}\right)$ é geralmente usada como radiação de referência.

A sensibilidade S(D) é definida pela equação 3.33 .

$$
\mathrm{S}(\mathrm{D})=\mathrm{F}(\mathrm{D})_{\text {material }} / \mathrm{F}(\mathrm{D})_{\mathrm{TLD}-100}
$$

Onde, F(D) é a resposta em função da dose no material de interesse e F(D) TLD-100 é a resposta em função da dose do dosímetro TLD-100.

Ao atribuir o valor unitário a $\mathrm{F}(\mathrm{D})_{\mathrm{TLD}-100}$, o valor de $\mathrm{S}(\mathrm{D})$ indica quantas vezes o material é mais ou menos sensível que TLD-100. 


\subsubsection{Dependência energética da dose}

O sinal TL em função da dose pode variar com a energia da radiação incidente no material dosimétrico. Esta variação decorre do coeficiente de absorção de energia ou do coeficiente de absorção de energia de massa que é característico do material para o fóton de energia definida.

A resposta de energia do fóton $\mathrm{S}_{\mathrm{E}}(\mathrm{E})$ é dada por

$$
\mathrm{S}_{\mathrm{E}}(\mathrm{E})=\left(\mu_{\mathrm{en}} / \rho\right)_{\mathrm{m}} /\left(\mu_{\mathrm{en}} / \rho\right)_{\text {ref }}
$$

Para uma mistura de materiais,

$$
\left(\mu_{\mathrm{en}} / \rho\right)_{\mathrm{m}}=\Sigma\left(\mu_{\mathrm{en}} / \rho\right)_{\mathrm{i}} \mathrm{W}_{\mathrm{i}}
$$

Onde, $\mathrm{W}_{\mathrm{i}}$ é a fração por peso do elemento $\mathrm{i}$.

A perda de energia da radiação no material pode ocorrer pela produção de pares, espalhamento Compton e pelo efeito fotoelétrico. O processo dominante depende da energia do fóton incidente e do material, este caracterizado pelo número atômico efetivo $\left(Z_{\mathrm{ef}}\right)$.

Se o propósito é determinar a dose absorvida pelo tecido humano, é desejável que o material do dosímetro seja equivalente ao tecido mole. O tecido mole é constituído por elementos com números atômicos baixos: carbono (6), hidrogênio (1), nitrogênio (7) e oxigênio (8). O número atômico efetivo $\left(Z_{\mathrm{ef}}\right)$ do tecido mole do corpo é 7,4 e do osso é 14,3 .

Os dosímetros com valores de $\mathrm{Z}_{\mathrm{ef}}$ diferentes ao do corpo devem ter as doses corrigidas para a dependência energética. Bos (2001) apresentou uma tabela de valores de $\mathrm{Z}_{\mathrm{ef}}$ calculados para materiais comuns. O valor para o óxido de alumínio é $\mathrm{Z}_{\mathrm{ef}}=10,28$.

Os materiais com $\mathrm{Z}_{\mathrm{ef}}$ alto são fortemente dependentes da energia do fóton incidente e não são indicados para a dosimetria pessoal.

Cristais de ortoaluminato de ítrio impurificado com manganês $\left(\mathrm{YAlO}_{3}: \mathrm{Mn}^{2+}\right)$ que possui número atômico efetivo alto $($ Zef $=31,4)$ tem sido estudado para aplicação em dosimetria TL, quando não há necessidade da equivalência ao tecido (Zhydachevskii et al., 2005; 2010). 


\subsubsection{Tratamento térmico de reutilização}

É um tratamento em que o material é aquecido a uma determinada temperatura e durante um tempo. Designado também tratamento térmico de pré-irradiação tem o propósito de restabelecer o equilíbrio termodinâmico do defeito que existia antes da irradiação e leitura. Pretende-se pelo processo que os elétrons presos retornem ao estado fundamental, removendo qualquer resquício de sinal da TL ou da OSL e "zerar" o dosímetro. É importante que o tratamento completo seja simples e não altere a sensibilidade, para que o dosímetro seja utilizado várias vezes, com respostas reprodutíveis. A taxa de resfriamento pode afetar a sensibilidade e os parâmetros de armadilhamento.

O sinal OSL pode ser eliminado opticamente iluminando a amostra com luz de comprimento de onda e intensidade adequada. Pode ser completamente eliminado por aquecimento à temperatura de $500{ }^{\circ} \mathrm{C}$ (subseção 3.2).

\subsubsection{Decaimento térmico}

O decaimento térmico refere-se à diminuição do sinal da termoluminescência ao longo do tempo, após a irradiação do material dosimétrico. Para a cinética de $1^{\text {a }}$. ordem, a energia da profundidade da armadilha (E) e o fator de frequência (s) ditam a taxa do decaimento térmico. Baixo decaimento térmico do sinal TL significa que os elétrons e os buracos presos nas armadilhas permanecem estáveis por bastante tempo.

A meia-vida $\left(\mathrm{T}_{1 / 2}\right)$ de um tipo particular de armadilha é definida como o tempo em que o número de elétrons presos cai para a metade de seu valor original.

$$
\mathrm{T}_{1 / 2}=\ln 2\left[\mathrm{~s}^{-1} \exp (\mathrm{E} / \mathrm{kT})\right]
$$

O sinal OSL também é reduzido pelo aquecimento. Isto pode ser verificado experimentalmente pelo aquecimento escalonado do material ("step annealing").

\subsubsection{Espectro de emissão}

Refere-se à intensidade da TL ou da OSL em função do comprimento de onda. É característico de cada material. O espectro de emissão TL ou da OSL deve estar dentro da faixa detectável pela válvula fotomultiplicadora ou do sistema de detecção e não sofrer a interferência da emissão incandescente, resultante do aquecimento. O comprimento de onda deve estar preferencialmente entre 300 a $500 \mathrm{~nm}$. 


\subsubsection{Dose mínima detectável}

Os dosímetros submetidos ao tratamento térmico de reutilização (3.6.5) (porém não irradiados) apresentam leitura da dose zero $\left(\mathrm{TL}_{0}\right.$ ou $\left.\mathrm{OSL}_{0}\right)$.

O limite mínimo de detecção $\left(\mathrm{D}_{\text {lim }}\right)$ é definido como três desvios-padrão $(\sigma)$ do sinal de um dosímetro não irradiado (Furetta, 2003).

$$
\mathrm{D}_{\lim }=3 \sigma
$$

Esta definição se aplica não somente ao material, mas está relacionada ao sistema de medição que inclui filtros ópticos, sistema de detecção, programas de análise.

A dose mínima detectável $\left(\mathrm{D}_{\text {mín }}\right)$ pode ser calculada usando a expressão:

$$
\mathrm{D}_{\min }=\left(\mathrm{TL}_{0}+\mathrm{D}_{\lim }\right) \mathrm{f}_{\mathrm{c}}
$$

Onde, $\mathrm{f}_{\mathrm{c}}$ é o fator de calibração obtido da região linear da resposta com a dose descrita na subsecção 3.6.2.

\subsubsection{Transparência óptica}

A termoluminescência e a OSL são fenômenos ópticos. Para que a luz emitida seja detectada pelo leitor TL ou OSL com eficiência, o material deve ser transparente ou translúcido. No caso de materiais opacos, o leitor só detectará a TL da superfície externa do dosímetro.

$\mathrm{O} \mathrm{Al}_{2} \mathrm{O}_{3}$ pode-se apresentar na forma opaca, translúcida e transparente, dependendo de sua estrutura (Callister Jr., 2002). 


\section{MATERIAIS E MÉTODOS}

\subsection{Materiais e Equipamentos}

\subsubsection{Produtos químicos}

- Ácido cítrico monohidratado PA, marca Cinética.

- Ácido esteárico, lubrificante para molde de compactação.

- Álcool polivinílico, adjuvante de compactação.

- Álcool etílico absoluto (99,5\%) PA, marca Cromato Produtos Químicos LTDA., para lavagem do hidróxido de alumínio precipitado

- Álcool n-butílico, grau PA, para destilação azeotrópica.

- Cloreto de alumínio hexahidratado puríssimo, marca Vetec Química Fina, para precipitação do hidróxido de alumínio.

- Hidróxido de alumínio puríssimo $\mathrm{Al}(\mathrm{OH})_{3}$, marca Vetec Química Fina.

- Óxido de alumínio ácido 90, com atividade I, tamanho das partículas de 63 a $200 \mu \mathrm{m}$ marca Merck S.A, usado como meio adsorvente.

- Óxido de túlio $\mathrm{Tm}_{2} \mathrm{O}_{3}$, padronizado espectrograficamente, marca Johnson Matthey Chemicals Limited, para preparação da solução de ativador de $\mathrm{Tm}^{3+}$.

- Solução de nitrato de prata (1\%), para verificar presença de íons cloreto no filtrado.

- Solução de hidróxido de amônio (25\%), marca Merck S.A.

- Sulfato de manganês II monohidratado, marca Merck S.A., para preparação da solução de ativador.

- Sulfato de cobre pentahidratado, para preparação da solução de ativador.

\subsubsection{Materiais de laboratório}

- Balões volumétricos de $100 \mathrm{~mL}$. 
- Almofariz e pistilo de porcelana ou de ágata, para desagregações de pós e triturações.

- Cadinhos de porcelana com revestimento vítreo interno para aquecimento até cerca de $800{ }^{\circ} \mathrm{C}$.

- Cadinhos cerâmicos especiais sem revestimento vítreo, marca Chiarotti, tamanho M-37, para aquecimento até $1200{ }^{\circ} \mathrm{C}$.

- Cadinhos e placas de alumina sinterizada, para aquecimento acima de $1200{ }^{\circ} \mathrm{C}$.

- Copos de Becker de 250 e $600 \mathrm{~mL}$ de capacidade.

- Dessecadores de vidro com secante de sílica gel.

- Frascos de policarbonato e de vidro de diferentes tamanhos, para conservação de soluções e amostras sólidas.

- Funis de Büchner e kitassatos, para filtração à vácuo.

- Nitrogênio gasoso industrial comprimido, da White Martins Praxair, para sistemas de leitura da TL e da OSL.

- Pipetas graduadas de vidro de 0,1 mL, 1,0 mL e $10 \mathrm{~mL}$.

- Provetas graduadas

\subsubsection{Equipamentos}

As siglas dos Centros ou das Gerências aos quais os equipamentos pertencem estão indicadas entre parênteses e são respectivamente: (GMR) Gerência de Metrologia das Radiações, (CCTM) Centro de Ciência e Tecnologia de Materiais e (CTR) Centro de Tecnologia das Radiações.

- Agitador magnético, com aquecimento, marca Quimis, modelo 0261-12 (GMR).

- Agitador mecânico, marca IKA, modelo RW20, utilizado durante a reação de precipitação do hidróxido de alumínio (CCTM).

- Balanças marca Shimadzu, modelo AY220 (CCTM e GMR).

- Balança analítica Mettler, modelo H 35 (GMR).

- Balança semi-analítica marca CG LIBOR (GMR). 
- Bomba de vácuo de diafragma, marca FANEM, modelo CA (CCTM).

- Bomba de vácuo para a filtração e lavagem de precipitados, em conjunto com os funis e kitassatos, Marca HF Vácuo Ind. e Com. Eletrom. e Ap. Cientif. Ltda., modelo 05 (GMR).

- Estufa para secagem e esterilização, marca FANEM Ltda., modelo retilínea 315 ou similar (CCTM e GMR).

- Evaporador rotativo, marca Fisatom, modelo 802, com banho de glicerina, para destilação do butanol (CCTM).

- Forno elétrico marca EDG Equipamentos e Controles, modelo FIVE-2, para aquecimento até $1200{ }^{\circ} \mathrm{C}$ (GMR).

- Forno tipo mufla, modelo MAS-7000 da CEM Corporation, operado por microondas, para aquecimento até $1200^{\circ} \mathrm{C}$ (GMR).

- Forno de câmara marca Lindberg Blue, com elementos de aquecimento de dissiliceto de molibdênio (super kanthal), para aquecimento até $1700{ }^{\circ} \mathrm{C}$, (CCTM).

- Microcomputador marca Itautec, modelo Infoway, com programa Microsoft Office ${ }^{\circledR}(\mathrm{GMR})$.

- Micrômetro para medidas de 0 a $25 \mathrm{~mm}$ e incerteza de $\pm 0,01 \mathrm{~mm}$, marca Mitutoyo (CCTM) ou similar, para determinação das dimensões das pastilhas.

- Moldes de aço com três orifícios de diâmetros nominais de 5, 6 e 8 mm, para compactação da alumina em pó (GMR).

- Peneiras granulométricas com tela de aço inoxidável e aberturas de 0,075 mm (ABNT 200) e 0,180 mm (ABNT 80), com dimensões de 5 x 2 polegadas, marca Granutest. (GMR).

- Prensa hidráulica marca FEDFREY, com carga máxima de 5 toneladas, para a compactação de pó (GMR).

- Prensa hidráulica manual, marca SOMAR, com capacidade de carga de 15 toneladas, do laboratório de insumos (CCTM).

- Termopares do tipo $\mathrm{K}$ (NiCr/NiAl), com módulo de leitura marca SALVTERM $1200 \mathrm{~K}$, para medida da temperatura até $1200^{\circ} \mathrm{C}$ (GMR). 


\subsection{Métodos}

\subsubsection{Obtenção de alumina impurificada por adsorção}

O método para a obtenção da alumina impurificada por adsorção está esquematizado na FIG. 4.1.

Como adsorvente, utilizou-se óxido de alumínio ácido 90 da marca Merck S.A, com atividade I, tamanho das partículas de 63 a $200 \mu \mathrm{m}$. Foi utilizado também o hidróxido de alumínio puríssimo da marca Vetec Química Fina Ltda.

A massa necessária de hidróxido de alumínio foi inicialmente determinada em balança analítica, considerando-se o óxido de alumínio a ser formado. A perda de massa estimada para o hidróxido de alumínio da Vetec foi $\Delta_{\imath}=0,46$.

A solução de $\mathrm{Mn}^{2+}$ foi preparada utilizando-se sulfato de manganês monohidratado, $\mathrm{MnSO}_{4} \cdot \mathrm{H}_{2} \mathrm{O}$.

Um volume de $0,500 \mathrm{~mL}$ da solução de $\mathrm{MnSO}_{4}$ com a concentração de $9,812610^{-5} \mathrm{M}(\mathrm{mol} / \mathrm{L})$ foi transferido para um béquer de $250 \mathrm{~mL}$ e diluído para $50 \mathrm{~mL}$. A seguir, o hidróxido de alumínio foi introduzido à solução em quantidade correspondente a $5,0009 \mathrm{~g}$ de $\mathrm{Al}_{2} \mathrm{O}_{3}$ (ou 4,9038.10 $0^{-5} \mathrm{~mol}$ ), sob agitação.

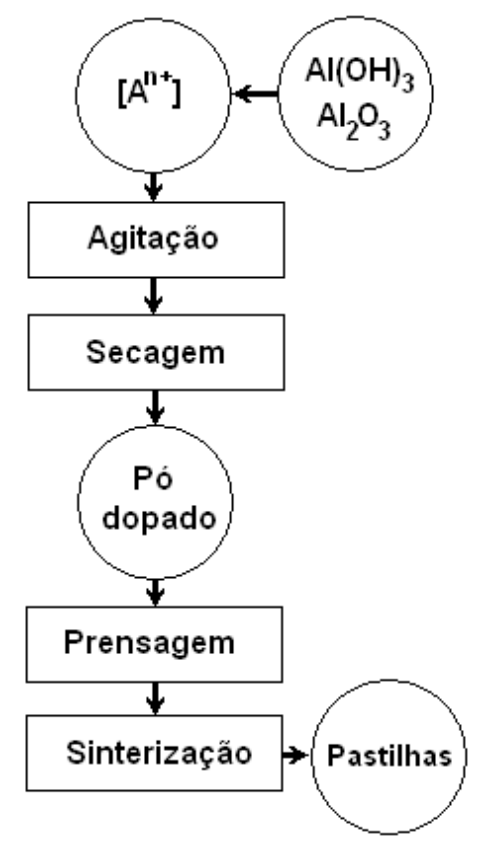

FIGURA 4.1 - Esquema para a produção de pastilhas pelo método da adsorção.

A suspensão foi aquecida em uma chapa elétrica entre 60 a $70^{\circ} \mathrm{C}$ até a secura. $\mathrm{O}$ sólido resultante foi submetido à calcinação a $280{ }^{\circ} \mathrm{C}$ durante 1 hora. 
As pastilhas foram compactadas, umedecendo o pó com uma solução de ácido cítrico 1M. As pastilhas $\mathrm{Al}_{2} \mathrm{O}_{3}: \mathrm{Mn}$ foram inicialmente aquecidas a $600{ }^{\circ} \mathrm{C}$ e a $1530{ }^{\circ} \mathrm{C}$ durante uma hora para a sinterização.

Um procedimento semelhante foi seguido para a impurificação da alumina com $\mathrm{Cu}^{2+}$, partindo da preparação da solução de sulfato de cobre $\left(\mathrm{CuSO}_{4} \cdot 5 \mathrm{H}_{2} \mathrm{O}\right)$.

\subsubsection{Obtenção de alumina impurificada por coprecipitação}

Um esquema para a obtenção da alumina impurificada pelo método da coprecipitação é apresentado na FIG. 4.2. O procedimento foi descrito a seguir.

Preparação da solução de $\mathrm{Al}^{3+}$ e $\mathrm{Tm}^{3+}$. Uma solução concentrada de $\mathrm{Al}^{3+}$ foi preparada, dissolvendo uma quantidade de cloreto de alumínio hexahidratado $\left(\mathrm{AlCl}_{3} \cdot 6 \mathrm{H}_{2} \mathrm{O}\right.$ da Vetec Química Fina Ltda.) correspondente a $10 \mathrm{~g}$ de $\mathrm{Al}_{2} \mathrm{O}_{3}$. A solução do dopante $\mathrm{Tm}^{3+}$ foi preparada dissolvendo o $\mathrm{Tm}_{2} \mathrm{O}_{3}$ em ácido clorídrico. Adicionou-se a quantidade de $\mathrm{Tm}^{3+}$ correspondente a $0,1 \%$ em mol em relação $\mathrm{Al}_{2} \mathrm{O}_{3}$ à solução de $\mathrm{Al}^{3+}$. $\mathrm{O}$ volume da solução com a mistura de íons foi completado para $100 \mathrm{~mL}$.

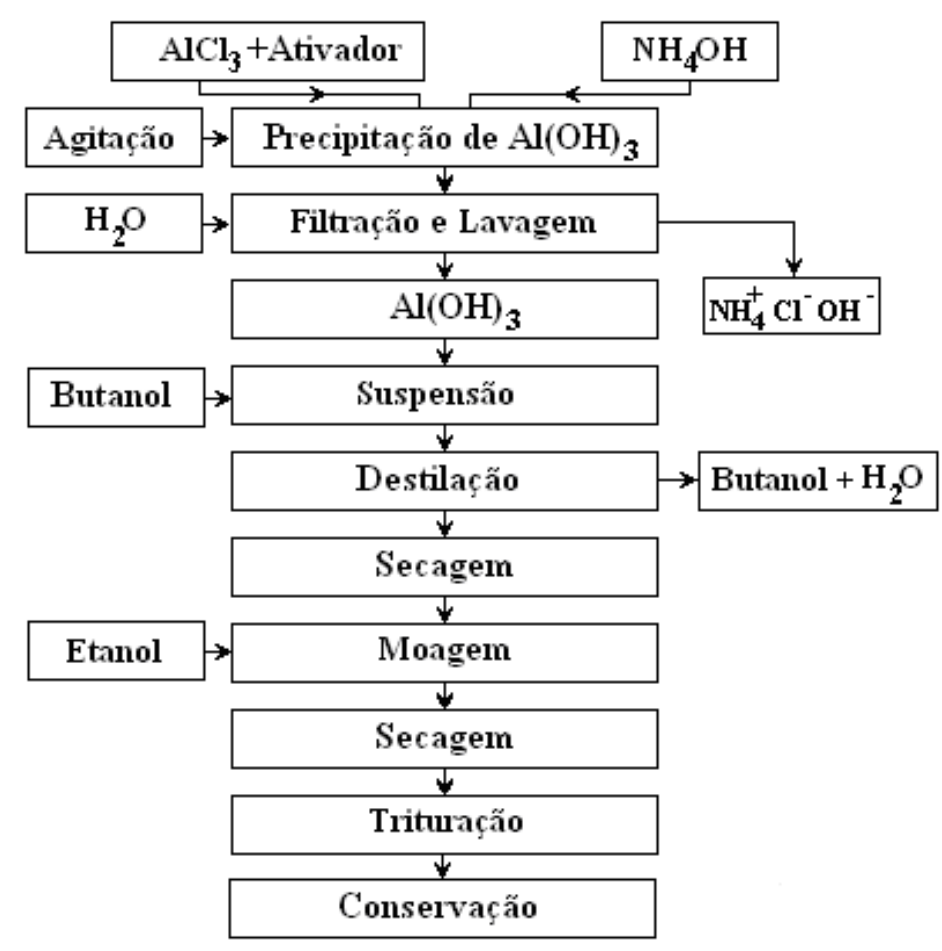

FIGURA 4.2 - Esquema para a obtenção da alumina impurificada pelo método da coprecipitação. 
Coprecipitação do $\mathbf{A l}(\mathbf{O H})_{3}$ e $\mathbf{T m}(\mathbf{O H})_{3}$. A solução com os íons de $\mathrm{Al}^{3+}$ e $\mathrm{Tm}^{3+}$ foi introduzida lentamente a uma solução de hidróxido de amônio contida em um béquer de $600 \mathrm{~mL}$, sob agitação. A solução de hidróxido de amônio foi preparada dissolvendo-se 100 mL de solução de amônia p.a 25\% da Merck S.A. em 100 mL de água.

Filtração e lavagem do precipitado. O precipitado foi filtrado e lavado com uma solução diluída de $\mathrm{NH}_{4} \mathrm{OH}$, para a eliminação dos íons solúveis provenientes dos reagentes precursores. Esta operação foi realizada com funil de Büchner, kitassato e sistema de vácuo. A lavagem foi continuada até a indicação negativa de íons cloreto no filtrado.

Suspensão em álcool. O precipitado lavado foi transferido para um béquer, suspenso em álcool etílico absoluto e filtrado. Foi suspenso em n-butanol e conservado até o dia seguinte.

Destilação do butanol. A separação do hidróxido de alumínio foi feita por destilação do n-butanol em balão rotativo, em banho de glicerina aquecido de 110 a $145^{\circ} \mathrm{C}$, com rotação de 60 a $120 \mathrm{rpm}$.

Moagem e secagem. O precipitado seco foi submetido à moagem com esferas de alumina sinterizada, durante 15 horas em etanol absoluto, para a redução do tamanho das partículas. O material moído e com aspecto leitoso foi seco em estufa.

Trituração e conservação. O material seco com aspecto de lascas é triturado em almofariz de ágata, transferido para um recipiente e identificado.

Variantes desse procedimento, com quantidades diferentes de reagentes, sem a suspensão em álcool e sem a moagem também foram testados.

\subsubsection{Confecção de pastilhas por compactação e sinterização}

Verificou-se que a alumina calcinada em temperatura acima de $1200{ }^{\circ} \mathrm{C}$ é abrasiva e não apresenta plasticidade para a moldagem. A abrasividade da alumina provoca o desgaste do molde e as bordas do compactado tornam-se escurecidas. Partículas muito finas da alumina penetram no vão entre o molde e o pino de compactação, dificultando a 
posterior remoção do compactado. A alumina calcinada a $600{ }^{\circ} \mathrm{C}$ é reativa e adere nas superfícies do molde.

A compactação foi feita em moldes de aço com três orifícios de $6 \mathrm{~mm}$ de diâmetro. O álcool polivinílico, ácido cítrico e o ácido esteárico foram utilizados como adjuvantes de compactação para contornar as questões referentes à abrasividade e à falta de plasticidade da alumina. Para evitar a aderência da alumina, as faces dos pinos de prensagem foram recobertas com fita adesiva.

Citam-se diferentes procedimentos adotados:

(a) Compactação de alumina calcinada a $600{ }^{\circ} \mathrm{C}$ feita manualmente com adjuvantes e sem utilização de prensa,

(b) Compactação de alumina calcinada a $600{ }^{\circ} \mathrm{C}$ feita sem adjuvantes e com prensa hidráulica manual (CCTM) e

(c) Compactação de alumina calcinada a $1200{ }^{\circ} \mathrm{C}$ feita com adjuvantes e prensa hidráulica FredFrey (GMR).

As pastilhas prensadas foram sinterizadas entre $1500{ }^{\circ} \mathrm{C}$ a $1550{ }^{\circ} \mathrm{C}$ no forno marca Lindberg Blue do Laboratório de Insumos do CCTM.

A perda de massa e a retração foram determinadas pelas medições da pastilha antes e após a sinterização. As massas foram determinadas em balança analítica.

O diâmetro e a espessura foram medidos com micrômetro para medidas até $25 \mathrm{~mm}$, com incerteza de $\pm 0,01 \mathrm{~mm}$.

A densidade aparente das pastilhas foi determinada pela equação 3.28.

A retração linear foi determinada pela medição das dimensões das pastilhas antes e depois da sinterização, conforme a equação 3.29.

\subsubsection{Confecção de pastilhas de alumina eletrofundida}

A alumina eletrofundida branca foi fornecida pela ELFUSA Geral de Eletrofusão Ltda, identificada sob a sigla ALR 120. Os cristais foram classificados com peneiras granulométricas, no tamanho de 75 a $180 \mu \mathrm{m}$, lavados e calcinados a $600{ }^{\circ} \mathrm{C}$. O vidro de cal e soda foi triturado e peneirado com dimensões menores que $75 \mu \mathrm{m}$.

Os cristais de alumina e o vidro foram misturados na proporção de 1:1 em peso. A mistura foi acrescida de uma solução de álcool polivinílico $10 \%$ em peso para facilitar a compactação. 
As pastilhas foram compactadas sem a utilização de prensa, pesando-se porções com massas determinadas por uma balança analítica, considerando a massa a ser perdida na secagem e na sinterização.

A sinterização foi feita no forno tipo mufla operado com microondas, da CEM Corporation, modelo MAS 7000. O forno foi programado em três patamares de temperatura de $90{ }^{\circ} \mathrm{C}, 600{ }^{\circ} \mathrm{C}$ e de $732{ }^{\circ} \mathrm{C}$, para a sinterização durante 40 minutos. $\mathrm{O}$ material sinterizado foi mantido no forno até seu resfriamento à temperatura ambiente.

\subsection{Verificação experimental das propriedades TL e OSL}

\subsubsection{Sistemas de irradiação.}

Os sistemas de irradiação relacionados a seguir foram utilizados para verificar experimentalmente as propriedades TL e OSL das amostras.

- Irradiador Gamma Cell - 220, Atomic Energy of Canada Limited, com fonte radioativa selada de ${ }^{60} \mathrm{Co}$ com atividade de $7,33376710^{13} \mathrm{~Bq}$ de atividade em julho de 2011 , do CTR.

- Irradiador tipo Panorâmico, com fonte radioativa selada de ${ }^{60} \mathrm{Co}$ com $1,346648310^{13} \mathrm{~Bq}(363,959 \mathrm{Ci})$ de atividade em julho de 2011, do CTR.

- Irradiador para teleterapia, marca Siemens, com fonte de ${ }^{60} \mathrm{Co}$ com atividade de 0,339 $10^{12} \mathrm{~Bq}$ em setembro de 1999, do Laboratório de Calibração de Instrumentos (LCI) da GMR.

- Irradiador JLShepherd and Associates, modelo Mark IV, com fonte de ${ }^{137}$ Cs do tipo A com atividade de $3,7010^{9} \mathrm{~Bq}(100 \mathrm{mCi})$ em 14 de outubro de 1987 , localizado no Laboratório Materiais Dosimétricos (LMD) da GMR.

- Irradiador beta com fonte de ${ }^{90} \mathrm{Sr} /{ }^{90} \mathrm{Y}$ do leitor RIS $\varnothing$, modelo TL/OSL-DA-20, com atividade de 1,48 GBq, que fornece uma taxa de dose em quartzo na posição da amostra de aproximadamente $0,1 \mathrm{~Gy} \mathrm{~s}^{-1}$ (RISø DTU, 2010).

O irradiador Gamma Cell possui um conjunto de fontes de ${ }^{60} \mathrm{Co}$ no seu interior com atividade bastante elevada e que fornecem taxa intensa de dose. Para a irradiação, as amostras foram introduzidas numa câmara interna do irradiador onde recebe a radiação. A irradiação das amostras com doses da ordem de Gray (Gy) foi feita com o uso atenuador. A 
dose foi determinada considerando a atividade da fonte e o tempo de irradiação. Para a irradiação da amostra com dose de 5 Gy foram necessários cerca de dois minutos, usando atenuador de $90 \%$. A atividade da fonte é corrigida no tempo, considerando o decaimento do ${ }^{60} \mathrm{Co}$.

O arranjo físico do irradiador tipo Panorâmico é diferente do Gamma Cell. Para a irradiação no irradiador Panorâmico, consideram-se a atividade da fonte, a distância da amostra em relação à fonte radioativa e o tempo de irradiação. A fonte de radiação é exposta no momento da irradiação. O irradiador Panorâmico do CTR permitiu a irradiação das amostras com doses de 1, 2, 5 e 10 Gy.

$\mathrm{O}$ irradiador para teleterapia instalado no LCI com fonte de ${ }^{60} \mathrm{Co}$ permitiu a irradiação das amostras com doses de 100, 200, 500 e 800 mGy em termos de Kerma no ar, com incerteza de $3,10 \%$.

O irradiador JLShepherd do LMD possui um sistema pneumático para a introdução das amostras para a irradiação e um temporizador que faz retornar a amostra após um tempo determinado de irradiação.

O irradiador beta com fonte de ${ }^{90} \mathrm{Sr} /{ }^{90} \mathrm{Y}$ é parte integrante do sistema RIS $\varnothing$ de leitura TL e OSL. O sistema permite estabelecer o tempo de irradiação da amostra por meio de um programa de computador. A descrição mais detalhada desse equipamento foi feita na subsecção 4.3.3 (RISØ DTU, 2010).

\subsubsection{Sistema HARSHAW de leitura TL}

O leitor de TL marca Harshaw modelo 2000 consiste de dois módulos A e B (FIG. 4.3). O módulo A possui uma gaveta com uma placa de aquecimento onde se põe a amostra para a medição da TL. O aquecimento ou o perfil de aquecimento da placa pode ser alterado por ajustes externos. O aquecimento pode incluir um pré-aquecimento rápido, aumento linear de temperatura ajustável e um patamar de temperatura máxima.

Vários acessórios permitem o sistema "ler" amostras em pó, pastilhas, bastonetes e outras formas de detectores sólidos.

A própria placa onde se coloca a amostra funciona como resistência elétrica. É essencial que haja um contato térmico ótimo entre a placa e a amostra para que a temperatura indicada seja de fato a temperatura da amostra.

O sistema de detecção de luz consiste fundamentalmente de um tubo fotomultiplicador (TFM) inserido dentro de uma câmara escura, para que apenas a 
luminosidade da termoluminescência seja detectada, sem a interferência de qualquer luz externa. A luz que incide no TFM gera uma corrente ou tensão elétrica. Essa corrente gerada é amplificada e medida no picoamperímetro. A termoluminescência é apresentada no painel do módulo B, como corrente elétrica integrada no tempo, em unidade de carga elétrica $(\mathrm{nC}$ ou $\mu \mathrm{C})$.

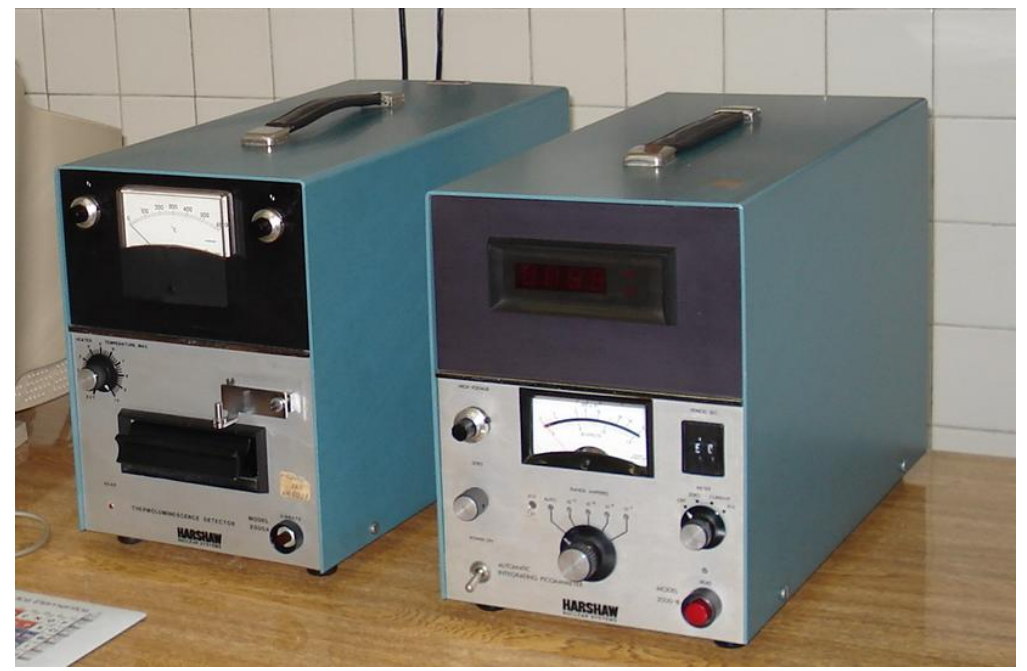

FIGURA 4.3 - Leitor de TL marca Harshaw modelo 2000. O módulo A à esquerda encerra o tubo fotomultiplicador que detecta a TL. O módulo B à direita é um picoamperímetro integrador automático.

O módulo B é o picoamperímetro integrador automático. O período de tempo de integração pode ser variado de 1 até 99 s. O sinal da TL é medido como a área integrada sob o pico "glow", representado pela carga total liberada pelo TFM durante o ciclo de leitura. A integração da TL entre duas temperaturas predeterminadas é opcional.

O módulo B do leitor de TL Harshaw 2000 possui conexões de saída que permite obter a curva da TL por meio de um registrador gráfico do tipo XY. No registrador, a corrente ou a tensão proveniente do sinal da TL é registrada em função do tempo ou da temperatura de aquecimento.

O leitor de TL Harshaw 2000 concebido em sistemas eletrônicos analógicos é um equipamento praticamente em desuso por ser antigo. Com o desenvolvimento da eletrônica, tornou-se possível converter os sinais analógicos gerados pelo leitor da TL por meio de um conversor analógico-digital ou placa de aquisição de dados. 
Uma placa de aquisição de dados foi instalada no módulo B do leitor de TL Harshaw 2000 (FIG. 4.4). Por meio desse sistema, a corrente gerada em função da termoluminescência e a tensão do termopar indicativa da temperatura foram transformadas em códigos binários e os dados puderam ser armazenados e analisados em computador.

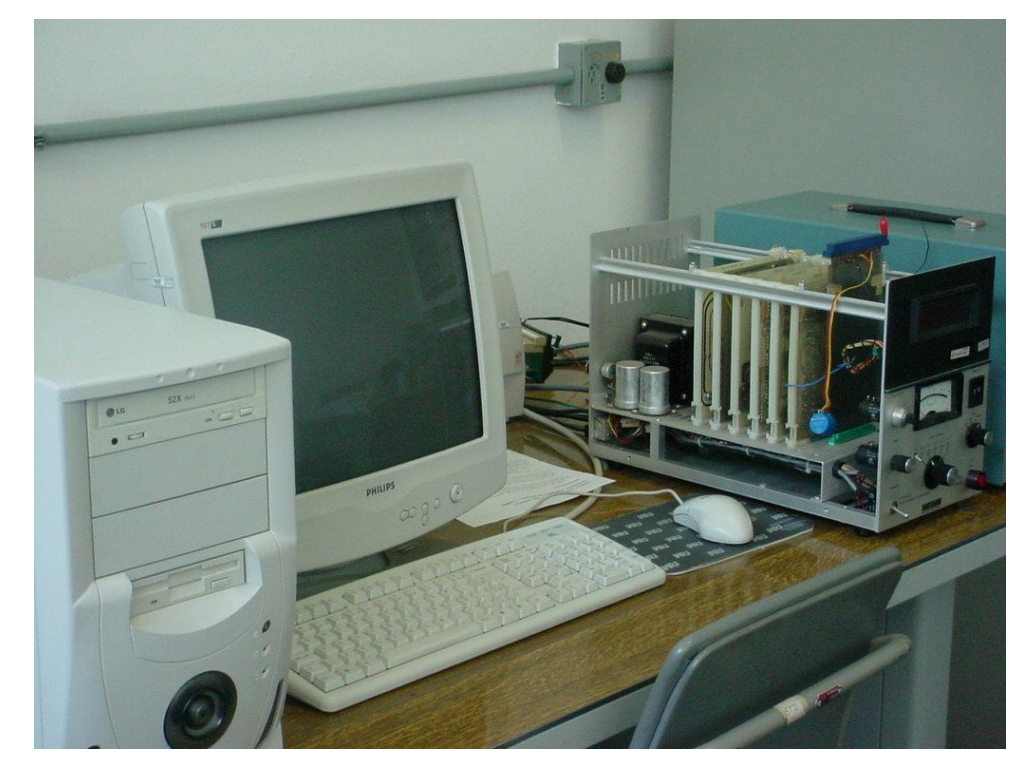

FIGURA 4.4 - Módulo B do leitor Harshaw modelo 2000, com a parte interna à mostra, onde foi posicionada a placa de aquisição de dados.

Os dados de leitura da TL foram coletados por meio de um programa de computador desenvolvido em LabView ${ }^{\circledR}$ e foram analisados em planilha Excel da Microsoft®.

\subsubsection{Sistema RISØ de leitura TL e OSL}

O sistema de leitura TL/OSL produzido pelo Laboratório Nacional da Dinamarca RISØ, modelo TL/OSL-DA-20, é constituído de três partes principais: o leitor propriamente dito, o controlador e um computador com programas para instrução, coleta e análise dos dados (RISø DTU, 2010).

O leitor e o controlador são mostrados na FIG. 4.5. O sistema foi designado leitor RIS $\emptyset$, por simplificação. 


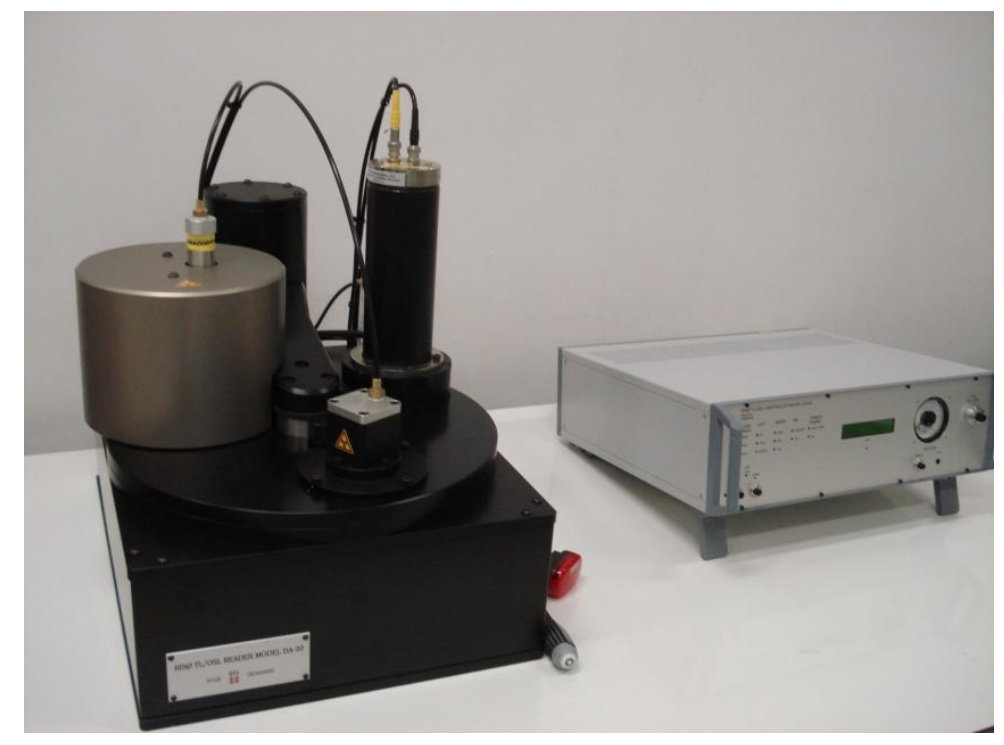

FIGURA 4.5 - Leitor TL/OSL RIS $\varnothing$ modelo DA-20 e seu controlador.

O leitor RIS $\varnothing$ possui fontes de radiação $\alpha$ e $\beta$, sistemas de estimulação térmica e óptica, e um sistema de detecção da luminescência que compreende um tubo fotomultiplicador (TFM) combinado com filtros ópticos.

A fonte de radiação "beta" integrante do leitor é de ${ }^{90} \mathrm{Sr} /{ }^{90} \mathrm{Y}$ com $1,48 \mathrm{GBq}$ de atividade que fornece uma taxa de dose de aproximadamente $0,1 \mathrm{~Gy} \mathrm{~s}^{-1}$ em quartzo, na posição da amostra.

O equipamento permite medir tanto a TL como a OSL. Possui capacidade para leitura de 48 amostras individuais, em vácuo ou em ambiente de $\mathrm{N}_{2}$. A FIG. 4.6 mostra o leitor RIS $\varnothing$ com o compartimento das amostras aberto.

As amostras podem ser aquecidas individualmente de forma linear para a leitura da TL, com taxa de aquecimento de 0,1 a $10 \mathrm{~K} \mathrm{~s}^{-1}$, desde a temperatura ambiente até $700{ }^{\circ} \mathrm{C}$.

O sistema RISØ é programável e controlado por computador. As instruções são fornecidas ao equipamento por meio do programa "Sequence Editor", cuja tela é mostrada na FIG.4.7. Por meio desse programa vários parâmetros de leitura são estabelecidos ou alterados. Um exemplo de ensaio de "repetibilidade" foi apresentado esquematicamente no ANEXO B. 


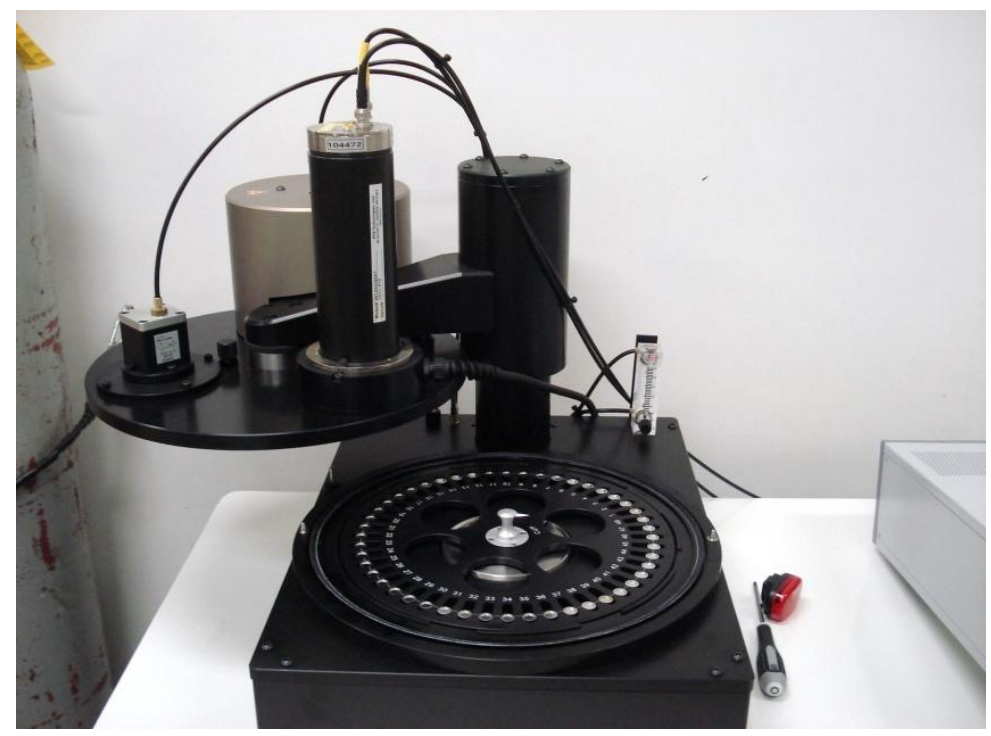

FIGURA 4.6 - Leitor RIS $\varnothing$ com o compartimento de amostras aberto.

As medidas da TL e da OSL são coletadas em arquivo do tipo “*.BIN”. O programa "Analist" permite abrir o arquivo com os dados das medidas, visualizar e analisar as curvas TL e OSL, e "exportar" os dados no formato ASCII (FIG.4.8).

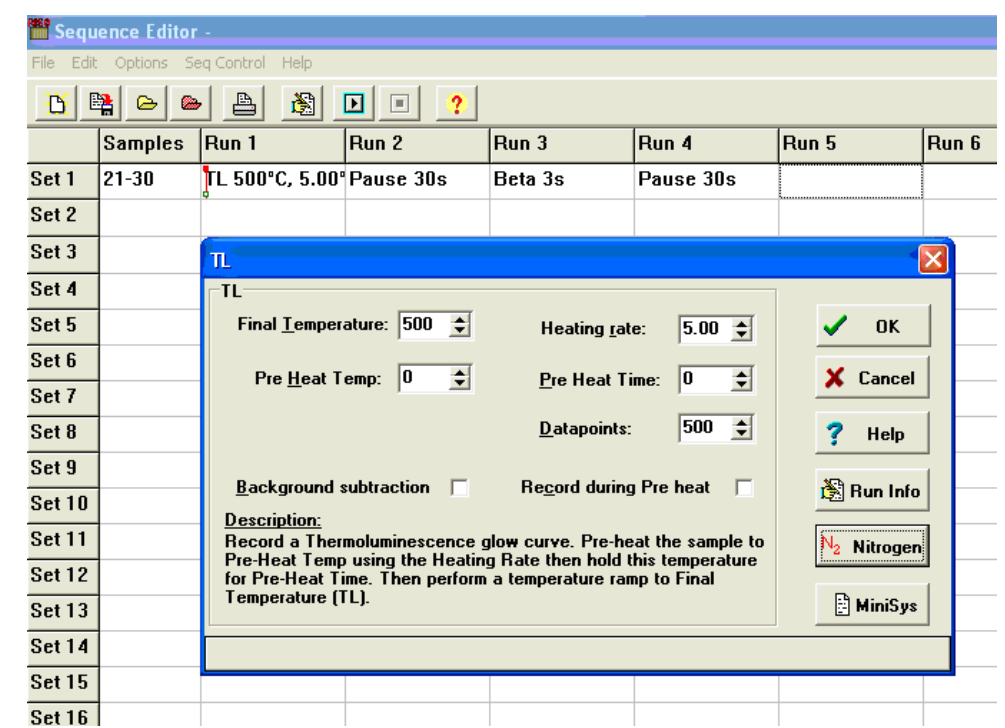

FIGURA 4.7 - Tela do programa "Sequence Editor" para fornecer instruções ao leitor RIS $\emptyset$. 


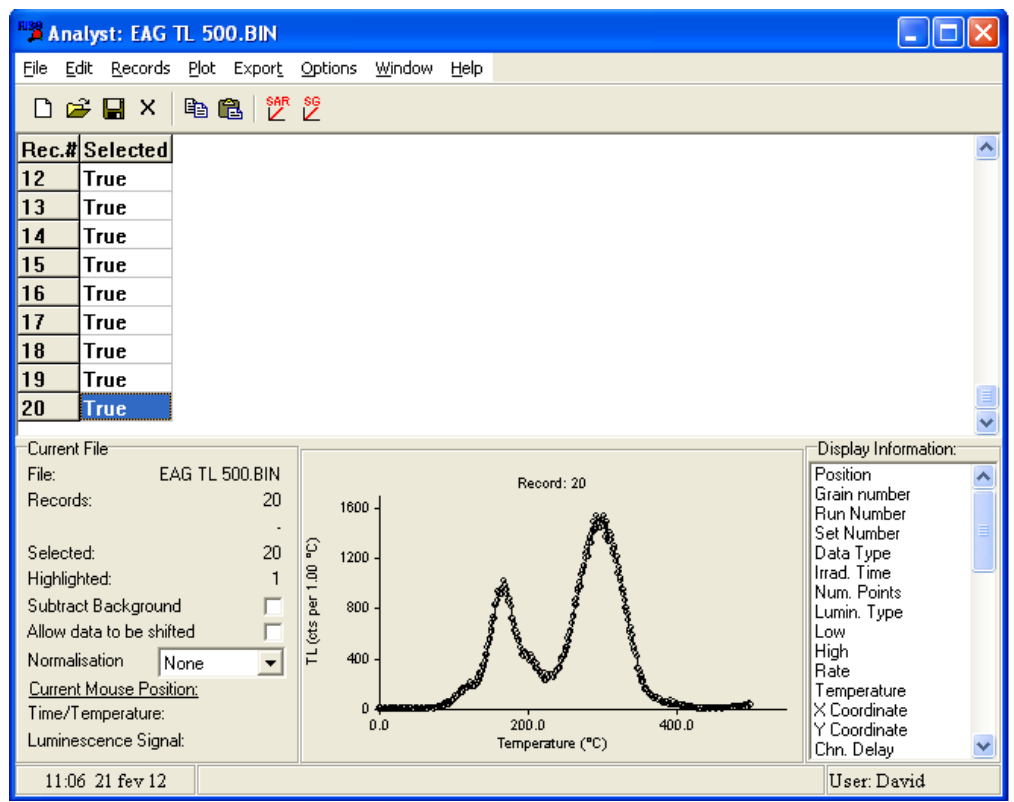

FIGURA 4.8 - Tela do programa "Analist" que permite visualizar e analisar as curvas da TL e da OSL.

Os perfis da resposta OSL dependem dos parâmetros estabelecidos para a leitura da amostra. Os principais parâmetros são fonte de radiação, tempo de irradiação da amostra, modo de iluminação, comprimento de onda da luz de estimulação, filtros ópticos, potência óptica da luz de estimulação (\%), duração da iluminação e o número de leituras durante a iluminação (número de pontos).

As amostras podem ser estimuladas opticamente para leitura OSL, por luz azul $(470 \mathrm{~nm})$ ou luz infravermelha $(830 \mathrm{~nm})$ em modo onda contínua e linearmente modulado. As medições da OSL foram feitas na modalidade de leitura CW-OSL, utilizando LEDs azuis como fonte de luz de iluminação e filtro Hoya U-340, conforme a ilustração da FIG. 4.9. 


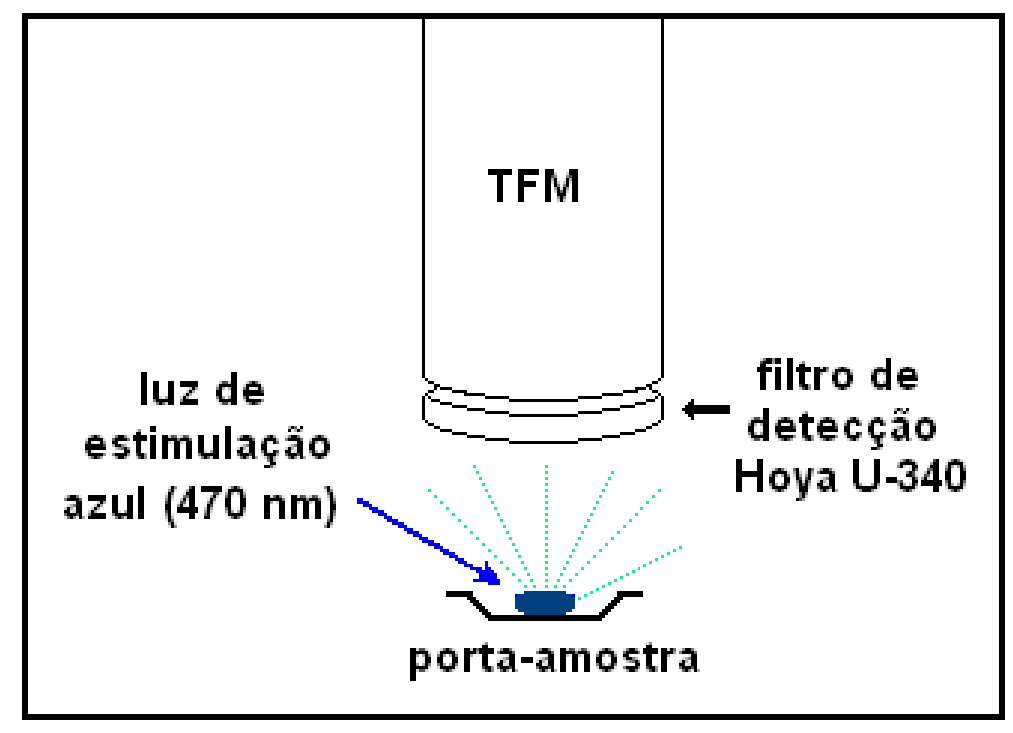

FIGURA 4.9 - Ilustração mostrando a luz de estimulação e o filtro de detecção utilizado para a leitura OSL (adaptado de Yukihara \& McKeever, 2008).

Os dados de leitura da TL e da OSL foram analisados por meio do programa Excel da Microsoft ${ }^{\circledR}$.

\subsection{Análises realizadas}

4.3.1 Análise por ativação neutrônica. A análise por ativação neutrônica foi solicitada ao setor de radioquímica do Centro de Reatores de Pesquisas (CRPq) - para a determinação de impurezas de amostras de alumina de diferentes origens. As impurezas podem resultar do processo de sua produção e podem estar em concentrações que podem interferir na termoluminescência. O óxido de alumínio produzido pelo processo "Bayer" geralmente contém $\mathrm{FeO}_{2}, \mathrm{NaO}_{2}$ e $\mathrm{SiO}_{2}$. Essas impurezas acompanham inclusive o óxido de alumínio considerado de alta pureza $(99,7 \%)$. Além desses óxidos, são encontrados $\mathrm{MgO}$ e $\mathrm{TiO}_{2}$ em alumina utilizada em cerâmica. Os teores de algumas impurezas foram fornecidos pelos fabricantes em certificados de análise que acompanham o produto.

4.3.2 Difração de raios $X$. A difração de raios $X$ foi utilizada como método de análise para determinar a estrutura cristalina da alumina e para verificar as transições de fase da alumina com a temperatura. $\mathrm{O}$ difratômetro de raios $\mathrm{X}$ utilizado foi da marca RIGAKU, modelo Multiflex pertencente ao Centro de Ciências e Tecnologia de Materiais 
(CCTM). Para a obtenção dos difratogramas foi operado com tubo de ânodo de cobre (radiação $\mathrm{Cu}-\mathrm{K} \alpha$ ), com tensão de $40 \mathrm{kV}$ e corrente de $20 \mathrm{~mA}$.

4.3.3 Fluorescência de raios $\mathbf{X}$. É um método de análise multielementar não-destrutivo por fluorescência de raios X por energia dispersiva. Permite a identificação rápida dos elementos presentes em baixas concentrações de $\mathrm{Na}(Z=11)$ a $U(Z=92)$ das amostras de cerâmica, cimento e de vidro. O princípio de funcionamento consiste em irradiar a amostra com raios $\mathrm{X}$. A amostra absorve os raios incidentes e emitem raios $\mathrm{X}$ característicos dos elementos que a compõem. A amostra permanece inalterada após a análise. Foi utilizada para a análise do vidro de cal e soda. O equipamento utilizado foi o espectrômetro de fluorescência de raios X por energia dispersiva, marca Shimadzu, modelo EDX-720, do Centro de Química do Meio Ambiente (CQMA).

4.3.4 Microscopia eletrônica de varredura. A microscopia eletrônica de varredura foi empregada para a visualização das partículas de alumina e das superfícies de fratura das pastilhas sinterizadas. O microscópio eletrônico de varredura (MEV) utilizado foi da marca Philips, modelo XL-30, do Laboratório de Caracterização de Materiais do CCTM. As pastilhas foram quebradas e os fragmentos das pastilhas foram fixados no porta-amostra com uma cola especial contendo prata metálica. As micrografias das superfícies de fratura das pastilhas foram obtidas com diferentes ampliações.

4.3.5 Análise termogravimétrica. A análise termogravimétrica foi empregada para verificar a perda de massa em função da temperatura das amostras de alumina impurificada com túlio. O equipamento utilizado foi da marca TA Instruments, modelo SDT Q600, do Laboratório de Análise Térmica (CTR). Esse equipamento fornece medidas simultâneas das alterações de massa (TGA) e do fluxo de calor diferencial (DSC) (TA INSTRUMENTS, 2010). Amostras com massa de $10 \mathrm{mg}$ contidas em cadinhos de platina foram submetidas ao aquecimento a uma taxa de $20{ }^{\circ} \mathrm{C} \min ^{-1}$, em atmosfera de ar sintético com fluxo de $100 \mathrm{~mL} \mathrm{~min}{ }^{-1}$, desde a temperatura ambiente até aproximadamente $1500{ }^{\circ} \mathrm{C}$. 


\section{RESULTADOS E DISCUSSÕES}

\subsection{Materiais obtidos}

Os diferentes tipos de amostras obtidas estão relacionados na TAB. 5.1, identificados pelas letras maiúsculas. A pastilha ALCP foi confeccionada sem a inserção de elementos químicos para os estudos preliminares das etapas do processo da coprecipitação. ALMN refere-se à pastilha de alumina impurificada com manganês pelo método da adsorção. ALTM é a pastilha de alumina impurificada com túlio, pelo método da coprecipitação. A pastilha ALBT com massa aproximada de $20 \mathrm{mg}$ foi obtida para verificar a reprodutibilidade do método da coprecipitação. EAG refere-se à pastilha de alumina eletrofundida sinterizada com vidro de cal e soda.

A massa, o diâmetro e a espessura das amostras selecionadas do lote foram determinados e os valores médios estão apresentados na TAB. 5.1. O número de pastilhas utilizado para a determinação da média é dado por n. A densidade aparente (d) foi calculada por meio da equação 3.28 a partir das medidas realizadas.

TABELA 5.1 - Valores médios da massa, diâmetro, espessura e da densidade das amostras de pastilhas obtidas

\begin{tabular}{cccccc}
\hline Pastilha & $\mathrm{n}$ & $\begin{array}{c}\text { Massa } \\
(\mathrm{mg})\end{array}$ & $\begin{array}{c}\text { Diâmetro } \\
(\mathrm{mm})\end{array}$ & $\begin{array}{c}\text { Espessura } \\
(\mathrm{mm})\end{array}$ & $\begin{array}{c}\text { Densidade } \\
\left(\mathrm{g} \mathrm{cm}^{-3}\right)\end{array}$ \\
\hline ALCP & 4 & $50,3 \pm 1,1$ & $4,29 \pm 0,05$ & $0,97 \pm 0,03$ & $3,59 \pm 0,05$ \\
ALMN & 10 & $25,0 \pm 1,0$ & $4,28 \pm 0,03$ & $0,96 \pm 0,02$ & --- \\
ALTM & 10 & $48,4 \pm 0,4$ & $4,27 \pm 0,02$ & $1,20 \pm 0,01$ & $2,81 \pm 0,04$ \\
ALBT & 10 & $19,8 \pm 0,3$ & $4,04 \pm 0,07$ & $0,67 \pm 0,02$ & $2,32 \pm 0,14$ \\
EAG & 10 & $51,4 \pm 0,4$ & $5,53 \pm 0,02$ & $1,04 \pm 0,02$ & $2,05 \pm 0,03$ \\
\hline
\end{tabular}

As pastilhas ALTM e EAG apresentaram sinais de TL verificados inicialmente com o leitor Harshaw 2000. Os sinais de TL e de OSL foram confirmados pelo leitor RIS $\emptyset$. As curvas da TL em função da temperatura e as respostas TL e OSL em função da dose foram determinadas. A reprodutibilidade do processo para a obtenção de pastilhas de alumina impurificada com túlio foi verificada pela confecção de pastilhas ALBT. As pastilhas EAG, ALTM e ALBT estão mostradas na FIG. 5.1. 


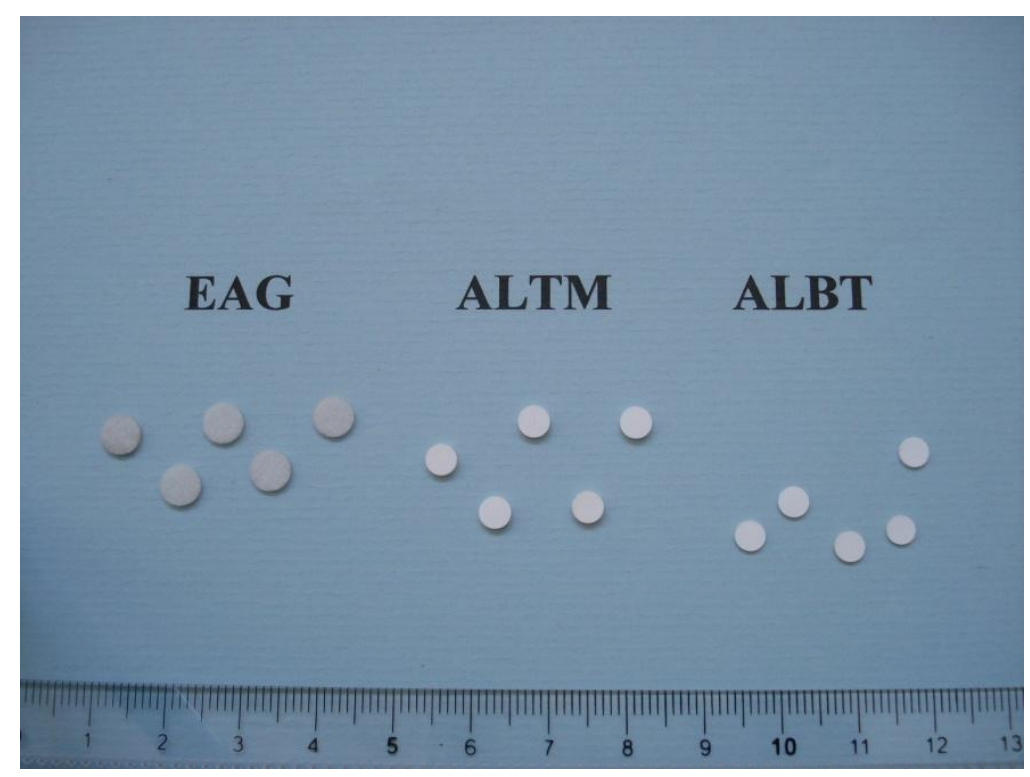

FIGURA 5.1 - Pastilhas EAG, ALTM e ALBT.

\subsection{Pastilha de alumina sem ativador}

A pastilha ALCP foi confeccionada para os estudos preliminares das etapas do processo da coprecipitação. O hidróxido de alumínio foi obtido por precipitação sem adição de íons para impurificação.

Os resultados da análise por ativação neutrônica (AAN) apresentados na TAB. 5.2 revelaram que a alumina obtida pela calcinação de hidróxido de alumínio precipitado possui concentrações menores de $\mathrm{Fe}, \mathrm{K}$ e de $\mathrm{Na}$ que a alumina obtida pela calcinação de hidróxido de alumínio comercial.

TABELA 5.2 - Concentração de Fe, K e de Na em alumina obtida por calcinação de hidróxido comercial e precipitado em laboratório

\begin{tabular}{cccc}
\hline Alumina & $\mathrm{Fe}(\% \mathrm{~mol})$ & $\mathrm{K}(\% \mathrm{~mol})$ & $\mathrm{Na}(\% \mathrm{~mol})$ \\
\hline Comercial & 0,035 & 0,350 & 3,253 \\
Precipitada & 0,025 & 0,010 & 0,047 \\
\hline
\end{tabular}

O hidróxido de alumínio precipitado foi submetido à destilação azeotrópica com butanol, moído em atritor de alta energia e calcinado em temperatura de 400, 600, 800, 1000 e $1200{ }^{\circ} \mathrm{C}$. Os difratogramas de raios X mostrados na FIG. 5.2 revelaram que as amostras calcinadas até $800{ }^{\circ} \mathrm{C}$ estão na forma gama. A amostra aquecida a $1000{ }^{\circ} \mathrm{C}$ 
apresenta-se na forma theta. A amostra calcinada na temperatura de $1200{ }^{\circ} \mathrm{C}$ é constituída principalmente da forma estável $\alpha-\mathrm{Al}_{2} \mathrm{O}_{3}$.

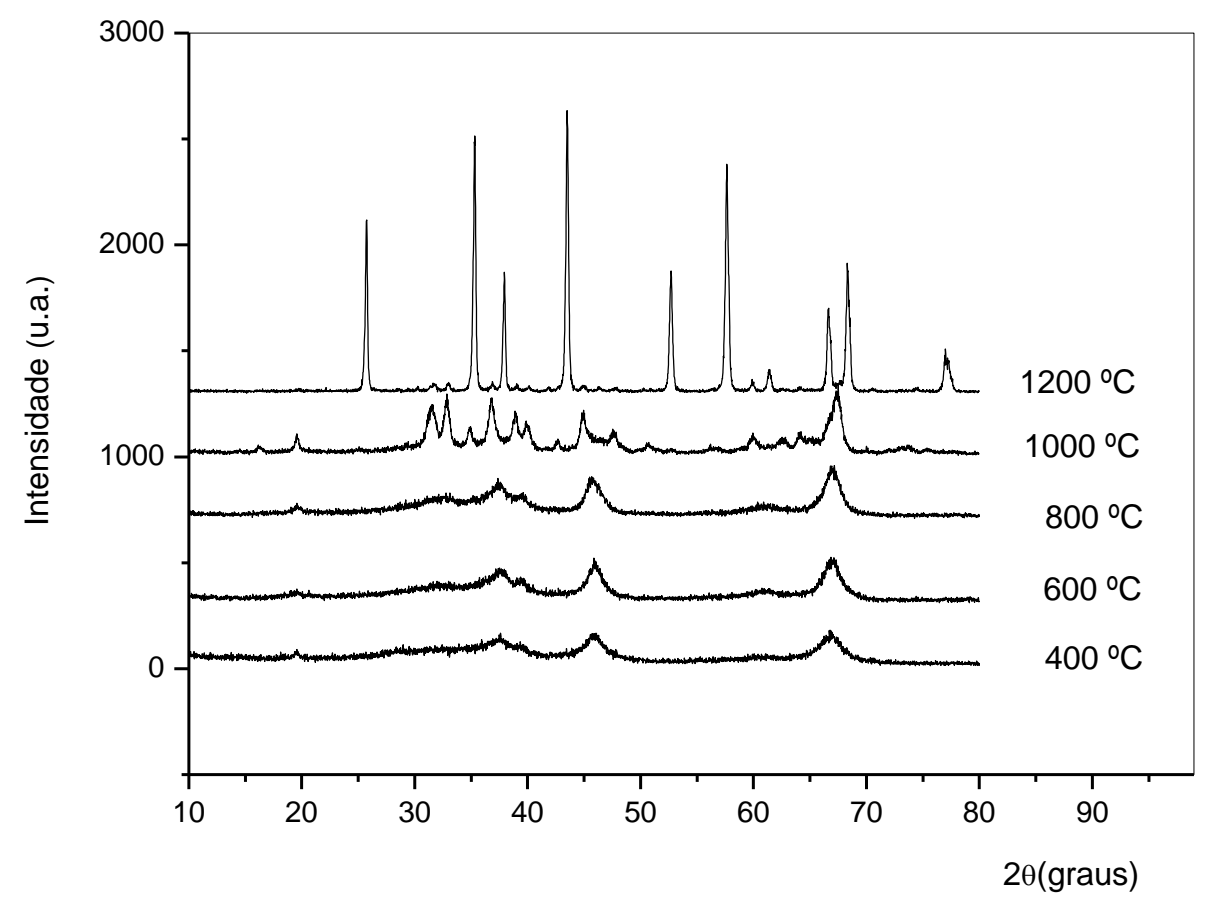

FIGURA 5.2 - Difratogramas de raios X das amostras da alumina calcinada em diferentes temperaturas.

A pastilha ALCP foi obtida pela sinterização do óxido de alumínio calcinado a $1200^{\circ} \mathrm{C}$. A sinterização foi realizada a $1530^{\circ} \mathrm{C}$ durante uma hora.

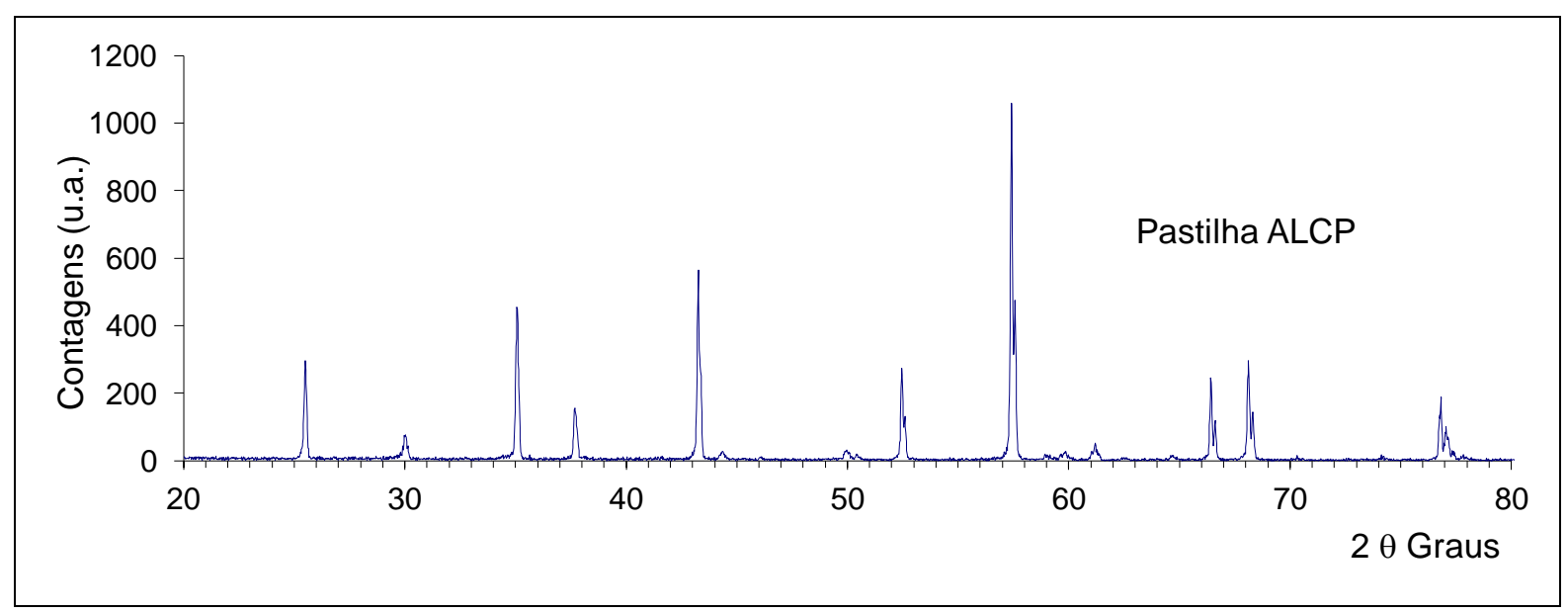

FIGURA 5.3 - Difratograma de raios X da pastilha ALCP. 
A FIG. 5.3 apresenta o difratograma de raios X da pastilha ALCP. Os picos característicos de $\alpha-\mathrm{Al}_{2} \mathrm{O}_{3}$ coincidem com aqueles da alumina calcinada a $1200{ }^{\circ} \mathrm{C}$, evidenciados na FIG. 5.2.

A micrografia de superfície de fratura da pastilha ALCP pode ser vista na FIG. 5.4. A pastilha apresentou boa densificação. Conforme mostrada na TAB. 5.1, a densidade aparente calculada foi de $\mathrm{d}=(3,59 \pm 0,05) \mathrm{g} \mathrm{cm}^{-3}$, isto é, $90,2 \%$ da densidade do coríndon.

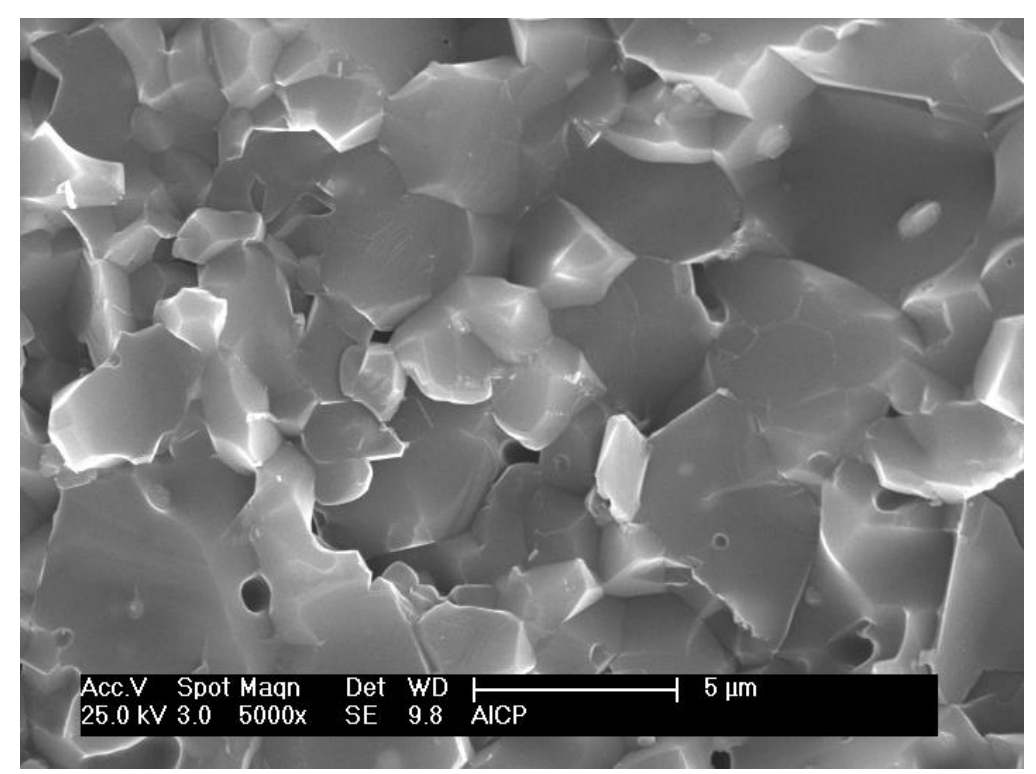

FIGURA 5.4 - Micrografia da superfície de fratura da pastilha ALCP.

No entanto, a pastilha ALCP mostrou-se contaminada apresentando uma coloração esverdeada, provavelmente durante seu processamento. As medidas detalhadas da TL e da OSL não foram realizadas.

\subsection{Pastilha de alumina impurificada por adsorção}

A pastilha ALMN foi obtida acrescentando o hidróxido de alumínio comercial à solução de $\mathrm{Mn}^{2+}$, pelo método da adsorção. As micrografias das FIG. 5.5, 5.6 e 5.7 obtidas por microscopia eletrônica de varredura mostram as partículas de hidróxido de alumínio.

As partículas com dimensões maiores que $20 \mu \mathrm{m}$ da FIG. 5.6 são constituídas por aglomerados de partículas ainda menores que $1 \mu \mathrm{m}$ (FIG. 5.7). Os aglomerados se formam por causa das hidroxilas e das moléculas de água incorporadas. São prejudiciais às operações de compactação e consequentemente à densificação das pastilhas. 
A suspensão do hidróxido do alumínio em álcool e a destilação azeotrópica do butanol foram incluídas no processo para produzir alumina com teor reduzido de água e de aglomerados. As técnicas para reduzir o teor de água e de aglomerados foram apontadas por Ussui et al. (1996) para o processamento de pós cerâmicos à base de zircônio.

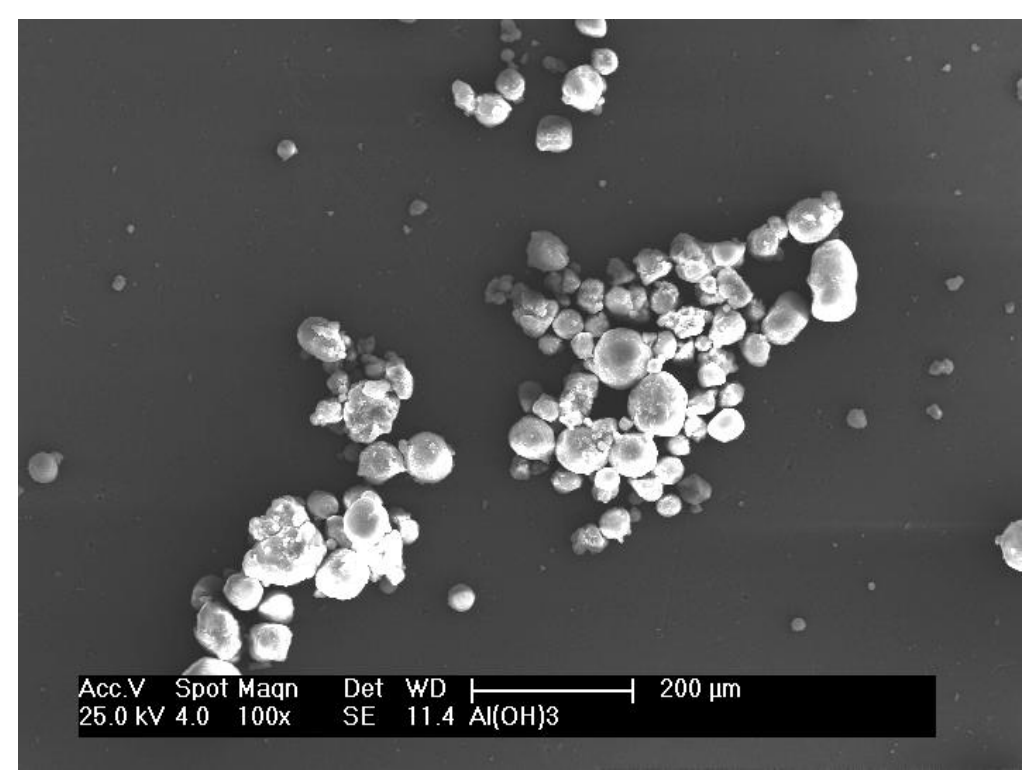

FIGURA 5.5 - Micrografia do hidróxido de alumínio impurificado com $\mathrm{Mn}^{2+}$, com ampliação de 100x.

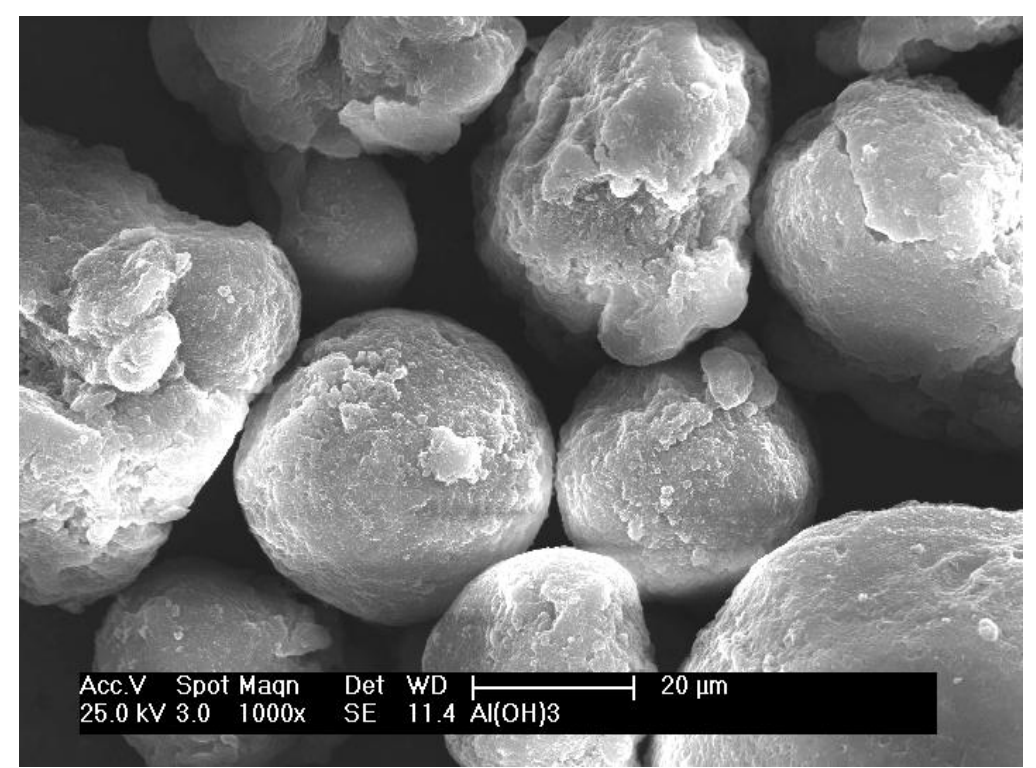

FIGURA 5.6 - Micrografia do hidróxido de alumínio impurificado com $\mathrm{Mn}^{2+}$, com ampliação de 1000x. 
A pastilha ALMN quando sinterizada apresentou uma densificação baixa. A micrografia da superfície de fratura da pastilha ALMN mostrada na FIG. 5.8 revela sua porosidade e baixa densificação.

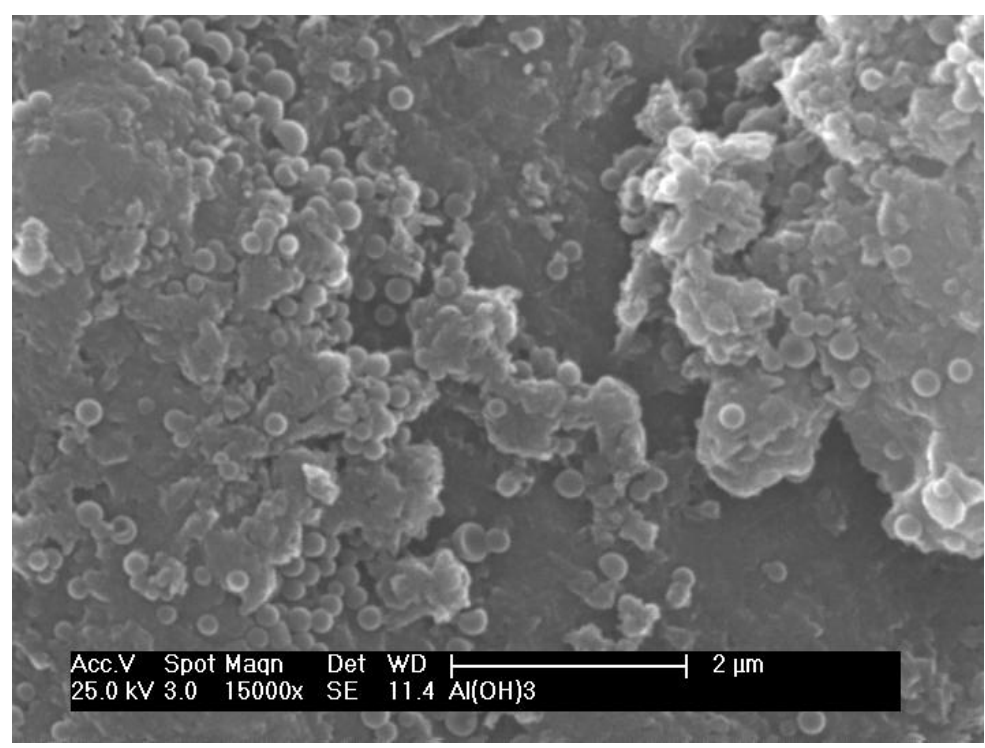

FIGURA 5.7 - Micrografia do hidróxido de alumínio impurificado com $\mathrm{Mn}^{2+}$, com ampliação de 15000x.

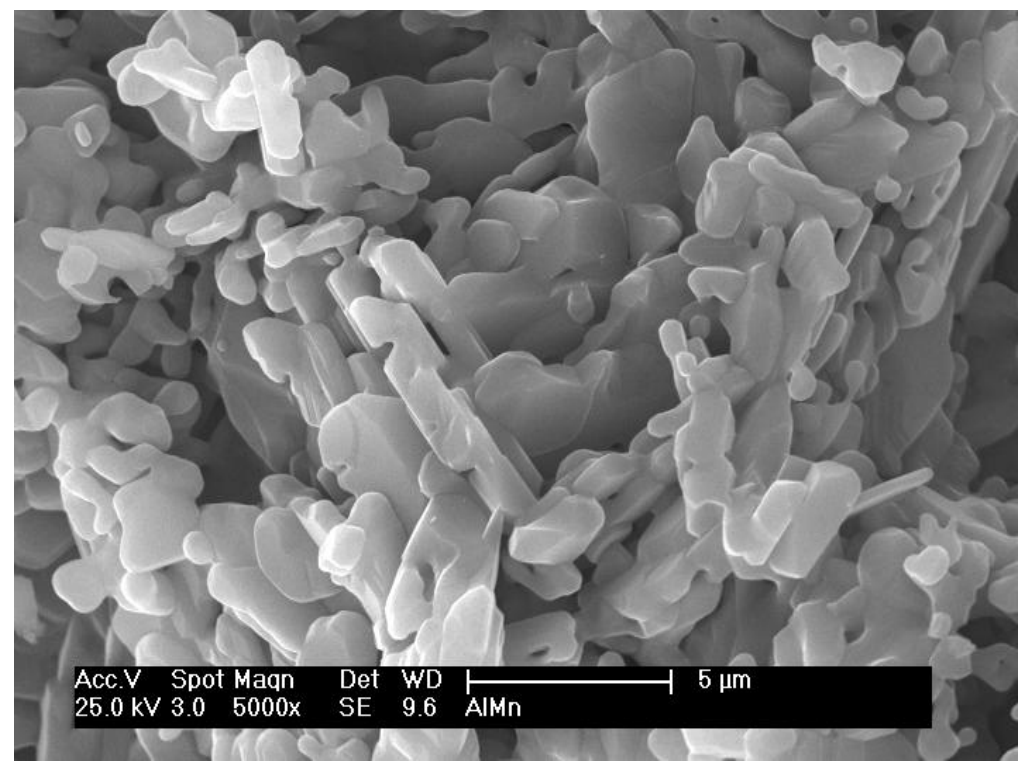

FIGURA 5.8 - Micrografia da superfície de fratura da pastilha ALMN. 
Na FIG. 5.9 são apresentados comparativamente os difratogramas de raios $\mathrm{X}$ do hidróxido de alumínio impurificado com $\mathrm{Mn}^{2+}$ e da pastilha ALMN.

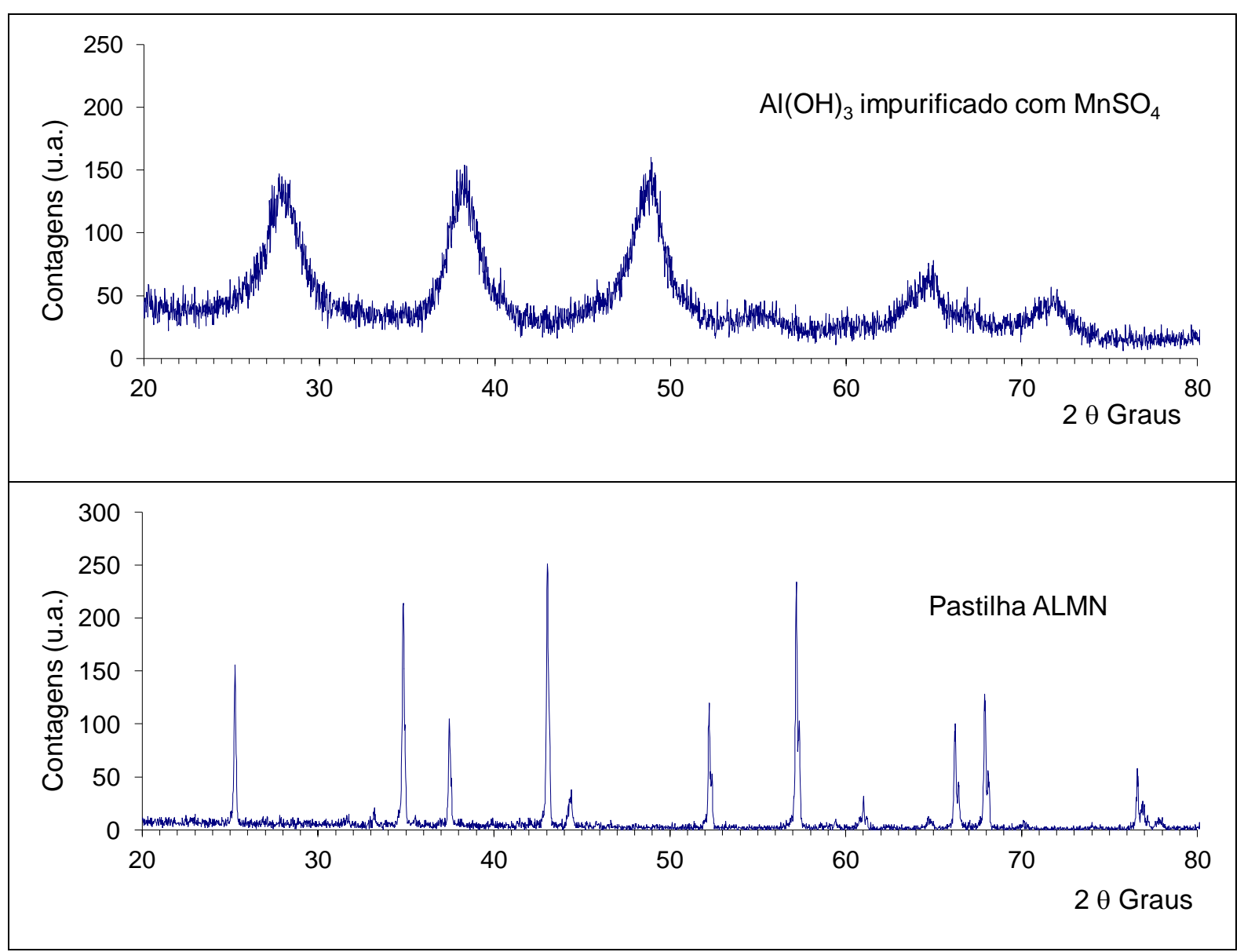

FIGURA 5.9 - Difratogramas de raios X do hidróxido de alumínio impurificado com $\mathrm{MnSO}_{4}$ e da pastilha ALMN.

$\mathrm{O}$ difratograma do hidróxido de alumínio impurificado com $\mathrm{MnSO}_{4}$ é semelhante ao hidróxido de alumínio sintético ou da pseudo-boemita com certa desordem na estrutura cristalina referida por Santos et al (2009).

As pastilhas ALMN sinterizadas apresentaram picos de difração característicos do $\alpha-\mathrm{Al}_{2} \mathrm{O}_{3}$. No entanto, foi verificado que a placa de alumina utilizada na sinterização apresentou manchas, provavelmente em decorrência da perda de dopante. As leituras da TL das pastilhas ALMN não apresentaram sinais significativos e as análises posteriores foram interrompidas. 
Alumina impurificada com $\mathrm{Cu}^{2+}$ foi obtida pelo método da adsorção, de modo similar à técnica utilizada para a impurificação com $\mathrm{Mn}^{2+}$. As pastilhas de alumina impurificada por $\mathrm{Cu}^{2+}$ também não apresentaram sinais significativos de TL e as análises posteriores foram interrompidas.

\subsection{Pastilha de alumina impurificada por coprecipitação}

A pastilha ALTM foi obtida com a alumina impurificada com túlio pelo método da coprecipitação. A sinterização foi realizada em temperatura de $1530^{\circ} \mathrm{C}$, durante uma hora.

As curvas da TL de uma pastilha submetida a doses de 100, 200, 300, 500 e $800 \mathrm{mGy}$, irradiada com a fonte beta ${ }^{90} \mathrm{Sr} /{ }^{90} \mathrm{Y}$ e determinadas com o leitor RIS $\varnothing$ estão apresentadas na FIG 5.10.

O pico dosimétrico está localizado ao redor de $208{ }^{\circ} \mathrm{C}$, utilizando taxa de aquecimento de $5{ }^{\circ} \mathrm{C} \mathrm{s}^{-1}$. Um valor muito próximo foi relatado por Barros e colab. (2010) para a alumina dopada com túlio, obtida pelo método da combustão e medida com leitor Harshaw modelo 3500.

O teste da repetibilidade das leituras TL foi realizado irradiando uma pastilha ALTM com dose de 1 Gy e fazendo a leitura da TL integrada até $400{ }^{\circ} \mathrm{C}$. A irradiação e a leitura foram repetidas por 5 vezes. A média das leituras foi $\mathrm{TL}=(14710 \pm 209) \mathrm{cps}$, o que corresponde a um desvio relativo de $1,42 \%$.

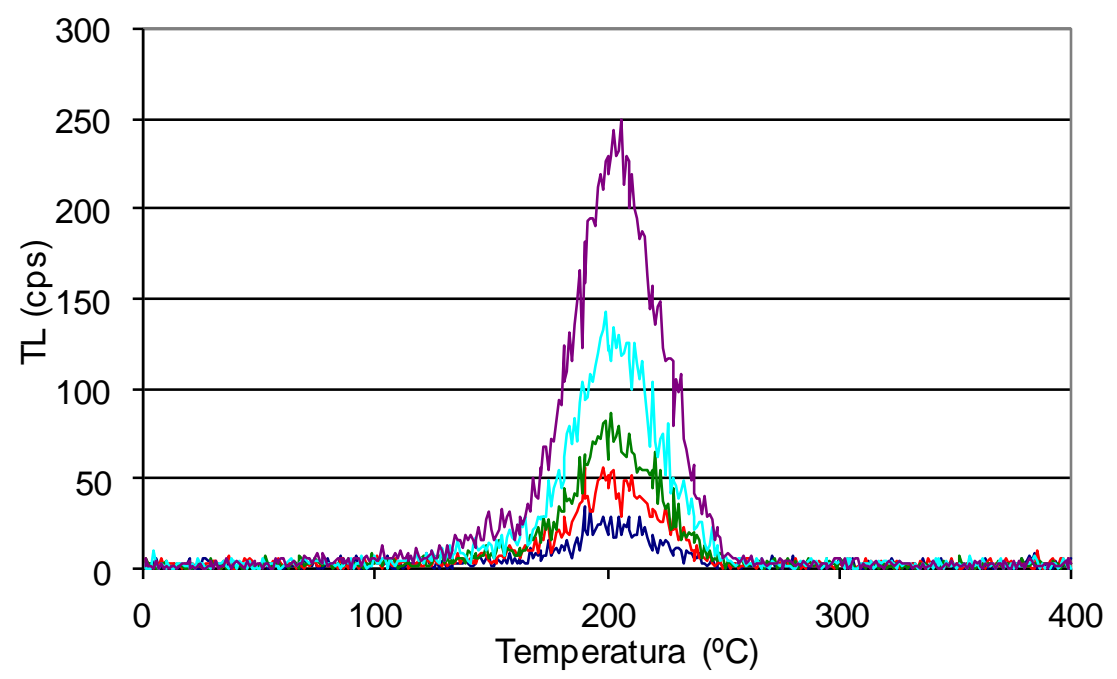

FIGURA 5.10 - Curvas da TL da pastilha ALTM irradiada com fonte beta de ${ }^{90} \mathrm{Sr} /{ }^{90} \mathrm{Y}$ com doses de 100, 200, 300, 500 e 800 mGy. 
Os valores da resposta TL em contagens por segundo (cps) em função da dose em mGy etão na TAB. 5.3. A TL da pastilha ALTM sem irradiação determinada com o leitor RIS $\varnothing$ foi $\mathrm{TL}_{0}=(571 \pm 24) \mathrm{cps}$. Os valores da TL da TAB. 5.3 foram subtraídos de $\mathrm{TL}_{0}$.

TABELA 5.3 - Resposta TL em função da dose da pastilha ALTM

\begin{tabular}{cc}
\hline $\begin{array}{c}\text { Dose } \\
(\mathrm{mGy})\end{array}$ & $\begin{array}{c}\text { TL } \\
(\mathrm{cps})\end{array}$ \\
\hline 0 & 0 \\
100 & 1182 \\
200 & 2410 \\
300 & 3602 \\
500 & 6275 \\
800 & 11299 \\
1000 & 14139 \\
2000 & 43410 \\
3000 & 114570 \\
6000 & 2659282 \\
12000 & --- \\
\hline
\end{tabular}

O gráfico correspondente da TL em função da dose é mostrado na FIG. 5.11. A região linear alcança aproximadamente até 1000 mGy. A linha de tendência definida pelos pontos até a dose de $800 \mathrm{mGy}$, apresenta um coeficiente angular $\mathrm{y} / \mathrm{x}=13,545 \mathrm{cps} \mathrm{mGy}^{-1}$.

Acima de 1000 mGy, a resposta TL foge da linearidade. Ao redor de $12000 \mathrm{mGy}$ atinge o limite de detecção da fotomultiplicadora do leitor RIS $\varnothing$.

A FIG. 5.12 apresenta as curvas da OSL da pastilha ALTM irradiada com fonte beta durante 10 e $20 \mathrm{~s}$. A estimulação foi feita com LEDs azuis com $10 \%$ de potência. Observa-se na figura que o primeiro ponto da OSL da curva superior é aproximadamente o dobro do primeiro ponto da curva inferior, indicando a possível proporcionalidade da OSL em função da dose conforme previsto pelos conceitos teóricos (Yukihara \& McKeever, 2008). 


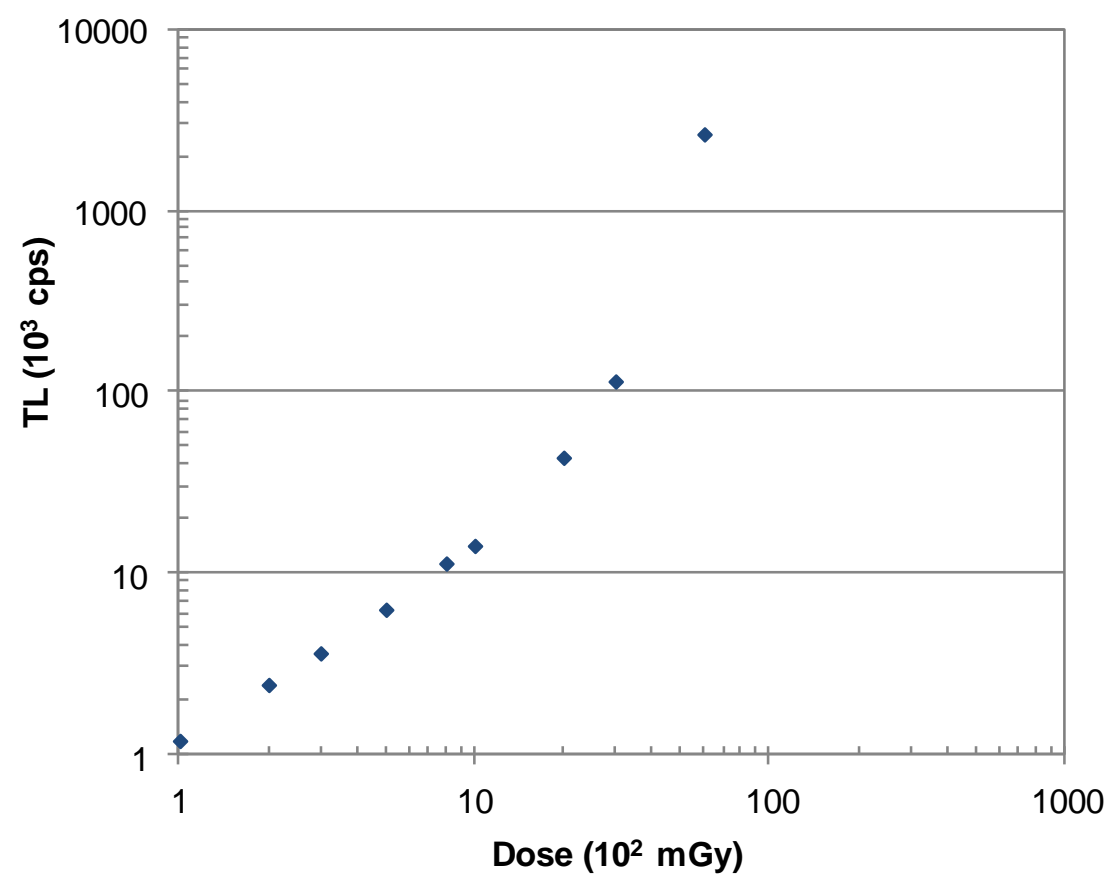

FIGURA 5.11 - Resposta TL em função da dose da pastilha ALTM.

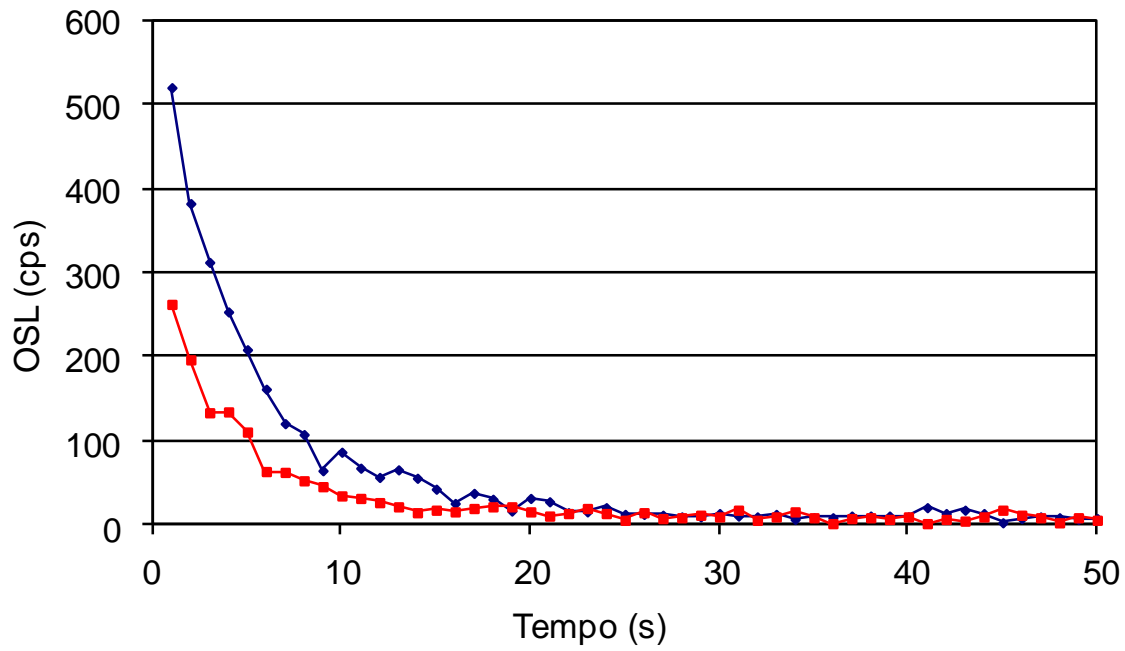

FIGURA 5.12 - Curvas da OSL da pastilha ALTM.

\subsection{Reprodutibilidade e padronização do processo}

É desejável que as pastilhas de um mesmo lote tenham características idênticas. A finalidade da padronização do processo é a obtenção de pastilhas uniformes que 
apresentem propriedades TL e OSL definidas e constantes. Muitas variáveis do processo podem influenciar as características individuais das pastilhas.

As amostras ALBT foram obtidas para verificar a reprodutibilidade do processo via método da coprecipitação e a homogeneidade do lote das pastilhas, com massa menor que as amostras ALTM.

A alumina impurificada com túlio foi obtida pelo procedimento descrito em 4.2.2. O hidróxido de alumínio foi calcinado a $600{ }^{\circ} \mathrm{C}$ durante uma hora. Após a calcinação, a alumina foi submetida à trituração com esferas de alumina e com etanol absoluto durante 15 horas. As pastilhas ALBT foram produzidas a partir de $25 \mathrm{mg}$ de pó, compactadas em molde de $6 \mathrm{~mm}$ de diâmetro com prensa manual do CCTM, aplicando uma carga de compactação ao redor de 1 tonelada. A sinterização foi realizada no forno Lidberg Blue à temperatura de $1500{ }^{\circ} \mathrm{C}$ durante uma hora.

As grandezas físicas medidas e as respostas TL e OSL de pastilhas ALTM e ALBT são mostradas respectivamente nas TAB. 5.4 e 5.5. As amostras foram selecionadas considerando a massa e os aspectos físicos.

TABELA 5.4 - Grandezas físicas medidas e as respostas TL e OSL das pastilhas ALTM selecionadas

\begin{tabular}{cccccccc}
\hline $\begin{array}{c}\text { Amostra } \\
(\text { ALTM })\end{array}$ & $\begin{array}{c}\text { massa } \\
(\mathrm{mg})\end{array}$ & $\begin{array}{c}\text { espessura } \\
(\mathrm{mm})\end{array}$ & $\begin{array}{c}\text { diâmetro } \\
(\mathrm{mm})\end{array}$ & $\begin{array}{c}\text { volume } \\
\left(\mathrm{mm}^{3}\right)\end{array}$ & $\begin{array}{c}\text { densidade } \\
\left(\mathrm{g} \mathrm{cm}^{-3}\right)\end{array}$ & $\begin{array}{c}\text { TL } \\
\left(10^{5} \mathrm{cps}\right)\end{array}$ & $\begin{array}{c}\text { OSL } \\
\left(10^{5} \mathrm{cps}\right)\end{array}$ \\
\hline 1 & 48,0 & 1,20 & 4,24 & 16,94 & 2,83 & 13,91 & 35,43 \\
2 & 47,8 & 1,20 & 4,27 & 17,18 & 2,78 & 3,89 & 4,39 \\
3 & 48,1 & 1,19 & 4,28 & 17,12 & 2,81 & 9,15 & 26,62 \\
4 & 48,3 & 1,20 & 4,32 & 17,59 & 2,75 & 4,89 & 6,56 \\
5 & 48,8 & 1,22 & 4,27 & 17,47 & 2,79 & 5,05 & 6,60 \\
6 & 48,9 & 1,20 & 4,26 & 17,10 & 2,86 & 5,13 & 5,68 \\
7 & 48,3 & 1,20 & 4,28 & 17,26 & 2,80 & 4,30 & 5,43 \\
8 & 48,8 & 1,22 & 4,28 & 17,55 & 2,78 & 3,60 & 5,07 \\
9 & 48,5 & 1,20 & 4,25 & 17,02 & 2,85 & 4,85 & 5,66 \\
10 & 48,6 & 1,20 & 4,24 & 16,94 & 2,87 & 3,88 & 6,14 \\
\hline Média & 48,4 & 1,20 & 4,27 & 17,22 & 2,81 & 5,86 & 10,76 \\
\hline s & $\pm 0,4$ & $\pm 0,01$ & $\pm 0,02$ & $\pm 0,24$ & $\pm 0,04$ & $\pm 3,24$ & $\pm 10,90$ \\
\hline DPR $(\%)$ & 0,83 & 0,83 & 0,47 & 1,39 & 1,42 & 55 & 101 \\
\hline
\end{tabular}

Apesar de possuírem massas semelhantes, os valores dos desvios padrão relativos (DPR) das leituras de TL e de OSL são elevados, mostrando uma dispersão das medidas. A 
densidade das pastilhas também apresenta uma variação significativa, provavelmente relacionada ao modo artesanal de produção.

TABELA 5.5 - Grandezas físicas medidas e as respostas TL e OSL das pastilhas ALBT selecionadas

\begin{tabular}{cccccccc}
\hline $\begin{array}{c}\text { Amostra } \\
(\text { ALBT })\end{array}$ & $\begin{array}{c}\text { massa } \\
(\mathrm{mg})\end{array}$ & $\begin{array}{c}\text { espessura } \\
(\mathrm{mm})\end{array}$ & $\begin{array}{c}\text { diâmetro } \\
(\mathrm{mm})\end{array}$ & $\begin{array}{c}\text { volume } \\
\left(\mathrm{mm}^{3}\right)\end{array}$ & $\begin{array}{c}\text { densidade } \\
\left(\mathrm{g} \mathrm{cm}^{-3}\right)\end{array}$ & $\begin{array}{c}\text { TL } \\
\left(10^{3} \mathrm{cps}\right)\end{array}$ & $\begin{array}{c}\text { OSL } \\
\left(10^{3} \mathrm{cps}\right)\end{array}$ \\
\hline 1 & 19,8 & 0,66 & 4,04 & 8,46 & 2,34 & 9,84 & 24,42 \\
2 & 19,9 & 0,68 & 4,04 & 8,72 & 2,28 & 8,72 & 23,25 \\
3 & 19,8 & 0,68 & 4,08 & 8,89 & 2,23 & 12,36 & 49,49 \\
4 & 20,3 & 0,65 & 3,87 & 7,65 & 2,66 & 18,44 & 102,60 \\
5 & 19,5 & 0,66 & 4,04 & 8,46 & 2,30 & 7,53 & 21,46 \\
6 & 19,4 & 0,68 & 4,05 & 8,76 & 2,21 & 15,19 & 66,00 \\
7 & 20,3 & 0,63 & 4,10 & 8,32 & 2,44 & 21,24 & 103,93 \\
8 & 19,8 & 0,70 & 4,07 & 9,11 & 2,17 & 6,05 & 16,72 \\
9 & 19,5 & 0,69 & 3,97 & 8,54 & 2,28 & 8,69 & 27,07 \\
10 & 19,7 & 0,66 & 4,10 & 8,71 & 2,26 & 12,10 & 54,92 \\
\hline Média & 19,8 & 0,67 & 4,04 & 8,56 & 2,32 & 12,02 & 48,99 \\
\hline s & 0,3 & 0,02 & 0,07 & 0,40 & 0,14 & 4,93 & 32,94 \\
\hline DPR $(\%)$ & 1,52 & 2,99 & 1,73 & 4,67 & 6,03 & 41 & 67 \\
\hline
\end{tabular}

As respostas TL e OSL das pastilhas ALTM e ALBT não guardam uma relação de proporcionalidade simples com a massa, indicando que a sensibilidade $(\mathrm{S})$ das pastilhas é dependente de outros fatores além da massa e da dose como indicada pela equação 3.32. Não há uma correlação simples entre as grandezas físicas medidas e as respostas TL e OSL.

À parte da dispersão das leituras TL e OSL entre as pastilhas, verificam-se:

a) O pico dosimétrico está localizado ao redor de $208{ }^{\circ} \mathrm{C}$ para ambas as pastilhas ALTM e ALBT, com taxa de aquecimento de $5{ }^{\circ} \mathrm{C} \mathrm{s}^{-1}$.

b) As leituras de uma mesma pastilha apresentaram boa repetibilidade. Três leituras OSL consecutivas da pastilha ALBT apresentaram DPR $=0,63 \%$, quando mantidas as mesmas condições de tratamento térmico, irradiação e de leitura.

c) A resposta em função da dose beta apresentaram uma ampla faixa linear tanto para a TL como para a OSL (FIG 5.13 e 5.15).

A resposta TL da pastilha ALBT mostrada na FIG. 5.13 é praticamente linear de 100 mGy a 30000 mGy. 


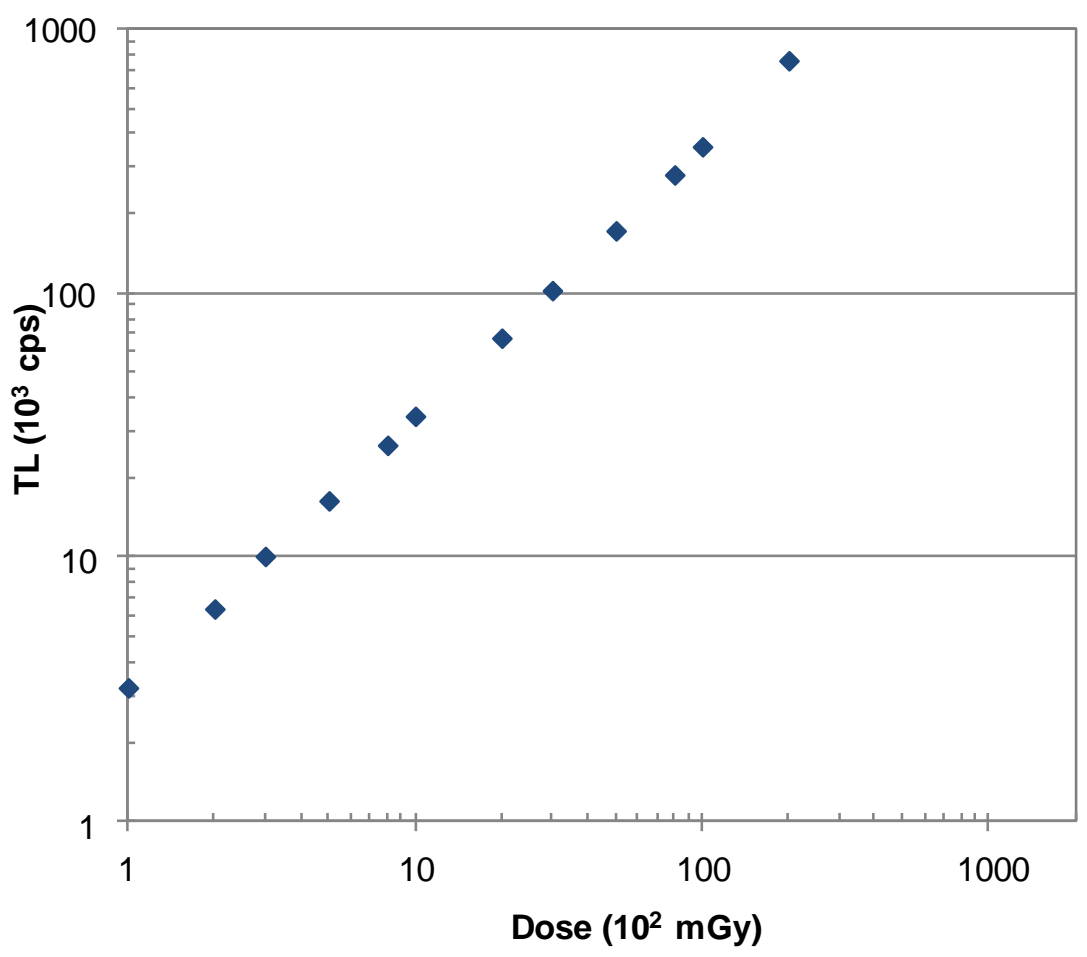

FIGURA 5.13 - Resposta TL da pastilha ALBT em função da dose beta

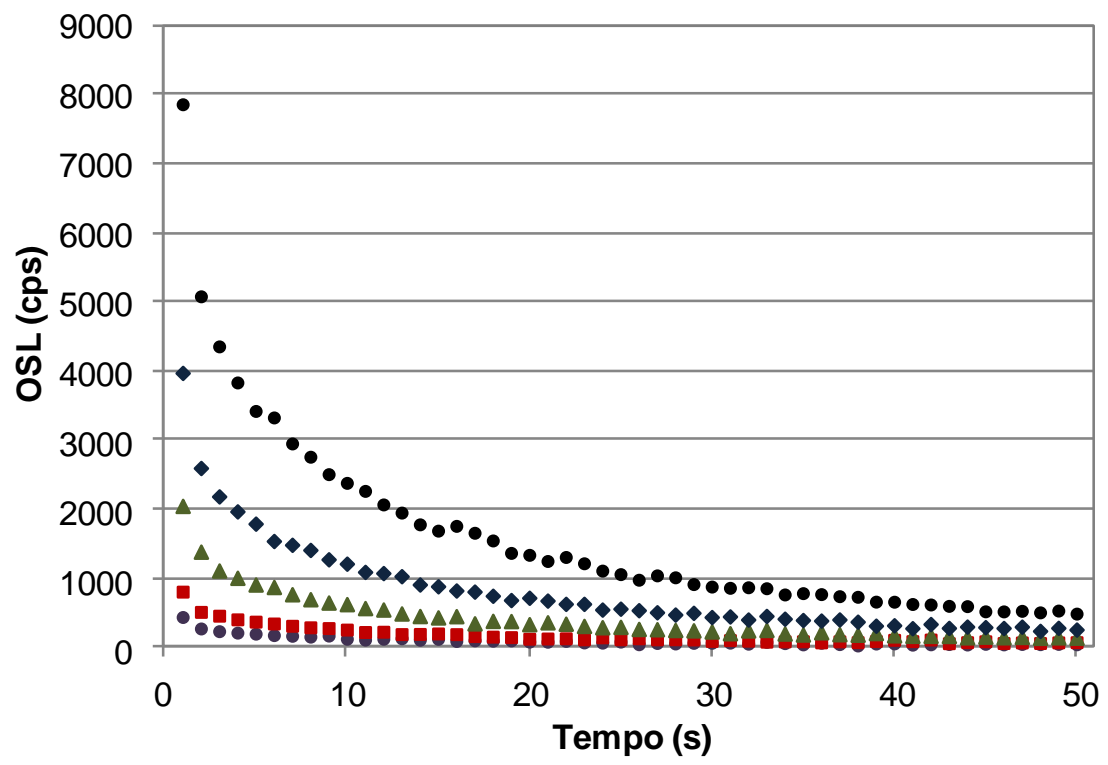

FIGURA 5.14 - Curvas OSL da pastilha ALBT irradiada com fonte beta. 
As curvas OSL da pastilha ALBT irradiada com fonte beta estão apresentadas na FIG 5.14. A linearidade da resposta OSL em função da dose foi verificada até 20 segundos de irradiação beta que corresponde à dose aproximada de 2000 mGy (FIG. 5.15).

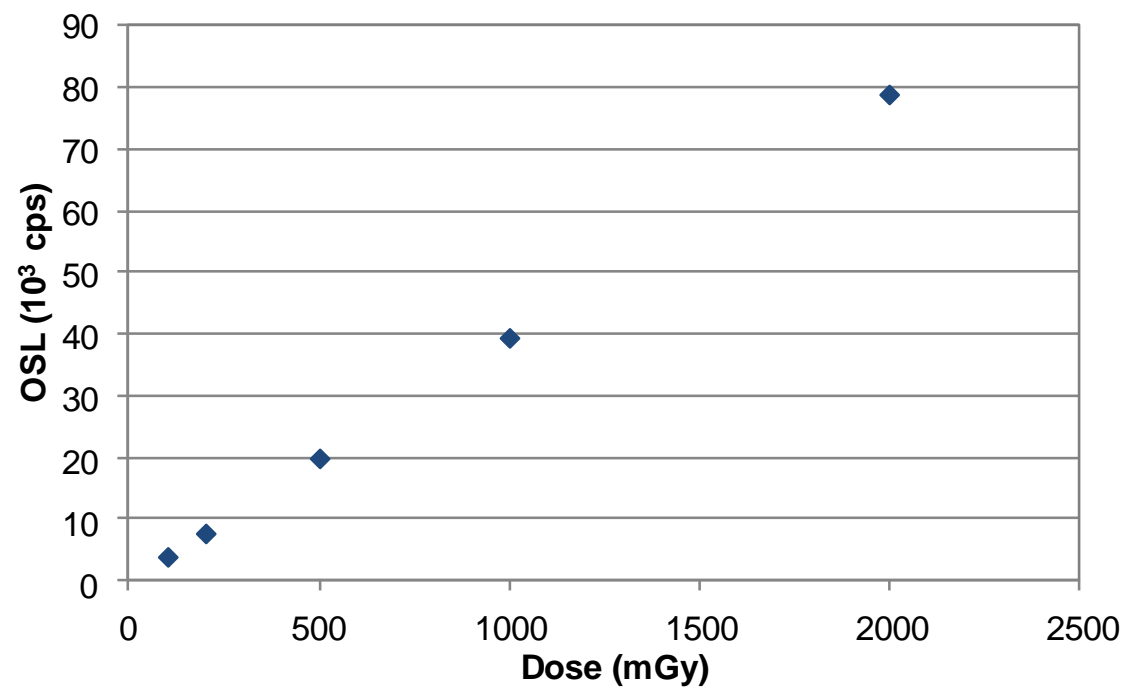

FIGURA 5.15 - Resposta OSL da pastilha ALBT em função da dose beta.

As grandezas medidas e calculadas antes e depois do processo de sinterização estão apresentadas na TAB. 5.6.

TABELA 5.6 - Grandezas medidas e calculadas antes e depois do processo de sinterização das pastilhas ALBT

\begin{tabular}{lcccc}
\hline \multicolumn{1}{c}{ Grandeza } & antes & depois & diferença & diferença $(\%)$ \\
\hline massa $(\mathrm{mg})$ & $25,3 \pm 0,6$ & $19,6 \pm 0,4$ & $5,7 \pm 0,7$ & 22,5 \\
diâmetro $(\mathrm{mm})$ & $5,95 \pm 0,01$ & $4,12 \pm 0,13$ & $1,83 \pm 0,13$ & 30,8 \\
espessura $(\mathrm{mm})$ & $1,28 \pm 0,19$ & $0,64 \pm 0,07$ & $0,64 \pm 0,20$ & 50,0 \\
volume $\left(\mathrm{mm}^{3}\right)$ & $35,6 \pm 5,2$ & $8,6 \pm 0,3$ & $27,0 \pm 5,2$ & 75,8 \\
densidade $\left(\mathrm{g} \mathrm{cm}^{-3}\right)$ & $0,72 \pm 0,09$ & $2,30 \pm 0,14$ & $1,58 \pm 0,17$ & 219 \\
\hline
\end{tabular}

A densificação é um parâmetro que pode indicar o grau de sinterização da alumina. As amostras ALTM e ALBT mostram valores baixos de densidade após a sinterização em relação ao coríndon, indicando uma estrutura porosa.

A diferença de massa entre a pastilha compactada verde e a sinterizada foi de $22,5 \%$, indicando elevado teor de água e de materiais voláteis. A retração linear calculada a partir do diâmetro e da espessura foram respectivamente $\mathrm{RL}_{\mathrm{D}}=30,8 \%$ e $\mathrm{RL}_{\mathrm{e}}=50,0 \%$. A 
densidade aparente calculada aumentou $219 \%$, porém a densificação não foi suficiente para atingir a densidade do coríndon.

Os resultados da análise termogravimétrica (TGA) e da calorimetria diferencial do fluxo de calor (DSC) de três amostras obtidas pelo processo da coprecipitação estão mostrados na FIG. 5.16. As amostras na forma de pó foram identificadas por ALTM, ETO, BTO. Esses resultados foram obtidos por meio do equipamento marca TA instruments, modelo SDT Q600 do CTA descrito na subsecção 4.3.5.

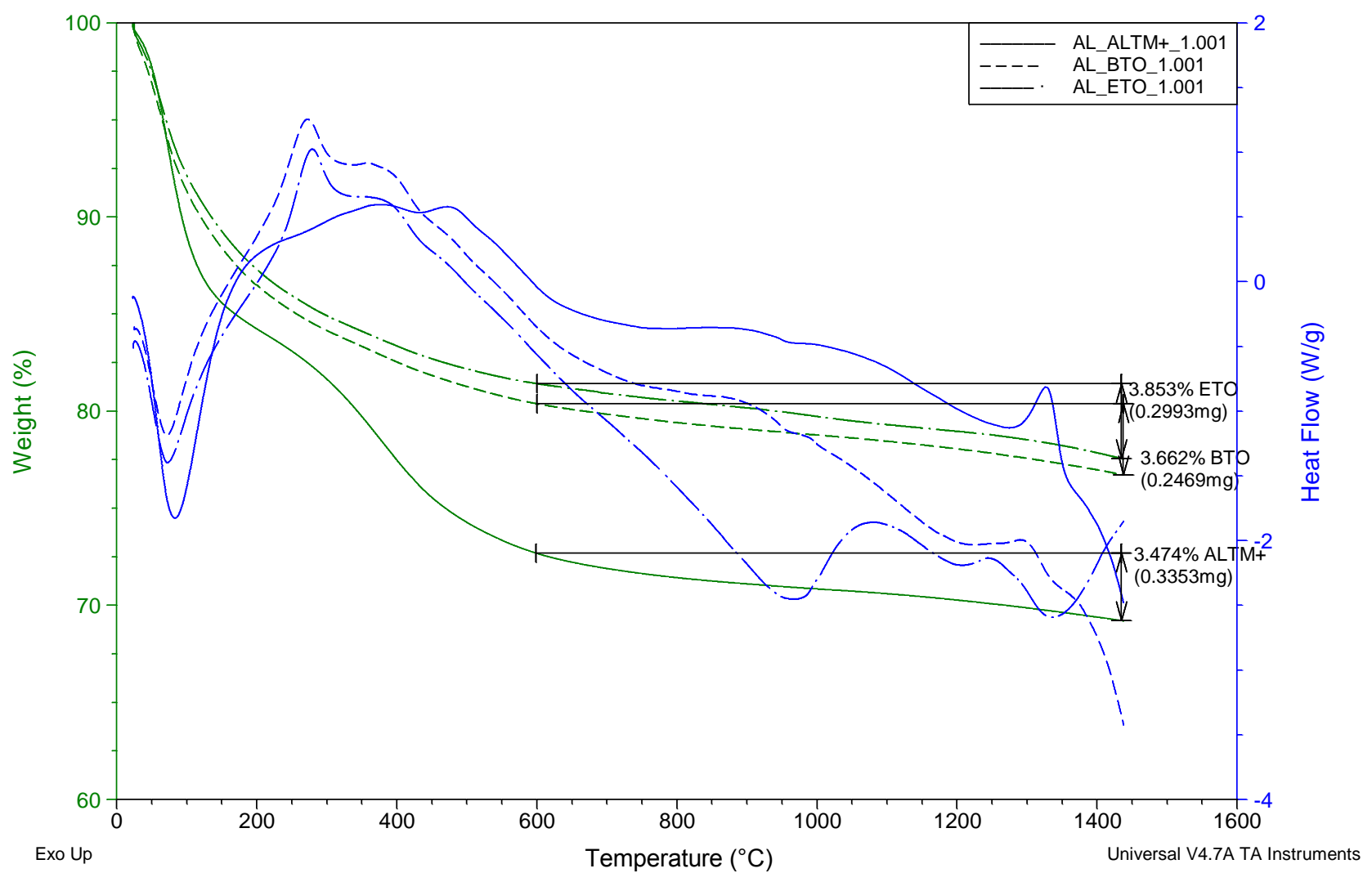

FIGURA 5.16 - Curvas da TGA e da DSC das amostras de $\mathrm{Al}_{2} \mathrm{O}_{3}$ impurificadas com túlio.

O gráfico da TGA cujo eixo das ordenadas é dado em porcentagem de massa (weight \%) indica que cerca de $10 \%$ da massa das amostras ETO e BTO é perdida até ao redor de $100{ }^{\circ} \mathrm{C}$. A amostra ALTM perde uma porcentagem maior ao redor de $15 \%$. O processo endotérmico atribuído à vaporização de água pode ser acompanhado no eixo correspondente à DSC, indicado por "Heat Flow (W/g)". 
À temperatura de $600{ }^{\circ} \mathrm{C}$, a fração perdida atinge $20 \%$ para as amostras ETO e BTO. A amostra ALTM perde cerca de 30\% de sua massa. Essas diferenças de massa podem ser atribuídas às liberações de moléculas de água e às reações exotérmicas resultantes da degradação de espécies orgânicas por oxidação.

Desde que as amostras foram previamente calcinadas a $600{ }^{\circ} \mathrm{C}$, pode-se afirmar que a alumina obtida por coprecipitação, mesmo calcinada a $600{ }^{\circ} \mathrm{C}$, torna a absorver água durante as operações subsequentes.

Acima de $600{ }^{\circ} \mathrm{C}$ até ao redor de $1450{ }^{\circ} \mathrm{C}$ ocorre uma diferença de massa ao redor de 3,5\% a 3,9\%, que pode ser relacionada à dehidroxilação da alumina.

Estudos adicionais são necessários para reduzir o desvio padrão relativo das respostas TL e OSL do lote das pastilhas ALTM e ALBT e também para melhorar suas propriedades. Esses estudos tem a finalidade de aumentar a densidade e a tenacidade da pastilha, melhorar a homogeneidade microestrutural e a transmitância óptica.

\subsection{Pastilha de alumina eletrofundida}

A pastilha de alumina eletrofundida (EAG) foi obtida pela sinterização da alumina eletrofundida com vidro de cal e soda. A alumina eletrofundida proveniente da alumina industrial contém impurezas na sua estrutura.

A TAB. 5.7 mostra a composição da alumina eletrofundida conforme o certificado de análise do fornecedor e as concentrações dos íons respectivos, calculadas em \% em mol. Salienta-se que as concentrações de $\mathrm{K}^{+}$e $\mathrm{Na}^{+}$ultrapassam o valor de $0,1 \%$ em mol.

TABELA 5.7 - Composição da alumina eletrofundida

\begin{tabular}{ccccccccc}
\hline Componente & $\mathrm{Al}_{2} \mathrm{O}_{3}$ & $\mathrm{CaO}$ & $\mathrm{Fe}_{2} \mathrm{O}_{3}$ & $\mathrm{~K}_{2} \mathrm{O}$ & $\mathrm{MgO}$ & $\mathrm{Na}_{2} \mathrm{O}$ & $\mathrm{SiO}_{2}$ & $\mathrm{TiO}_{2}$ \\
\hline$\%$ peso & 99,39 & 0,02 & 0,02 & 0,05 & 0,02 & 0,50 & 0,04 & 0,01 \\
$\%$ mol & - & 0,04 & 0,03 & 0,11 & 0,05 & 1,66 & 0,07 & 0,01 \\
\hline
\end{tabular}

O vidro de cal e soda utilizado para a sinterização da pastilha EAG é um material amorfo, cujos principais componentes são óxido de silício, óxido de cálcio e de sódio. A TAB 5.8 mostra os principais componentes do vidro de cal e soda, identificados pela análise por fluorescência de raios X. 
TABELA 5.8 - Composição do vidro utilizado na sinterização da pastilha EAG

\begin{tabular}{cccc}
\hline Elemento & \% & Óxido & \% \\
\hline $\mathrm{Si}$ & $60,24 \pm 0,06$ & $\mathrm{SiO}_{2}$ & $60,87 \pm 0,21$ \\
$\mathrm{Ca}$ & $22,28 \pm 0,03$ & $\mathrm{CaO}$ & $8,68 \pm 0,04$ \\
$\mathrm{Na}$ & $13,42 \pm 0,25$ & $\mathrm{Na}_{2} \mathrm{O}$ & $26,6 \pm 1,2$ \\
$\mathrm{Al}$ & $2,41 \pm 0,03$ & $\mathrm{Al}_{2} \mathrm{O}_{3}$ & $2,60 \pm 0,11$ \\
$\mathrm{~K}$ & $1,14 \pm 0,01$ & $\mathrm{~K}_{2} \mathrm{O}$ & $0,15 \pm 0,03$ \\
\hline
\end{tabular}

A FIG. 5.17 mostra os difratogramas do vidro de cal e soda, dos cristais de alumina eletrofundida e da pastilha EAG.

O perfil do difratograma do vidro de cal e soda é característico de materiais vítreos. Na pastilha EAG, o perfil do material vítreo é acrescido dos picos característicos da alumina eletrofundida.

A FIG. 5.18 mostra a micrografia da superfície de fratura da pastilha de alumina eletrofundida (EAG), sinterizada a $692{ }^{\circ} \mathrm{C}$ durante 30 minutos. Observa-se que o vidro se adere à superfície das partículas de alumina, agregando-as. Os espaços entre as partículas revelam a sua porosidade. As pastilhas utilizadas para as medições foram sinterizadas a $732{ }^{\circ} \mathrm{C}$, durante 40 minutos. 


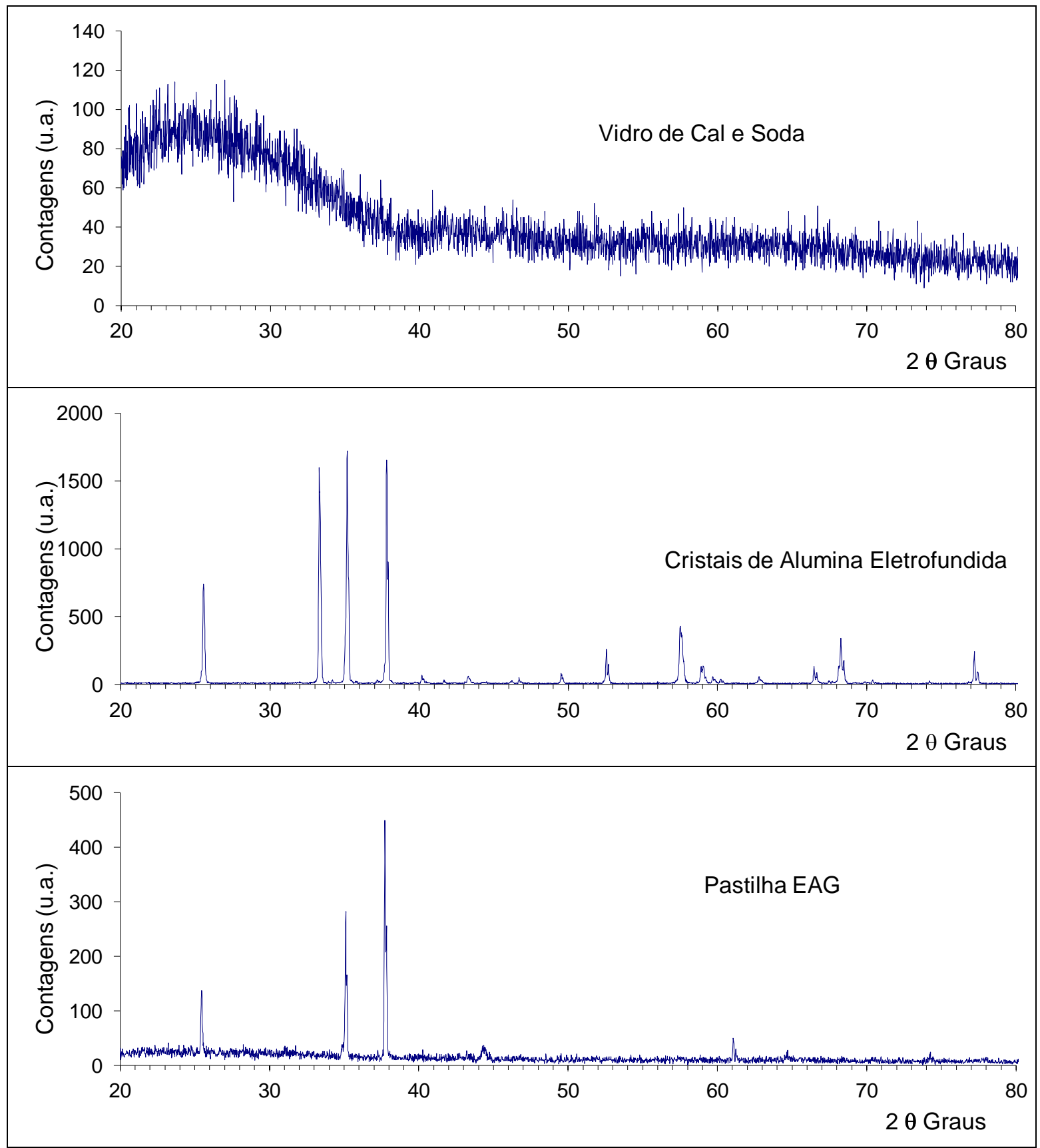

FIGURA 5.17 - Difratogramas de raios X do vidro de cal e soda, dos cristais de alumina eletrofundida e da pastilha EAG. 


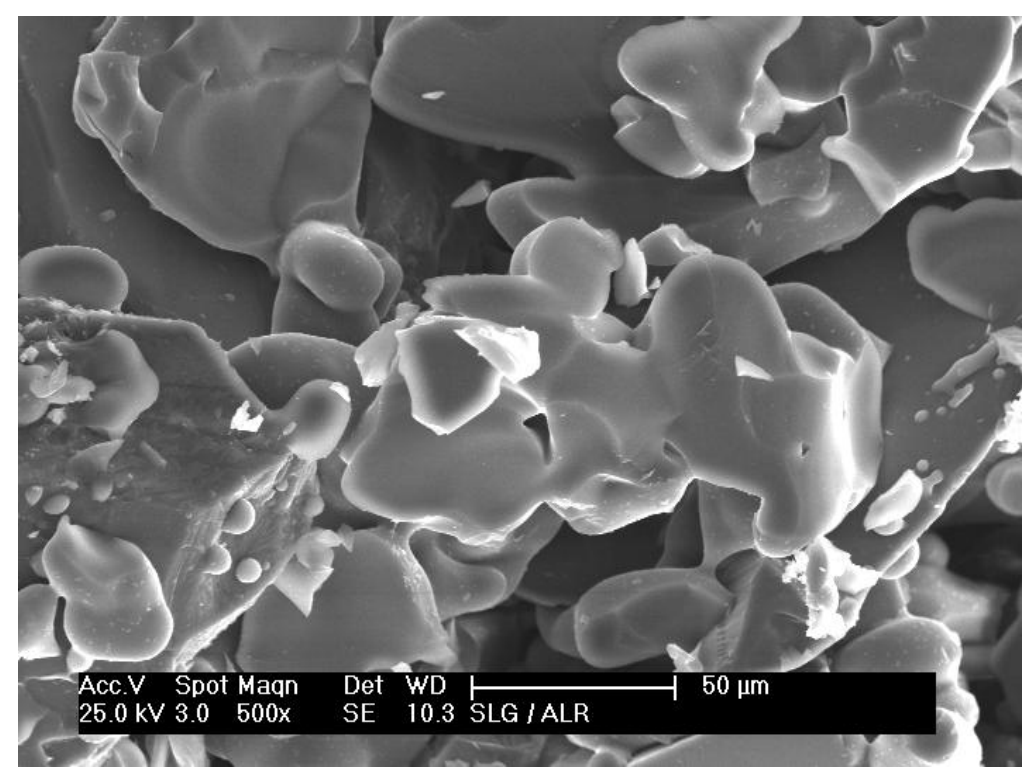

FIGURA - 5.18 Micrografia da superfície de fratura da pastilha de alumina eletrofundida sinterizada com vidro (EAG).

Uma amostra de alumina eletrofundida em pó apresentou a curva TL em função da temperatura com dois picos proeminentes, localizados em $123^{\circ} \mathrm{C}$ e em $226^{\circ} \mathrm{C}$, utilizando taxa de aquecimento de $10^{\circ} \mathrm{C} \mathrm{s}^{-1}$. Os dados foram obtidos por meio da placa de aquisição instalada no leitor Harshaw 2000. Os fatores de geometria calculados conforme a equação 3.4 foram respectivamente $\mu_{\mathrm{g} 1}=0,56$ e $\mu_{\mathrm{g} 2}=0,50$.

A curva TL da alumina eletrofundida branca fornecida pela ELFUSA é apresentada na FIG. 5.19. 


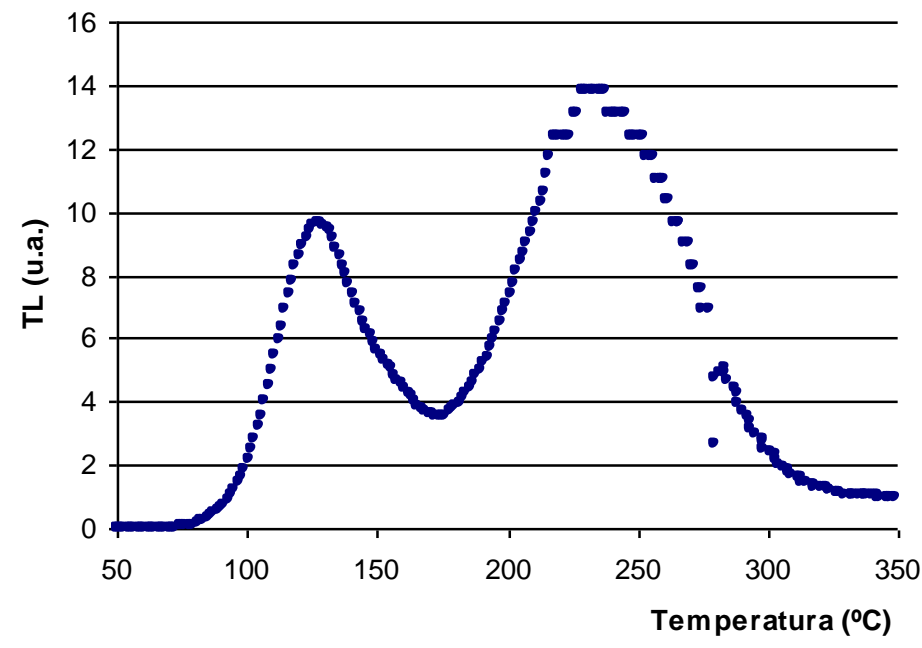

FIGURA 5.19 - Curva TL da alumina eletrofundida fornecida pela ELFUSA.

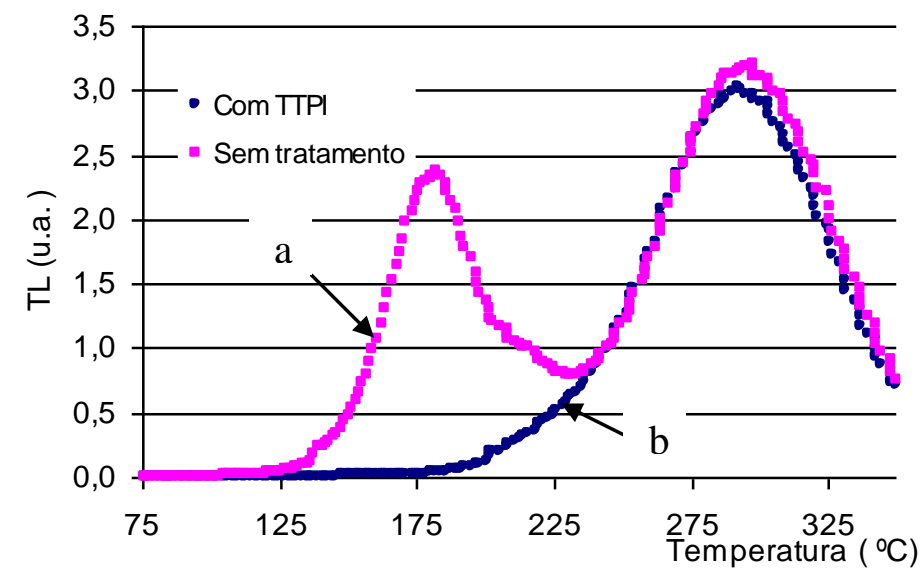

FIGURA 5.20 - Curvas TL da pastilha EAG (a) sem tratamento térmico de pós-irradiação (TTPI) e (b) com TTPI.

Ao transformar a alumina eletrofundida em pastilhas EAG por sinterização vítrea, os picos se deslocam para temperaturas mais altas, ao redor de 175 e $290{ }^{\circ} \mathrm{C}$ (FIG. 5.20). O deslocamento dos picos para temperaturas mais altas se deve provavelmente à condutividade térmica do vidro de cal e soda $\left(1,7 \mathrm{~W} \mathrm{~m}^{-1} \mathrm{~K}^{-1}\right)$ que é menor que a da alumina $96 \%$ (35 $\mathrm{W} \mathrm{m}^{-1} \mathrm{~K}^{-1}$ ) (Callister, 2002).

O primeiro pico da pastilha EAG sujeito ao decaimento térmico mais acentuado pode ser eliminado por meio do tratamento térmico de "pós-irradiação" (TTPI), aquecendo 
a amostra irradiada a $120^{\circ} \mathrm{C}$ durante 15 minutos. Esse efeito é mostrado na FIG. 5.20, onde a curva $b$ representa a TL da pastilha submetida ao TTPI.

A resposta TL em função da dose de radiação gama do ${ }^{60} \mathrm{Co}$ das pastilhas EAG irradiadas no ar em condições de equilíbrio eletrônico é aproximadamente linear até ao redor de 800 mGy (FIG. 5.21).

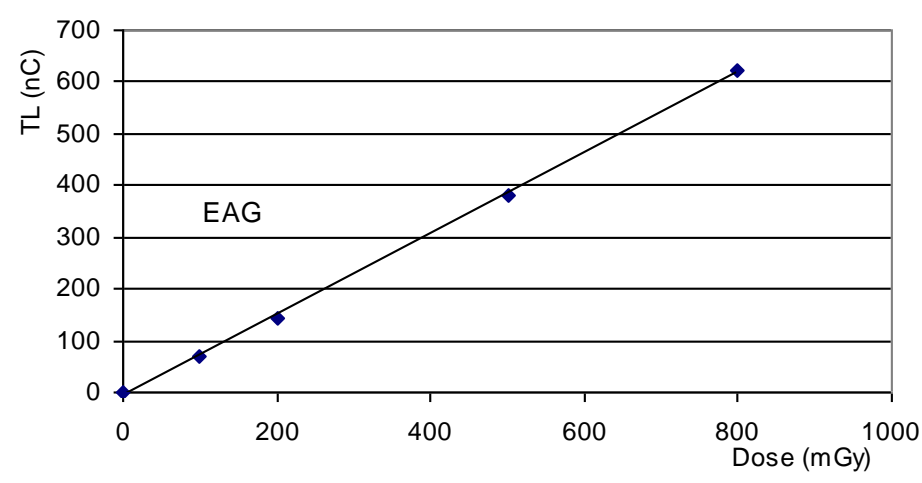

FIGURA 5.21 - Resposta TL em função da dose das pastilhas EAG.

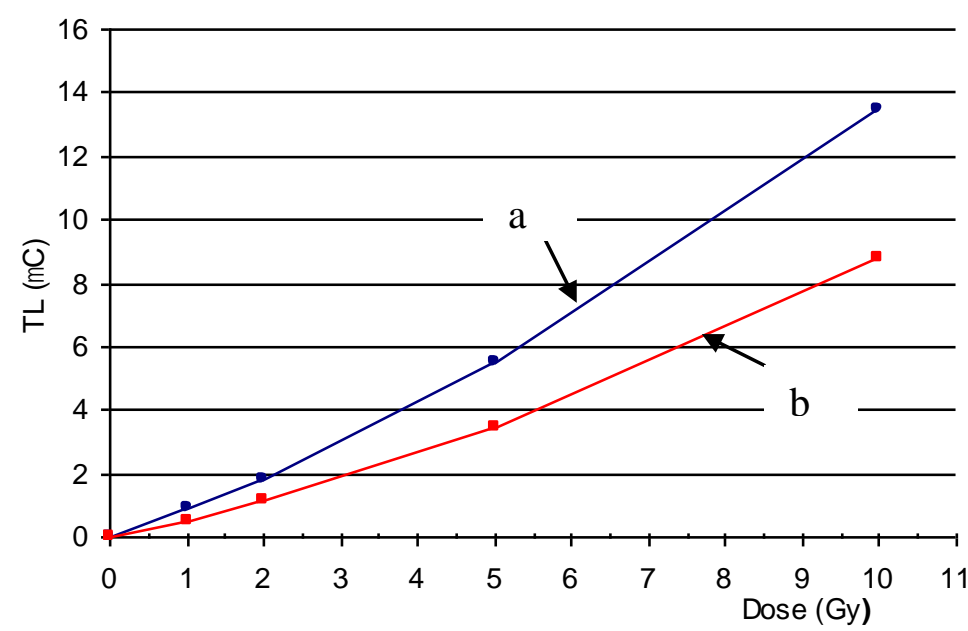

FIGURA 5.22 - Resposta TL das pastilhas EAG para doses acima de 800 mGy. (a) sem TTPI e (b) com TTPI.

$\mathrm{O}$ fator de calibração $\left(\mathrm{f}_{\mathrm{c}}\right)$ da região linear é $\mathrm{f}_{\mathrm{c}}=0,76 \mathrm{nC} \cdot \mathrm{mGy}^{-1}$ para os dados obtidos por meio do leitor Harshaw 2000.

Acima de 800 mGy, a resposta TL em função da dose tem tendência à supralinearidade, conforme é mostrado na FIG. 5.22. As pastilhas EAG foram irradiadas 
com $1,2,5$ e 10 Gy de radiação gama do ${ }^{60} \mathrm{Co}$. O conjunto de pontos ligados na parte superior (a) foi obtido com pastilhas sem TTPI considerando os dois picos da curva TL. O conjunto inferior (b) foi obtido excluindo o primeiro pico da curva TL com TTPI.

A curva TL da pastilha EAG obtida por meio do leitor RIS $\varnothing$, com taxa de aquecimento de $5^{\circ} \mathrm{C} \mathrm{s}^{-1}$ é mostrada na FIG. 5.23. O leitor foi programado para realizar um aquecimento inicial até $500{ }^{\circ} \mathrm{C}$, para eliminar o sinal da TL remanescente. A pastilha foi irradiada com a fonte beta de ${ }^{90} \mathrm{Sr} /{ }^{90} \mathrm{Y}$ durante 3 segundos. Os picos da curva TL foram localizados em $\mathrm{T}_{\mathrm{m} 1}=(174 \pm 4){ }^{\circ} \mathrm{C}$ e em $\mathrm{T}_{\mathrm{m} 2}=(307 \pm 7){ }^{\circ} \mathrm{C}$.

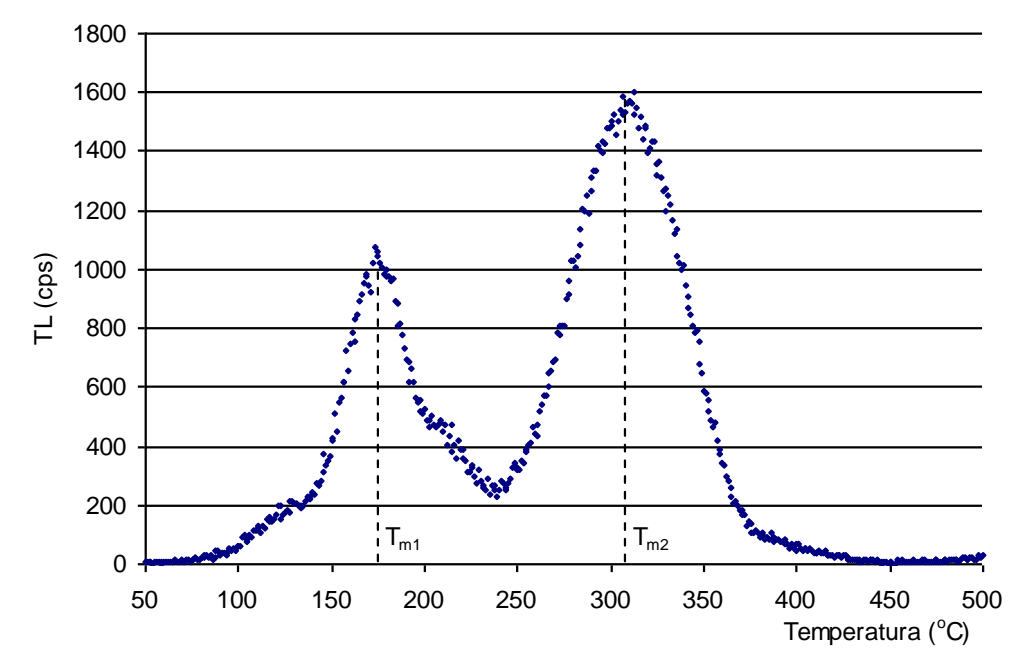

FIGURA 5.23 - Curva TL da pastilha EAG obtida por meio do leitor RIS $\emptyset$.

As curvas da TL das pastilhas EAG obtidas com o leitor RIS $\emptyset$, após a irradiação com dose beta de ${ }^{90} \mathrm{Sr} /{ }^{90} \mathrm{Y}$ estão mostradas na FIG. 5.24. Correspondem às doses betas de 2, 4, 8 e 12 Gy, na região de supralinearidade. As áreas sob as curvas não guardam proporcionalidade com a dose. 


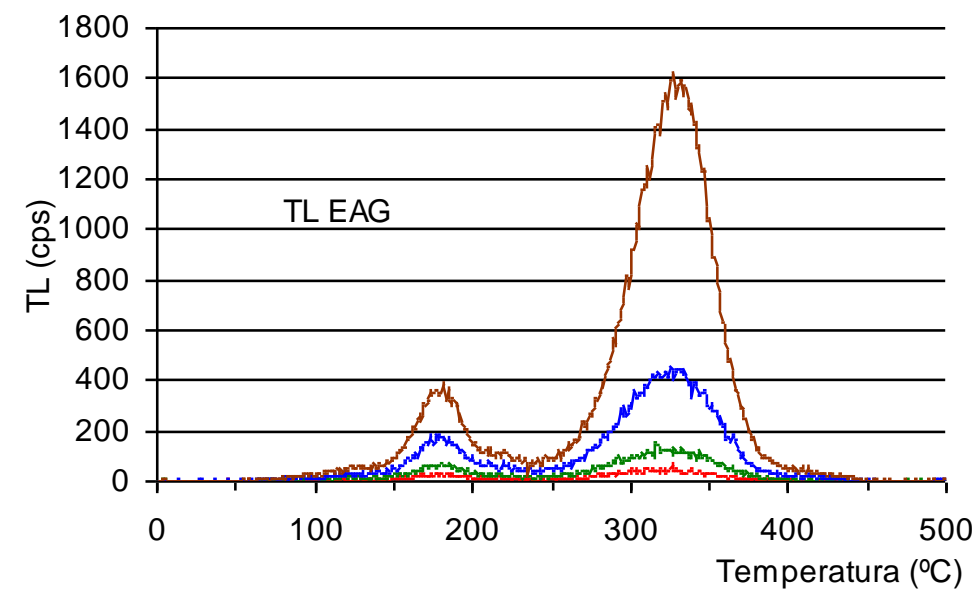

FIGURA 5.24 - Curvas da TL da pastilha EAG correspondentes a 2, 4, 8 e 12 Gy de radiação beta da fonte de ${ }^{90} \mathrm{Sr} /{ }^{90} \mathrm{Y}$.

Variando a taxa de aquecimento de $5^{\circ} \mathrm{C} \mathrm{s}^{-1}$ para $10{ }^{\circ} \mathrm{C} \mathrm{s}^{-1}$, a curva da TL desloca-se para a direita e os picos aparecem em temperaturas mais altas (FIG. 5.25). Essa técnica poderá ser utilizada para estudos mais avançados para a determinação dos parâmetros $\mathbf{E}$ e $\mathbf{S}$ descritos nos conceitos teóricos (capítulo 3).

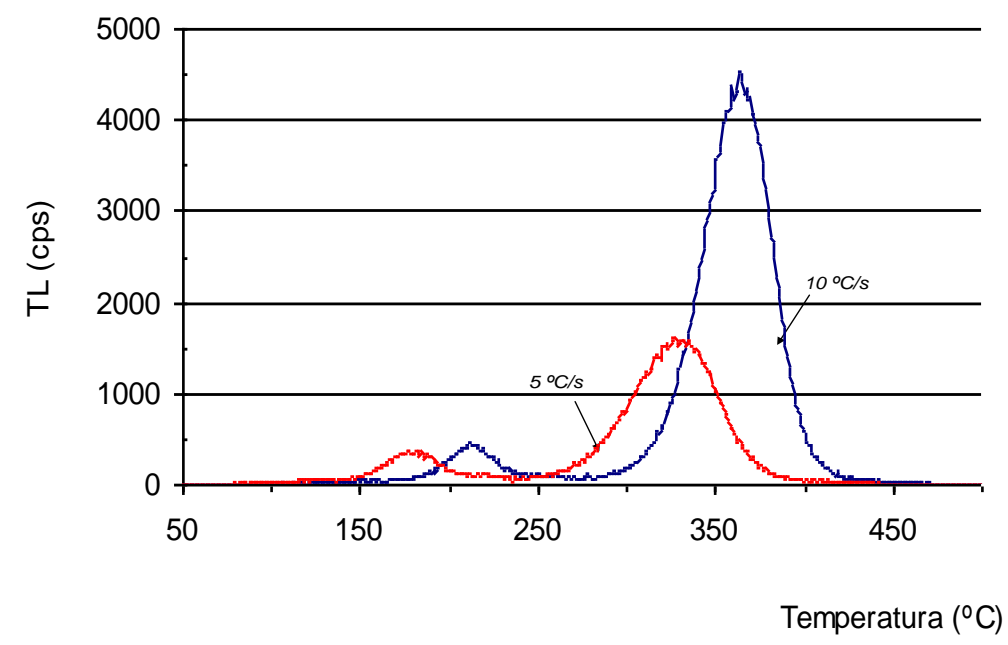

FIGURA 5.25 - Deslocamento dos picos da TL para temperaturas mais altas, com o aumento da taxa de aquecimento de 5 para $10^{\circ} \mathrm{C} \mathrm{s}^{-1}$.

A FIG. 5.26 apresenta a resposta TL da pastilha EAG em função da dose de radiação beta de ${ }^{90} \mathrm{Sr} /{ }^{90} \mathrm{Y}$, em gráfico na escala logarítmica, indica uma linearidade até aproximadamente $1 \mathrm{~Gy}$. Considerou-se a taxa de dose da fonte beta de 0,1 Gy s ${ }^{-1}$. Esses 
valores concordam aproximadamente com a resposta TL em função da dose de radiação gama de ${ }^{60} \mathrm{Co}$ apresentados anteriormente.

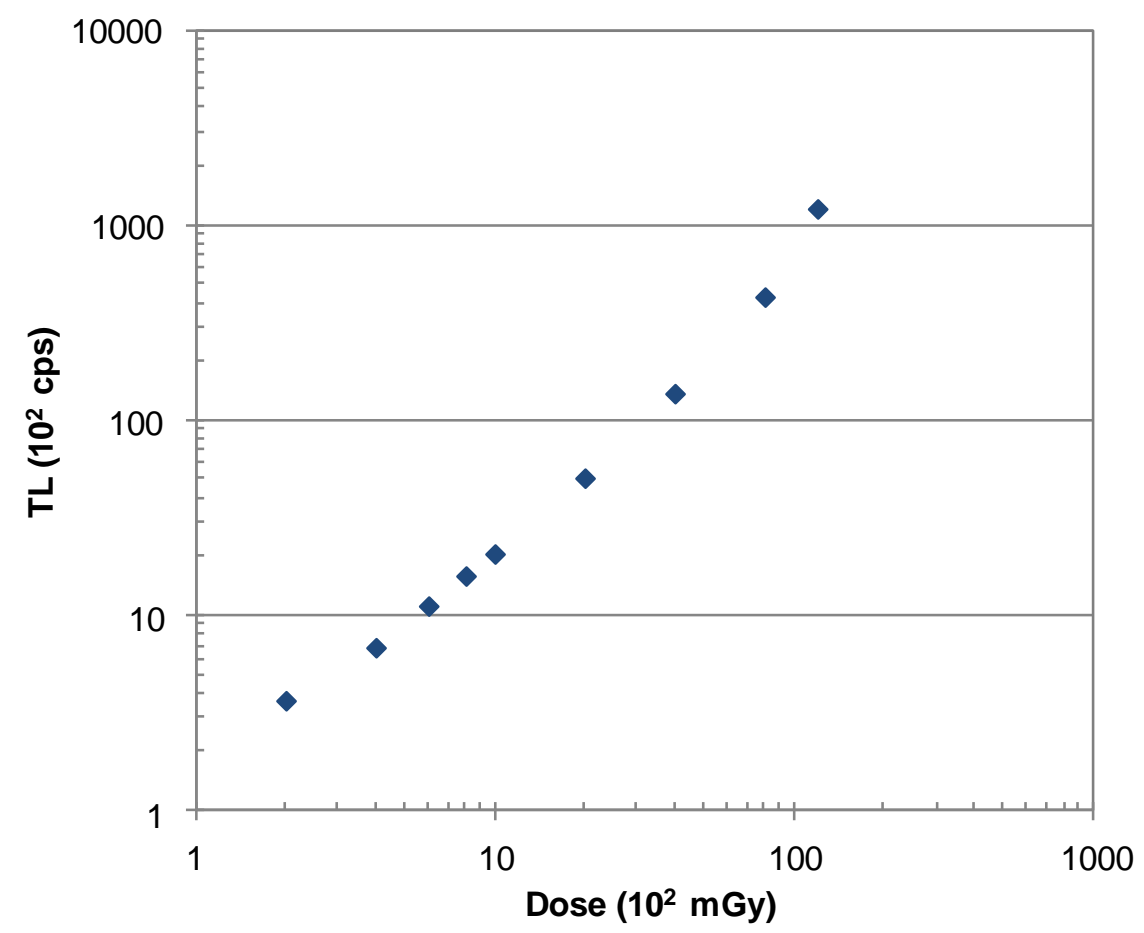

FIGURA 5.26 - Resposta TL em função da dose beta da pastilha EAG.

Na FIG 5.27 estão apresentadas as curvas OSL de seis pastilhas EAG. As pastilhas foram irradiadas com fonte beta durante 1, 2, 3, 5, 10 e 20 segundos. As curvas foram obtidas utilizando "LEDs" azuis, com $10 \%$ de potência luminosa e leituras OSL com duração de um segundo por ponto. 


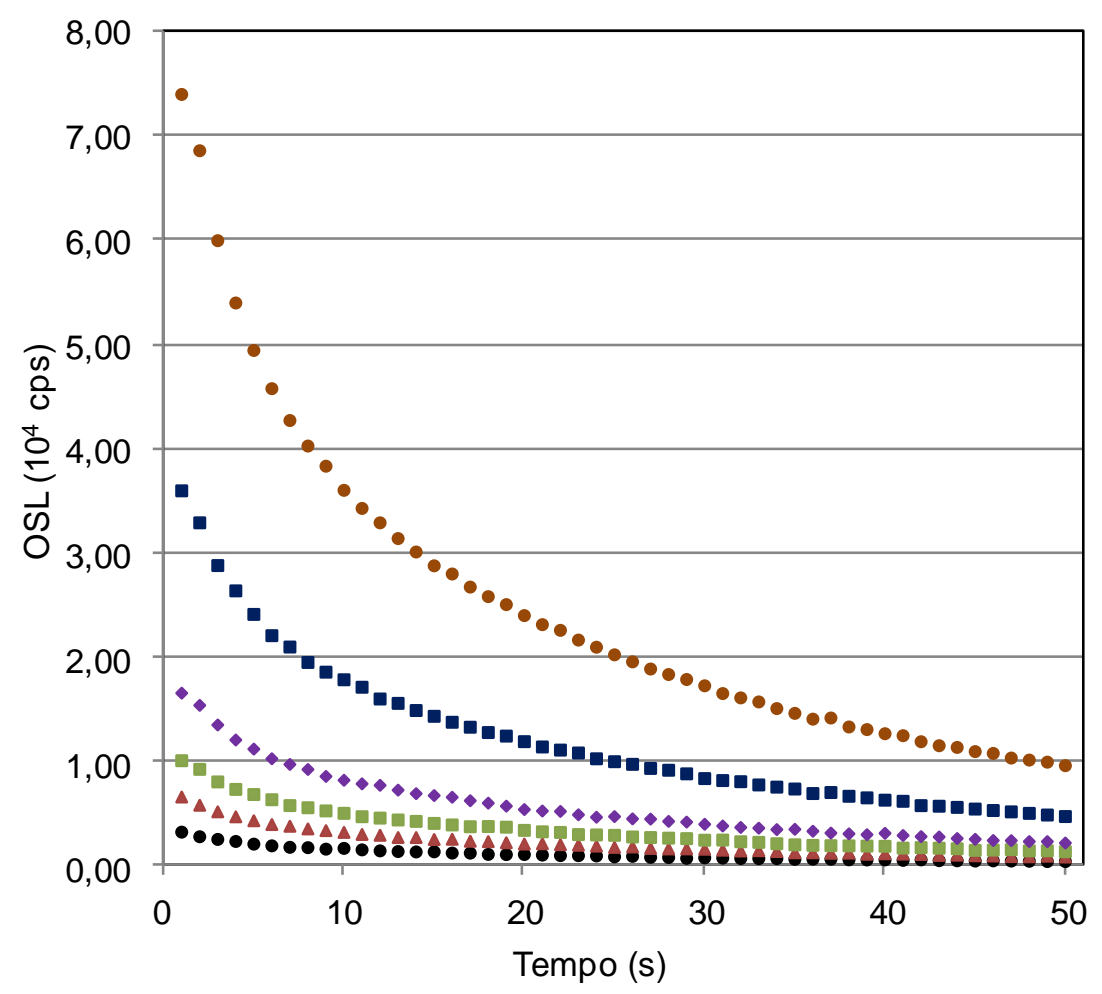

FIGURA 5.27 - Curvas OSL das pastilhas EAG irradiadas com fonte beta.

As integrais das curvas da FIG. 5.27 de $\mathrm{t}=1 \mathrm{~s}$ a $\mathrm{t}=50 \mathrm{~s}$ foram postas em gráfico em função da dose em mGy (FIG. 5.28). Os pontos resultaram em uma relação aproximadamente linear no intervalo verificado experimentalmente, de 100 a 2000 mGy.

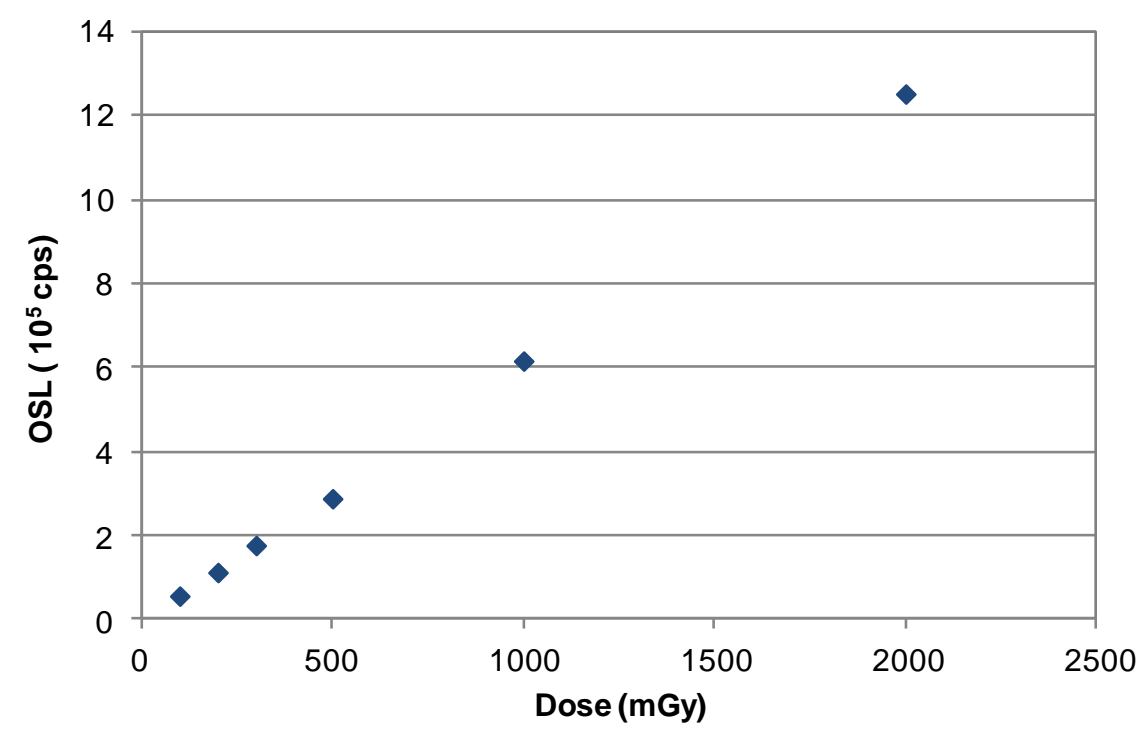

FIGURA 5.28 - Resposta OSL das pastilhas EAG em função da dose de radiação beta. 
$\mathrm{O}$ efeito do aquecimento escalonado no sinal OSL foi verificado por meio do procedimento "step annealing" (FIG. 5.29).

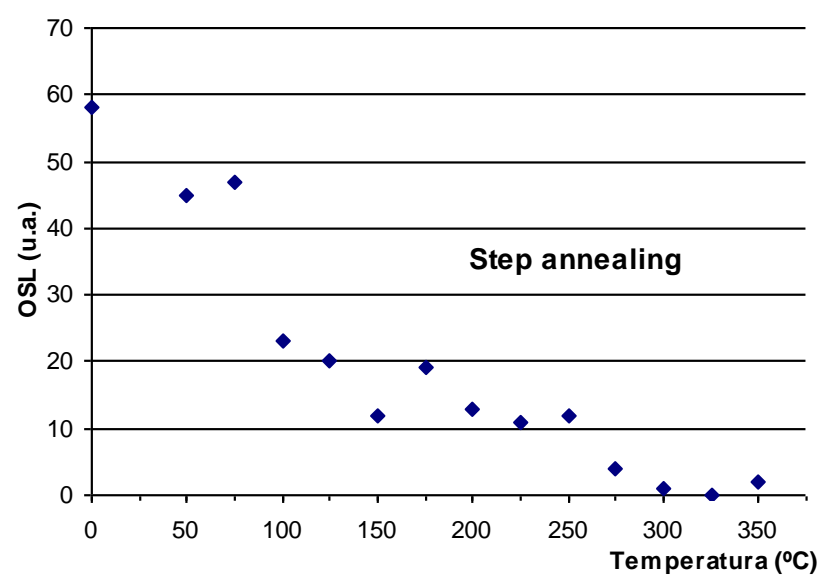

FIGURA 5.29 - Efeito do aquecimento escalonado no sinal da OSL (step annealing).

Verificam-se três regiões: uma redução acentuada da OSL até $100{ }^{\circ} \mathrm{C}$, de $100{ }^{\circ} \mathrm{C}$ a $250{ }^{\circ} \mathrm{C}$, onde a OSL diminui de forma relativamente constante e a terceira região acima de $250{ }^{\circ} \mathrm{C}$, quando o sinal da OSL é praticamente eliminado.

Um conjunto de dez amostras EAG foi selecionado para verificar a uniformidade das respostas TL e da OSL. Os dados individuais de cada amostra estão apresentados na TAB. 5.9.

TABELA 5.9 - Respostas TL e OSL das pastilhas EAG selecionadas

\begin{tabular}{cccccccc}
\hline $\begin{array}{c}\text { Amostra } \\
(\text { EAG })\end{array}$ & $\begin{array}{c}\text { massa } \\
(\mathrm{mg})\end{array}$ & $\begin{array}{c}\text { espessura } \\
(\mathrm{mm})\end{array}$ & $\begin{array}{c}\text { diâmetro } \\
(\mathrm{mm})\end{array}$ & $\begin{array}{c}\text { volume } \\
\left(\mathrm{mm}^{3}\right)\end{array}$ & $\begin{array}{c}\text { densidade } \\
\left(\mathrm{g} \mathrm{cm}^{-3}\right)\end{array}$ & $\begin{array}{c}\text { TL } \\
\left(10^{5} \mathrm{cps}\right)\end{array}$ & $\begin{array}{c}\text { OSL } \\
\left(10^{5} \mathrm{cps}\right)\end{array}$ \\
\hline 1 & 51,6 & 1,05 & 5,52 & 25,13 & 2,05 & 1,70 & 5,15 \\
2 & 51,8 & 1,06 & 5,50 & 25,18 & 2,06 & 1,84 & 5,66 \\
3 & 51,0 & 1,05 & 5,52 & 25,13 & 2,03 & 1,78 & 5,69 \\
4 & 51,0 & 1,02 & 5,52 & 24,41 & 2,09 & 1,86 & 5,76 \\
5 & 51,7 & 1,05 & 5,55 & 25,40 & 2,04 & 1,76 & 5,67 \\
6 & 51,4 & 1,03 & 5,55 & 24,92 & 2,06 & 1,79 & 5,64 \\
7 & 51,8 & 1,02 & 5,57 & 24,85 & 2,08 & 1,76 & 5,76 \\
8 & 51,9 & 1,06 & 5,50 & 25,18 & 2,06 & 1,77 & 5,69 \\
9 & 51,0 & 1,06 & 5,54 & 25,55 & 2,00 & 1,83 & 5,96 \\
10 & 51,0 & 1,04 & 5,51 & 24,80 & 2,06 & 1,74 & 5,73 \\
\hline Média & 51,4 & 1,04 & 5,53 & 25,06 & 2,05 & 1,78 & 5,67 \\
\hline s & $\pm 0,4$ & $\pm 0,02$ & $\pm 0,02$ & $\pm 0,33$ & $\pm 0,03$ & $\pm 0,05$ & $\pm 0,20$ \\
\hline DPR(\%) & 0,78 & 1,9 & 0,36 & 1,32 & 1,46 & 2,8 & 3,5 \\
\hline
\end{tabular}


Os desvios-padrão relativos expressos em percentagem são 2,8\% para as respostas TL e 3,5\% para as respostas OSL. Os valores da TL foram obtidos integrando até $500{ }^{\circ} \mathrm{C}$.

Os perfis das curvas TL e OSL das pastilhas EAG individuais são muito semelhantes, salvo pequenas diferenças, o que pode explicar a boa precisão das medidas realizadas com pastilhas selecionadas. As FIG. 5.30 e 5.31 apresentam os perfis das curvas TL e OSL de quatro pastilhas distintas observadas no leitor RIS $\varnothing$.

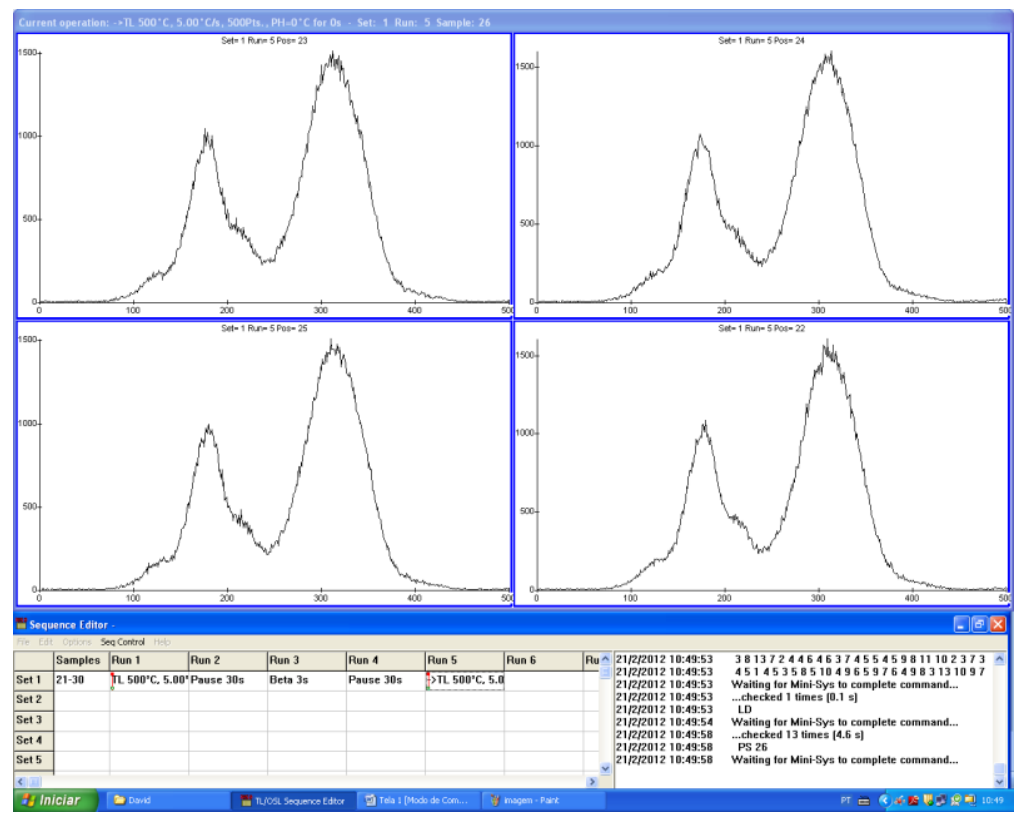

FIGURA 5.30 - Perfis das curvas TL de quatro pastilhas EAG distintas observados no leitor RIS $\varnothing$. 


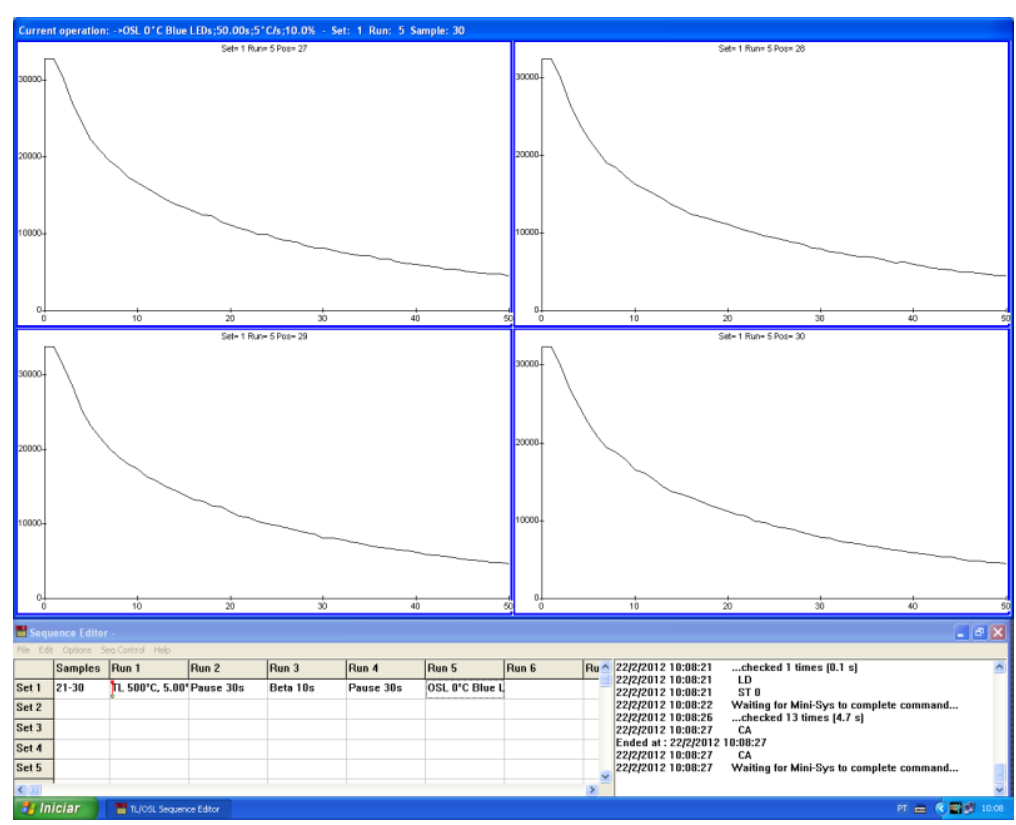

FIGURA 5.31 - Perfis das curvas OSL de quatro pastilhas EAG distintas observados no leitor RIS $\varnothing$.

\subsection{Comparações e comentários finais}

A FIG. 5.32 apresenta as curvas da resposta OSL das pastilhas EAG e ALTM, irradiadas com fonte de radiação $\beta$, durante 20 segundos. A leitura da OSL foi realizada sob luz azul de estimulação com $10 \%$ de potência óptica, durante 60 segundos. Nessas condições, verificou-se que o sinal da OSL da pastilha ALTM é mais intenso no início, porém decresce mais rapidamente que o da pastilha EAG.

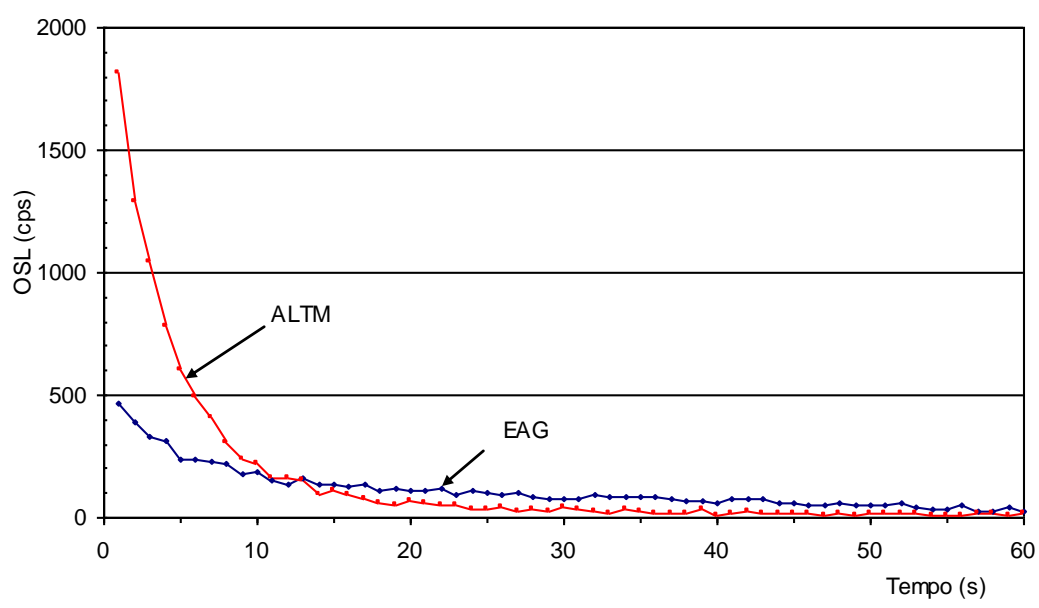

FIGURA 5.32 - Comparação entre a resposta OSL das pastilhas EAG e ALTM. 


\section{CONCLUSÕES}

\subsection{Gerais}

Verificou-se experimentalmente que o óxido de alumínio na sua forma estável $\left(\alpha-\mathrm{Al}_{2} \mathrm{O}_{3}\right)$ com determinados elementos químicos na estrutura cristalina pode apresentar TL e OSL.

Os métodos da adsorção e da coprecipitação foram estudados na tentativa de inserir íons metálicos no óxido de alumínio.

As amostras de alumina impurificada pelo método de adsorção com $\mathrm{Mn}^{2+}$ e com $\mathrm{Cu}^{2+}$ não apresentaram sinais de TL significativos. As causas não estão bem esclarecidas.

A alumina impurificada com túlio pelo método da coprecipitação e sinterizada na forma de pastilha em temperatura de 1500 a $1550{ }^{\circ} \mathrm{C}$ apresentou TL e OSL. O pico TL dosimétrico foi localizado ao redor de $208^{\circ} \mathrm{C}$, à taxa de $5^{\circ} \mathrm{C} \mathrm{s}^{-1}$. O pico possui um perfil simples.

As pastilhas de óxido de alumínio impurificado com túlio (ALTM e ALBT) apresentaram leituras de TL e de OSL com dispersão significativa, apesar de serem selecionadas de um mesmo lote. As pastilhas ALBT produzidas com massa menor que as pastilhas ALTM apresentaram dispersão de $41 \%$ e $67 \%$ para as leituras TL e OSL, respectivamente. No entanto, as leituras da TL e da OSL de uma mesma pastilha foram realizadas com boa repetibilidade e as respostas TL e OSL em função da dose mostraram um comportamento linear em um intervalo de dose razoável.

Os resultados indicaram a necessidade de estudos adicionais para produzir pastilhas de óxido de alumínio impurificado com túlio. A melhoria do processo de obtenção da alumina pelo método da coprecipitação poderá ser feita pela determinação das melhores condições de calcinação, compactação e de sinterização.

Verificou-se que a alumina eletrofundida branca é um material que apresenta sinais de TL e de OSL. Esse material foi transformado em pastilhas denominadas EAG por meio da sinterização com vidro de cal e soda. 
As pastilhas EAG apresentaram sinais de TL e de OSL. Os picos da TL foram localizados em $(174 \pm 4){ }^{\circ} \mathrm{C}$ e em $(307 \pm 7){ }^{\circ} \mathrm{C}$. O pico da temperatura mais baixa pode ser eliminado por um tratamento térmico de pós-irradiação de 15 minutos à temperatura de $120^{\circ} \mathrm{C}$.

A dose mínima detectável da pastilha EAG está ao redor de 7,2 mGy. A linearidade da resposta TL em função da dose foi verificada até aproximadamente $800 \mathrm{mGy}$, para radiação gama do ${ }^{60} \mathrm{Co}$. A linearidade da resposta é estendida para dose ao redor de 2 Gy quando se utiliza a técnica OSL e radiação beta.

As pastilhas EAG podem ser produzidas por meio da sinterização vítrea com boa reprodutibilidade e precisão.

As pastilhas de alumina eletrofundida e de alumina impurificada com túlio são dosímetros em potencial. No entanto, várias propriedades dosimétricas devem ser mais bem determinadas e analisadas.

\subsection{Sugestões para trabalhos futuros}

Sugerem-se os seguintes trabalhos futuros:

- Investigar a possibilidade de melhorar as características físicas das pastilhas ALTM e ALBT como a densidade, transparência, resistência à fratura.

- Desenvolver estudos avançados para a determinação os parâmetros $E$ e $s$ dos picos dosimétricos.

- Estudar o decaimento térmico e óptico e a dependência energética da resposta de dose dos produtos desenvolvidos.

- Obter novos materiais dosimétricos pela inserção de outros íons na estrutura do óxido de alumínio e determinar suas propriedades.

- Avaliar a aplicação dos dosímetros desenvolvidos em diferentes áreas da dosimetria. 


\section{ANEXO A - Constante de Boltzmann}

$\mathrm{O}$ valor da constante de Boltzmann é $\mathrm{k}=8,617(35) 10^{-5} \mathrm{eV} \mathrm{K}^{-1}$.

$\mathrm{O}$ eV (elétron-volt) é unidade de medida de energia, igual a que recebe um elétron ao passar num campo elétrico por dois pontos cuja diferença de potencial é igual a um volt. É utilizada frequentemente em física atômica e nuclear e não é uma unidade do SI. Pode ser convertida pela relação $1 \mathrm{eV}=1,602110^{-19} \mathrm{~J}$.

A constante de Boltzmann no SI têm valor $\mathrm{k}=1,38110^{-23} \mathrm{~J} \mathrm{~K}^{-1}$. Está relacionada com a constante dos gases perfeitos $(\mathrm{R})$ e o número de Avogradro $\left(\mathrm{N}_{\mathrm{A}}\right)$, pela equação:

$$
\mathrm{k}=\mathrm{R} / \mathrm{N}_{\mathrm{A}}
$$

onde, $\mathrm{R}=8,314 \mathrm{~J} \mathrm{~K}^{-1} \mathrm{~mol}^{-1}$ e $\mathrm{N}_{\mathrm{A}}=6,02210^{23} \mathrm{~mol}^{-1}$. 


\section{ANEXO B - Ensaio de repetibilidade}

Objetivo: Determinar a repetibilidade da resposta OSL de uma pastilha após um tratamento térmico com taxa de aquecimento de $5{ }^{\circ} \mathrm{C} \mathrm{s}^{-1}$ até $500{ }^{\circ} \mathrm{C}$ e irradiação com fonte beta durante 5 segundos.

Equipamento: Leitor RIS $\varnothing$, modelo TL/OSL-DA-20

Amostra: Pastilha ALBT na posição 11 do "porta-amostras" do leitor

Data: $29 / 02 / 2012$

\begin{tabular}{|c|c|c|c|}
\hline Amostra & "Run" & Instruções no "Sequence Editor" & Resultado \\
\hline \multirow[t]{19}{*}{11} & 1 & TL até $500^{\circ} \mathrm{C}, 5^{\circ} \mathrm{s}^{-1}$, fluxo de $\mathrm{N}_{2}, 500$ pontos & \\
\hline & 2 & Pausa durante $120 \mathrm{~s}$ & \\
\hline & 3 & OSL, "leds" azuis, $10 \%$ potência, $50 \mathrm{~s}$, 1 s ponto $^{-1}$ & $1486 \mathrm{cps}$ \\
\hline & 4 & TL até $500^{\circ} \mathrm{C}, 5^{\circ} \mathrm{s}^{-1}$, fluxo de $\mathrm{N}_{2}, 500$ pontos & \\
\hline & 5 & Pausa durante $120 \mathrm{~s}$ & \\
\hline & 6 & Irradiação com fonte beta durante $5 \mathrm{~s}$ & \\
\hline & 7 & Pausa durante $120 \mathrm{~s}$ & \\
\hline & 8 & OSL, "leds" azuis, $10 \%$ potência, $50 \mathrm{~s}$, 1 s ponto $^{-1}$ & 21741cps \\
\hline & 9 & TL até $500^{\circ} \mathrm{C}, 5^{\circ} \mathrm{s}^{-1}$, fluxo de $\mathrm{N}_{2}, 500$ pontos & \\
\hline & 10 & Pausa durante $120 \mathrm{~s}$ & \\
\hline & 11 & Irradiação com fonte beta durante $5 \mathrm{~s}$ & \\
\hline & 12 & Pausa durante $120 \mathrm{~s}$ & \\
\hline & 13 & OSL, "leds" azuis, $10 \%$ potência, $50 \mathrm{~s}$, $1 \mathrm{~s}^{\text {ponto }}{ }^{-1}$ & $21671 \mathrm{cps}$ \\
\hline & 14 & TL até $500^{\circ} \mathrm{C}, 5^{\circ} \mathrm{s}^{-1}$, fluxo de $\mathrm{N}_{2}, 500$ pontos & \\
\hline & 15 & Pausa durante $120 \mathrm{~s}$ & \\
\hline & 16 & Irradiação com fonte beta durante $5 \mathrm{~s}$ & \\
\hline & 17 & Pausa durante $120 \mathrm{~s}$ & \\
\hline & 18 & OSL, "leds" azuis, $10 \%$ potência, $50 \mathrm{~s}$, $1 \mathrm{~s}^{\text {p ponto }}{ }^{-1}$ & $21934 \mathrm{cps}$ \\
\hline & & Média $=$ & $32 \pm 136) \mathrm{cps}$ \\
\hline
\end{tabular}




\section{REFERÊNCIAS BIBLIOGRÁFICAS}

1. ABRÃO; A. Química e tecnologia das terras-raras.. Rio de Janeiro: Centro de Tecnologia Mineral, 1994. (Série Tecnologia Mineral, n. 66).

2. AIROLDI, C.; FERNANDES DE FARIAS, R. "Alcóxidos como precursores na síntese de novos materiais através do processo sol-gel”. Quim. Nova, v. 27, n.1, p. 84-88, 2004.

3. AKSELROD, M. S.; BØTTER-JENSEN, L.; MCKEEVER, S. W. S. Optically stimulated luminescence and its use in medical dosimetry. Radiat. Meas. v. 41, p. S78S99, 2007

4. AKSELROD, M. S.; KORTOV, V. S.; GORELOVA, E. A. Preparation and properties of $\alpha-\mathrm{Al}_{2} \mathrm{O}_{3}:$ C. Radiat. Prot. Dosim., v. 47, p. 159-164, 1993.

5. AKSELROD, M. S.; KORTOV, V. S.; KRAVETSKY, D. J., GOTLIB, V. I. Highly sensitive thermoluminescent anion-defective $\alpha-\mathrm{Al}_{2} \mathrm{O}_{3}: \mathrm{C}$ single crystal detectors. Radiat. Prot. Dosim., v. 32, p.15-20, 1990.

6. AKSELROD, M. S.; LUCAS, A. C.; POLF, J. C.; McKEEVER, S. W. S. Optically stimulated luminescence of $\mathrm{Al}_{2} \mathrm{O}_{3}$. Radiat. Meas., v. 29, n. 3-4, p. 391-399, 1998.

7. BARROS, V. S. M.; AZEVEDO, W. M.; KHOURY, H. J.; ANDRADE, M. E. A.; LINHARES FILHO, P. Thermoluminescence study of aluminum oxide doped with therbium and thulium. Radiat. Meas., v. 45, p. 435-437, 2010.

8. BARROS, V. S. M.; AZEVEDO, W. M.; KHOURY, H. J.; LINHARES FILHO, P. Preparation and characterization of thermoluminescent aluminum oxide doped with $\mathrm{Tb}^{3+}$ and $\mathrm{Tb}^{3+}-\mathrm{Mg}^{2+}$. In: INTERNATIONAL CONFERENCE ON DEFECTS IN INSULATING MATERIALS. J. Phys.: Conf. Ser., 249, 2010.

9. BAUMGARTEN, E. Adsorption of ions onto alumina. In: SCHWARZ, J. A.; CONTESCU, C. I. (Ed.). Surfaces of nanoparticles and porous materials. New York, N.Y.:Marcel Dekker, 1999. v. 78. p. 711-741. (Surfactant science series)

10. BECKER, K. Thermoluminescence. In: BECKER, K. (Ed.). Solid State Dosimetry. CRC Press, Cleveland, Ohio, p. 27-109, 1973.

11. BHATT, B. C.; PAGE, P. S.; RAWAT, N. S.; DHABEKAR, B. S., MISHRA, D. R.; KULKARNI, M. S. TL, OSL and PL studies in $\mathrm{Al}_{2} \mathrm{O}_{3}:$ Si,Ti phosphor. Radiat. Meas., v. 43, pp. 327-331, 2008.

12. BOS, A. J. J. High sensitivity thermoluminescence dosimetry. Nucl. Instr. Meth. Phys. Res. B, v.184, p. 3-28, 2001.

13. BOS, A. J. J. Theory of thermoluminescence. Radiat. Meas., v. 41, p. S45-S56, 2007.

14. ВØTTER-JENSEN, L. Development of optically stimulated luminescence techniques using natural minerals and ceramics, and their application to retrospective dosimetry. 2000. Tese (Doutorado) - Riso National Laboratory, Roskilde, Dinamarca.

15. BØTTER-JENSEN, L.; MCKEEVER, S. W. S.; WINTLE, A. G. Optically Stimulated Luminescence Dosimetry. Elsevier Science, Netherlands, 2003.

16. CALLISTER Jr, W. D. Materials science and engineering an introduction. Tradução SOARES, S. M. S. 5. ed., Rio de Janeiro: LTC-Livros Tecnicos e Científicos, 2002. 
17. CAMERON, J. R.; SUNTHARALINGAM, N.; KENNEY, G.N. Thermoluminescent Dosimetry. University of Wisconsin, London, 1968.

18. CAMPOS, L. L. Termoluminescência de materiais e sua aplicação em dosimetria da radiação. Cerâmica, v. 44, p. 244-251, 1998.

19. CAMPOS, L. L.; LIMA, M. F. Pastilhas dosimétricas de $\mathrm{CaSO}_{4}: \mathrm{Dy}+$ teflon para detecção da radiação X, beta e gama. São Paulo, Instituto de Pesquisas Energéticas e Nucleares, 1987. (PUB. IPEN 120).

20. CAMPOS, L. L.; FRUTUOSO, P. H.; SOUTO, V. I. Aperfeiçoamento do método de obtenção de monocristais de $\mathrm{CaSO}_{4}$ :Dy dosimétrico. São Paulo, Instituto de Pesquisas Energéticas e Nucleares, 1989. (PUB. IPEN 265).

21. CASTRO, R. H. R.; GOUVÊA, D. Efeito do íon Mn como aditivo na transição de fase $\gamma-\alpha$ da alumina. Cerâmica, v. 49, p. 55-60, 2003.

22. CONSTANTINO, V.R.L.; ARAKAKI, K.; SILVA, D. de O.; DE OLIVEIRA, V. Preparação de compostos de alumínio a partir da bauxita: considerações sobre alguns aspectos envolvidos em um experimento didático. Quim. Nova, v. 25, No. 3, p. 490498, 2002.

23. COX, M. The Harshaw Chemical Company: as seen via one great series of stories. Radiation Protection Management, v. 21, 2004.

24. CWC. Densification, crystallization, and sticking behavior of crushed waste glass sintered in refractory molds with release agents. $\boldsymbol{C W C}, 2000$. (Technology brief) Disponível em: www.cwc.org

25. FUKUMORI, D. T.; YOSHITO, W. K.; USSUI, V., LAZAR, D. R. R.; CAMPOS, L. L. Preliminary results on TL and OSL aluminum oxide dosimeters developed at IPEN. In: INTERNATIONAL NUCLEAR ATLANTIC CONFERENCE, October 24-28, 2011, Belo Horizonte, Brazil. Disponível em: http://pintassilgo2.ipen.br/biblioteca/2011/inac/16891 Acesso em: 11 abril 2012.

26. FURETTA, C. Handbook of thermoluminescence. World Scientific, Singapore, 2003.

27. GITZEN, W. H. Ed. Alumina as a ceramic material. Am. Ceram. Soc. Columbus, Ohio, 1970. (Special Publication n. 4).

28. KINGERY, W. D. Introduction to ceramics. 2. ed. New York, Willey, 1976 (Wiley series on science and technology of materials)

29. KORTOV, V. Materials for thermoluminescent dosimetry: current status and future trends. Radiat. Meas. v. 42, p. 576-581, 2007.

30. KORTOV, V.S.; MILMAN, I. I.; KIRPA, V.I., LESZ, J. Some features of $\alpha-\mathrm{Al}_{2} \mathrm{O}_{3}$ dosimetric thermoluminescent crystals. Radiat. Prot. Dosim., v.55 (4), p. 279-283, 1994.

31. KORTOV, V.S.; MILMAN, I. I. Some new data on thermoluminescence properties of dosimetric $\alpha-\mathrm{Al}_{2} \mathrm{O}_{3}$ crystals. Radiat. Prot. Dosim., v.65 (1/4), p. 179-184, 1996.

32. KRISTIANPOLLER, N.; REHAVI, A.; SHMILEVICH, A.; WEISS, D.; CHEN, R. Radiation effects in pure and dopped $\mathrm{Al}_{2} \mathrm{O}_{3}$ cristals. Nucl. Instr. Meth. Phys. Res. B, v.141, p. 343-346, 1998.

33. KULKARNI, M.S., MISHRA, D.R., MUTHE, K.P., SINGH, A., ROY, M., GUPTA, S.K., KANNAN, S. An alternative method of preparation of dosimetric grade 
$\alpha-\mathrm{Al}_{2} \mathrm{O}_{3}: \mathrm{C}$ by vacuum-assisted post-growth thermal impurification technique. Radiat. Meas. v.39, p. 277-282, 2005.

34. LAZAR, D. R. R.; BOTTINO, M. C.; OZCAN, M.; VALANDRO, L. F.; AMARAL, R.; USSUI, V.; BRESSIANI, A. H. A. "Y-TZP ceramic processing from coprecipitated powders: a comparative study with three commercial dental ceramics", Dental Material, v. 24, p. 1676-1685, 2008.

35. LAZAR, D. R. R.; MENEZES; C. A. B., USSUI, V., BRESSIANI, A. H. A.; PASCHOAL, J. O. A. "The influence of sulphur on the processing of zirconia based ceramics”, Journal of the European Ceramic Society, v. 22, p. 2813-2820, 2002.

36. LEE, J. D. Concise Inorganic chemistry. Trads. TOMA, H. E.; ARAKAKI, K.; ROCHA, R. C. Química inorgãnica não tão concisa. Edgard Blucher Ltda, São Paulo, 2000.

37. MAHESH, K.; WENG, P.S.; FURETTA, C. Thermoluminescence in solids and its applications. Nuclear Technology, UK, 1989.

38. MARINESCU, I. D.; HITCHINER, M.; UHLMANN, E.; ROWE, W. B.; INASAKI, I. The nature of the abrasive. In: Handbook of Machining with Grinding Wheels. CRC Press, 2007. p. 75-101. Disponível em: www.crcnetbase.com Acesso em: 26 janeiro 2012.

39. MARTINS, T. S.; ISOLANI, P. C. Terras raras: aplicações industriais e biológicas. Quim. Nova, v. 28, p. 111-117, 2005.

40. MISRA, C. Aluminum oxide (alumina), hidrated. In: SEIDEL, A. (Ed.). Kirk-Othmer encyclopedia of chemical technology. 5. ed. Hoboken: Wiley-Interscience, 2004. v. 2. p. 421-433.

41. McKEEVER, S. W. S.; BLAIR, M. W.; BULUR, E.; GAZA, R.; GAZA, R.; KALCHGRUBER, R.; KLEIN, D. M.; YUKIHARA, E. G. Recent advances in dosimetry using the optically stimulated luminescence of $\mathrm{Al}_{2} \mathrm{O}_{3}:$ C. Radiat. Prot. Dosim. v.109, n. 4, p. 269-276, 2004.

42. McKEEVER, S. W. S.; MOSCOVITCH, M. On the advantages and disadvantages of optically stimulated luminescence dosimetry and thermoluminescence dosimetry.

Radiat. Prot. Dosim. v. 104, n. 3, p. 263-270, 2003.

43. McKEEVER, S. W. S.; MOSCOVITCH, M.; TOWNSEND, P. D.

Thermoluminescence dosimetry materials: properties and uses. England: Nuclear Technology, 1995.

44. OSVAY, M.; BIRÓ, T. Aluminium oxide in TL dosimetry. Nuclear Instrum. Methods, v.175, p. 60-61, 1980.

45. PAPIN, E. Influence des defauts ponctuels sur les proprietes dosimetriques et sur l'aptitude au frittage de l'alumine a.. 1997. Tese (Doutorado) - Ecole Nationale Superieure des Mines, Saint-Etienne, França.

46. PAPIN, E.; GROSSEAU, P.; GUILHOT, B.; BENABDESSELAM, M.; IACCONI, P.; LAPRAZ, D. Influence os the calcining conditions on the thermoluminescence of pure and doped $\alpha$-alumina powders. Radiat. Prot. Dosim., v. 65, n. 1-4, p. 243-246, 1996.

47. PEARSON, A. Aluminum oxide (alumina), activated. In: SEIDEL, A. (Ed.). KirkOthmer encyclopedia of chemical technology. 5th ed., Hoboken: Wiley-Interscience, 2004. v. 2. p. 391-403. 
48. PORTAL, G. Preparation and properties of principal TL products. In OBERHOFER, M.; SCHARMANN, A. (Ed.). Applied thermoluminescence dosimetry lectures of a course held at the Joint Research Centre, Ispra, Italy, 12-16 November 1979. Adam Hilger Ltd, Bristol, GB, 1981

49. PORTAL, G. Review of the principal materials available for thermoluminescent dosimetry, Radiat. Prot. Dosim. v. 17, p. 351-357, 1986.

50. PROKIC, M.; BØTTER-JENSEN, L. Comparison of main thermoluminescent properties of some TL dosemeters. Radiat. Prot. Dosim. v.47, n.(1/4), p. 195-199, 1993.

51. RADIATION DOSIMETRY LABORATORY. Oklahoma State University. Overview. Disponível em: <http://physics.okstate.edu/yukihara/dosimetry/index.htm> Acesso em: 19 janeiro 2012.

52. RAHAMAN, M.N. Ceramic Processing and Sintering. 2. ed., Boca Raton: CRC Press, 2003.

53. RIEKE, J. K.; DANIELS, F. Thermoluminescence studies of aluminum oxide. J. Phys. Chem., v. 61, p. 629 - 633, 1957.

54. RIS $\varnothing$ DTU. Guide to the RISO TL/OSL Reader. Dinamarca, agosto de 2010. Disponível em: http://www.risoe.dk Acesso em: 19 janeiro 2012.

55. RIS $\varnothing$ National Laboratory. Disponível em: http://www.risoe.dk. Acesso em 28/07/2003.

56. ROCHA, F. D. G.; CALDAS, L. V. E. Characterization of $\mathrm{Al}_{2} \mathrm{O}_{3}$ sintered pellets for dosimetric applications in radiotherapy. J. Radiol. Prot. v. 19, p. 51-55, 1999.

57. SANTOS, P. S.; COELHO, A. C. V.; SANTOS, H. S.; KIYOHARA, P. K. Preparação de sóis aquosos de pseudoboemita com fibrilas de comprimentos diferentes. Cerâmica, v. 55, p. 135-144, 2009.

58. SCHEEL, H. J., FUKUDA, T. (Ed.). Crystal growth technology, John Wiley \& Sons, Ltd, 2003. The development of crystal growth technology. p. 1-14.

59. SCHUMANN, W. Gemas do mundo. Tradução Rui Riberio Franco e Mario Del Rey. 8 ed., Rio de Janeiro: Ao Livro Técnico, 1995.

60. SEGAL, D. Chemical synthesis of advanced ceramic materials. Cambridge: Cambridge University Press, 1989.

61. SEIDEL, A. (Ed.). Kirk-Othmer encyclopedia of chemical technology. 5 ed. Hoboken, Wiley-Interscience, v. 2, 2004.

62. SHANI, G. Thermoluminescence Dosimetry. In: SHANI, G. Radiation Dosimetry: Instrumentation and Methods. CRC Press, USA, p. 63-116, 1991.

63. SILVA, M. R. O. ; ROCHA, F. D. G. ; BRESSIANI, J. C. . Sintered $\mathrm{Al}_{2} \mathrm{O}_{3}$ Based Materials for Radiotherapy Thermoluminescent Dosimeter Applications. In: 10th International Congress of the International Radiation Protection Association - IRPA 10, 2000, Hiroshima. Proceedings of the 10th International Congress of the International Radiation Protection Association, 2000.

64. SOUZA SANTOS, P.; SOUZA SANTOS, H.; TOLEDO, S. P. Standard transition aluminas. Electron microscopy studies. Materials Research, v. 3, p. 104-114, 2000. 
65. TA INSTRUMENTS. SDT Q600 Specifications. New Castle, 2010. (Catálogo Comercial)

66. TEMUUJIN, J.; JADAMBAA, T. S; MACKENZIE, K. J. D.; ANGERER, P; PORTE, F.; RILEY, F. Thermal formation of corundum from aluminium hydroxides prepared from various aluminium salts. Bull. Mater. Sci. v. 23, n. 4, p. 301-304, Indian Academy of Sciences, 2000.

67. USSUI, V.; LEITÃO, F.; MENEZES, C. A. B.; YAMAGATA, C., PASCHOAL, J. O. A. "Synthesis of $\mathrm{ZrO}_{2}$-based ceramics for applications in SOFC", Materials Science Forum, v. 416-418, p 681-687, 2003. Disponível em www.scientific.net

68. USSUI, V.; LAZAR, D. R. R.; MENEZES, C. A. B.; PASCHOAL, J. O. A. Aplicação da técnica de destilação azeotrópica na síntese de pós cerâmicos à base de zircônio. Cerâmica, v. 42, p. 415-418, 1996.

69. VICHENEWSKI, W. Cromatografia por adsorção. In: COLLINS, C. H.; BRAGA, G. L.; BONATO, P. S. Fundamentos de cromatografia. Editora da Unicamp, p. 87-101, 2007.

70. WEFERS, K. Nomenclature, preparation, and properties of aluminum oxides, oxide hydroxides, and trihydroxides. In: HART, L. D. (Ed.). Alumina chemicals: science and technology handbook. The American Ceramic Society, 1990. Pág. 13-20.

71. YUKIHARA, E. G.; McKEEVER, S. W. S. Optically stimulated luminescence (OSL) dosimetry in medicine. Phys. Med. Biol. v. 53, p. R351-R379, 2008.

72. YUKIHARA, E. G.; McKEEVER, S. W. S. Optically stimulated luminescence: fundamentals and applications. Wiley-Blackwel, 2011.

73. ZHYDACHEVSKII, YA.; DURYGIN, A.; SUCHOCKI, A.; MATKOVSKII, A.; SUGAK, D.; BILSKI, P., WARCHOL, S. Mn-doped $\mathrm{YAlO}_{3}$ crystal: a new potential TLD phosphor. Nucl. Instr. Meth. Phys. Res. B, v. 227, p. 545-550, 2005.

74. ZHYDACHEVSKII, YA.; SUCHOCKI, A; BERKOWSKI, M.; BILSKI, P.; WARCHOL, S. Characterization of $\mathrm{YAlO}_{3}: \mathrm{Mn}^{2+}$ thermoluminescent detectors. Radiat. Meas., v. 45, p. 516-518, 2010. 